ROSANA SOUZA BANZATO

\title{
Papel do receptor nicotínico alfa-7 nas alterações pulmonares em modelo experimental de enfisema pulmonar induzido por elastase
}

[tese] apresentada à Faculdade de Medicina da Universidade de São Paulo para obtenção de título de Doutor em Ciências

Programa de Ciências Médicas

Área de concentração: Processos Inflamatórios

e Alérgicos

Orientadora: Prof. ${ }^{\text {a }}$ Dr. ${ }^{\text {a }}$ Carla Máximo Prado

São Paulo

2021 


\section{Dados Internacionais de Catalogação na Publicação (CIP)}

Preparada pela Biblioteca da

Faculdade de Medicina da Universidade de São Paulo

Creprodução autorizada pelo autor

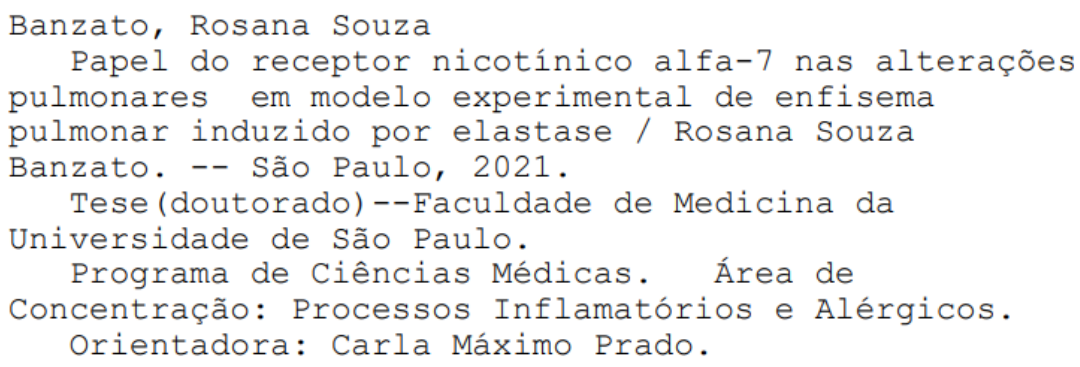

Descritores: 1.Enfisema pulmonar 2.Acetilcolina 3. Inflamação 4.Receptor nicotínico de acetilcolina alfa7 5.PNU282987 6.Modelos animais 7. Camundongos $\mathrm{USP} / \mathrm{FM} / \mathrm{DBD}-147 / 21$

Responsável: Erinalva da Conceição Batista, CRB-8 6755 
"O que fazemos por nós, morre conosco. o que fazemos pelos outros e pelo mundo, continua e é imortal." 


\section{$\mathcal{D E D I C A T O ́ R I \mathcal { A }}$}

Ao meu fítho Diogo,

por me ensinar e ajudar a ser uma pessoa methor. 


\section{AGRADECIMENTOS}

$\mathcal{E}$ assim fecho mais um cíclo em minha vida de muito aprendizado e dedicação.

$\mathcal{N}$ esses dez anos tive o privílégio de conhecer muitas pessoas com as quais aprendi como ser uma pesquisadora. Só posso agradecer a todos vocês:

À Carla Máxímo Prado, minha orientadora, uma muCher de étíca indiscutivel e uma pesquisadora determinada. Só tenho a agradecer por todos esses anos, os quais pude aprender muito com você e agradecer por sua confíança no meu trabalho.

$\dot{\mathcal{A}} \mathcal{N}$ athalia Pinheiro Montoro e à Fernanda $\mathcal{R}$. Santana, agradeço a essas amigas escorpianas (nascidas no mesmo dia) pelo companheirísmo nessa trajetória. Já disse uma vez, mas sempre é bom relembrar: Deus foí bondoso comigo ao colocá-las no meu caminho. Vocês sempre estarão em minhas melhores lembranças: obrigada amigas queridas, com vocês aprendí muito.

À Clarice $\mathcal{R}$. Ofivo, minha companheira nos experimentos desde o mestrado. Obrigada Claris por sua ajuda nesses anos, sempre disponivel para colaborar. 
’̀ Sílvía Fukuzaki, amiga de Conga data, já passamos tantos momentos juntas. Obrigada Sí por toda sua amizade nesses anos e principalmente agora por sua ajuda impar para a realização desse estudo, você foi mais que uma amiga.

ג̇ Fernanda D.T.Q.S. outra companheira desde o mestrado. Obrígada Fê por todos os seus ensinamentos nesses anos, levárei-la sempre comigo!

À Iolanda F.C. Tíbério, com você estive em minha primeira apresentação em um Congresso Internacional. Obrigada por seu apoio naqueles dias, me encorajando em poder mostrar o meu melhor.

Aos meus familiares: ao meu filho Diogo Banzato Franco que sempre me encorajou e auxiliou com os seus conhecimentos na elaboração dessa tese. À minha mãe Valdelice Souza Banzato que me acolheu novamente e com sua amizade me auxilio no término desse trabalho. Ao meu irmão Marcelo Banzato, minha cunhada Maricy Leal Banzato, e aos meus sobrinhos (Marcelinha e Gael); obrigada por me apoíarem nesses anos e compreenderem as várias recusas de convites durante essa fase de dedicação a essa tese. 
À Walcy Teodoro por seus ensinamentos pontuais e contríbuição para a realização das imagens das lâminas para essa tese.

Aos meus amigos do LIM-20: Beatriz, Edna, Francine, Luiz, Suellen, Júlia e Juliana. Obrigada, aprendi muito com vocês!

À Rosana Paz, por sempre estar disposta a ajudar.

Ao meu amigo Davi, sempre gentil, atencioso e muito prestativo.

ג̇ $\mathcal{F} \mathcal{A P E S P}$, pelo apoío financeiro para execução deste projeto $(2014 / 25689-4)$

"Enquanto a memóría de alguns amigos amados viver no meu coração, Eu direi sempre que a vida é boa" Helen Keller

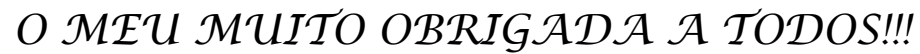


Esta dissertação está de acordo com as seguintes normas, em vigor no momento desta publicação:

Referências: adaptado de International Commitee of Medical Journals Editors (Vancouver)

Universidade de São Paulo. Faculdade de Medicina. Divisão de Biblioteca e Documentação. Guia de apresentação de dissertações, teses e monografias. Elaborado por Anneliese Carneiro da Cunha, Maria Julia de A. L. Freddi, Maria F. Crestana, Marinalva de Souza Aragão, Suely Campos Cardoso, Valéria Vilhena. 3ª̣ed. São Paulo: Divisão de Biblioteca e Documentação; 2011.

Abreviatura dos títulos e periódicos de acordo com List of Journals Indexed in Index Médicus. 
SUMÁRIO 


\section{Sumário}

\section{LISTA DE ABREVIATURAS E SIGLAS}

\section{LISTA DE FIGURAS}

\section{LISTA DE TABELAS}

RESUMO

\section{SUMMARY}

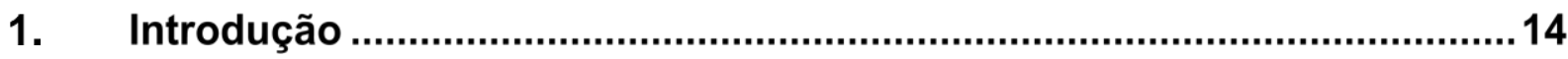

1.1. Doença pulmonar obstrutiva crônica............................................................

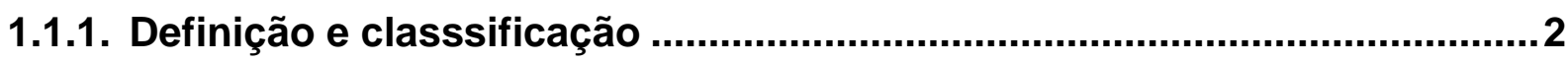

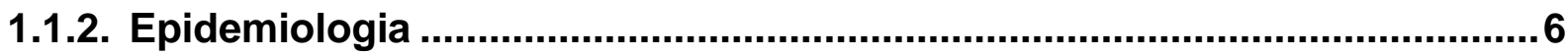

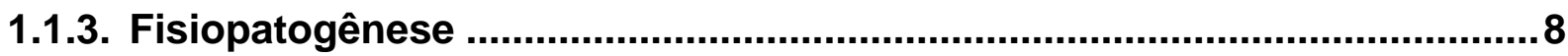

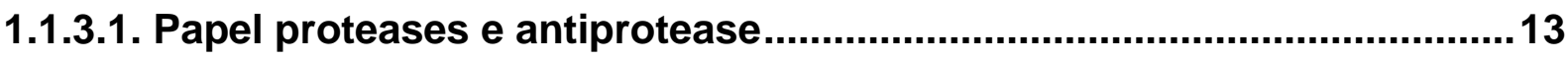

1.1.3.2. Papel do estresse oxidativo …................................................................14

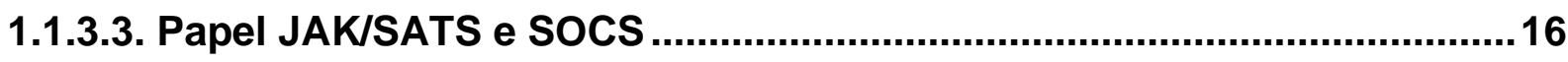

1.2. Sistema colinérgico na resposta inflamatória.........................................18

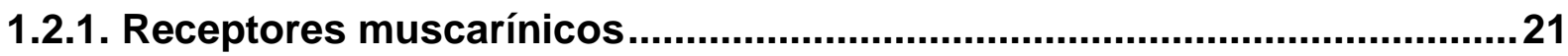

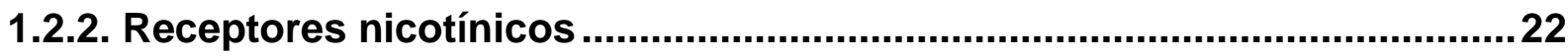

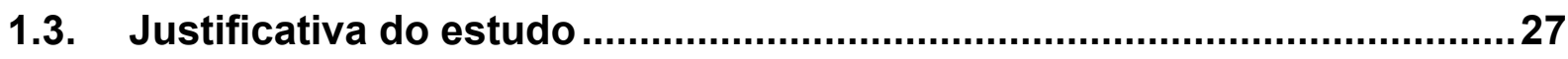

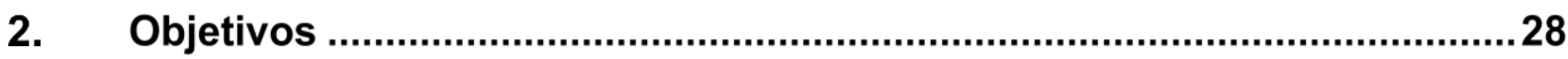

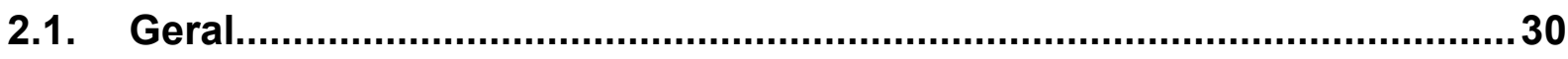

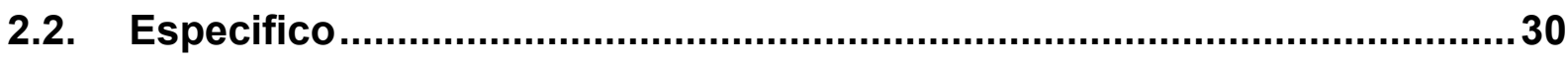

3. Material e Métodos........................................................................................

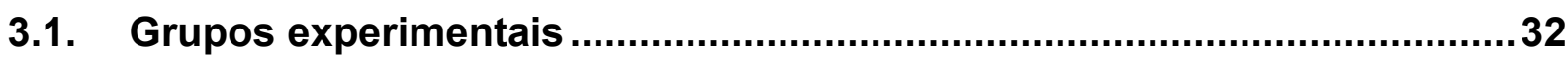

3.1.1. Protocolo de indução do enfisema pulmonar .............................................33

3.1.2. Tratamento do PNU 282987 e pré-tratamento com MLA ...........................34

3.2. Avaliação da mecânica do sistema respiratório ..........................................36 


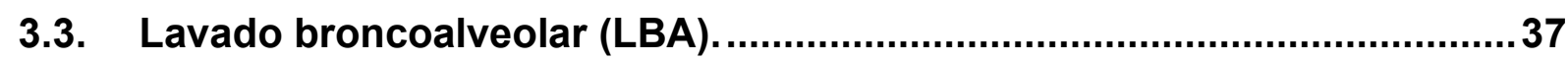

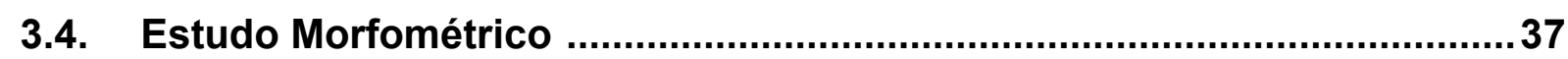

3.4.1. Medida do Intercepto linear médio (LM) ...............................................38

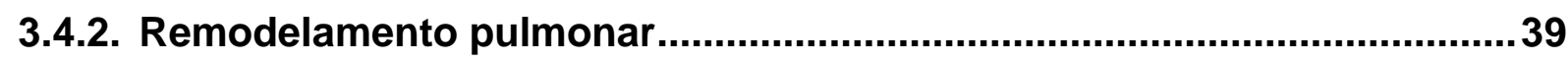

3.4.3. Avaliação de células inflamatórias no parênquima pulmonar...................40

3.5. Imunohistoquimica para a detecção de MMP-9, TIMP-1, a7 e

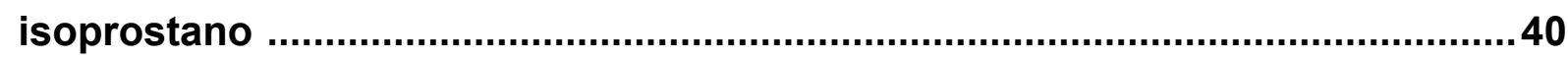

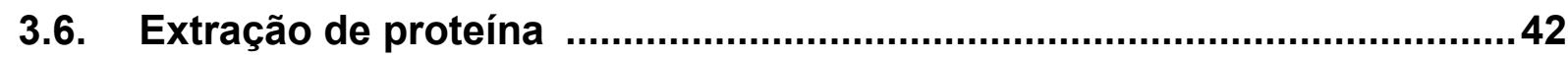

3.7. Western blotting para a detecção STAT3 total e fosforilado, SOCS3

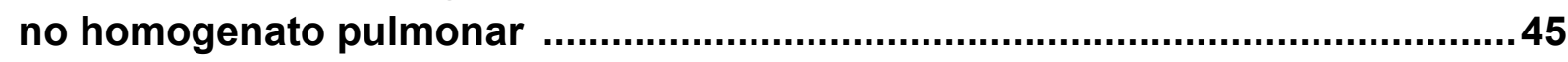

3.8. Análise citocinas no homogenato pulmonar pelo método ELISA de

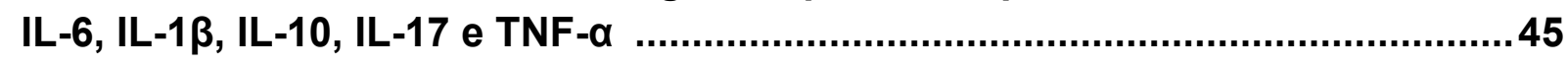

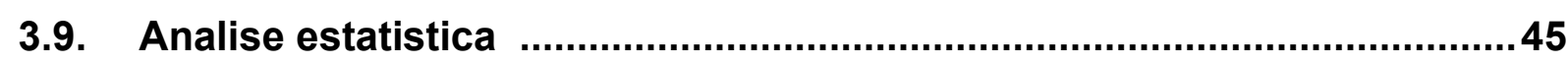

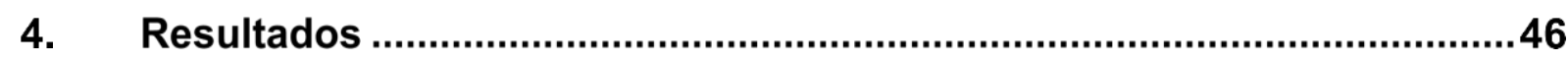

4.1. Efeito do tratamento com PNU 282987 nas células positivas de $\alpha 7$........47

4.2. Efeito do tratamento com PNU 282987 na destruição alveolar (LM) ........49

4.3. Efeito do tratamento com PNU 282987 na inflamação pulmonar .............51

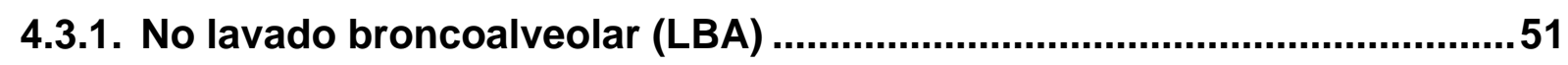

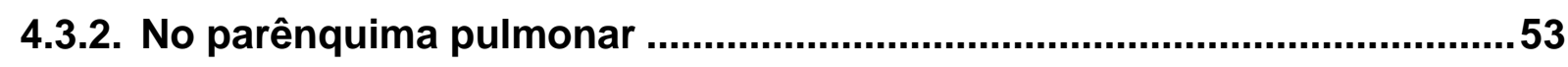

4.4. Efeito do tratamento com PNU 282987 no remodelamento pulmonar .....55

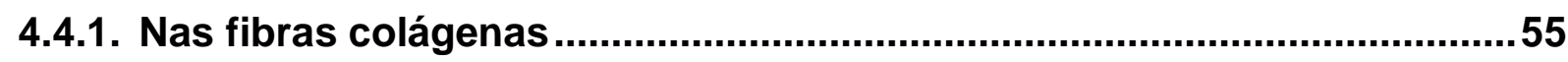

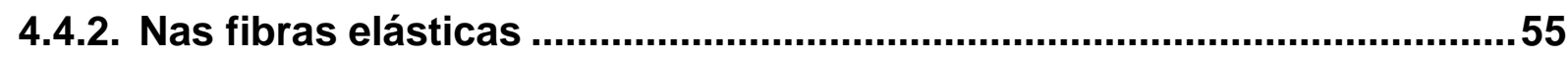

4.5. Efeito do tratamento com PNU 282987 na expressão de MMP-9, TIMP-1 e isoprostano 8-iso-PGF-2 $\alpha$ no parênquima pulmonar............................58

4.6. Efeito do tratamento com PNU 282987 nos níveis de citocinas IL-6, IL-1 $\beta$, IL-10, IL-17 e TNF- $\alpha$ no homogenato pulmonar..........................................63

4.7. Efeito do tratamento com PNU 282987 na expressão proteica do STAT3/p STAT3 e SOCS3 .66 
4.8. Efeito do antagonista do $\alpha 7$ (MLA) revertendo os efeitos do PNU na resposta inflamatória

4.9. Efeito do tratamento com PNU 282987 na função pulmonar ....................71

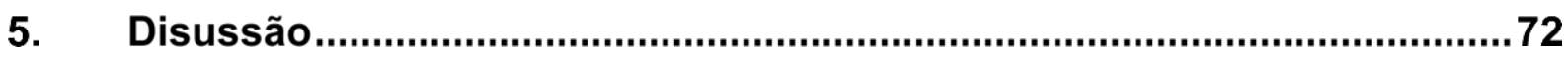

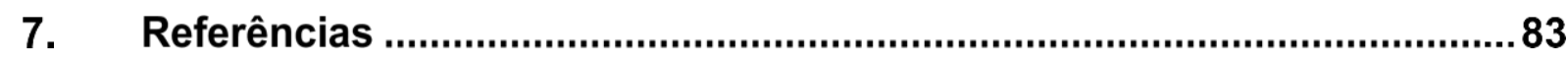


LISTA DE ABREVIATURAS E SIGLAS

$\mathrm{ACh}$

AChE

$\alpha 7 n A C h R$

AP1

BALF

ChAT

CHT1

CRF

CVF

CEUA

DPOC

EGF

EROs

GOLD

Gtis

GTS-21

Grupo Controle

Grupo PPE

Grupo PPE-Pré

Grupo PPE-Pós

Grupo MLA

$\mathrm{H}_{2} \mathrm{O}_{2}$

Htis

ICS
Acetilcolina

Acetilcolinesterase

Receptor Nicotínico a7

Proteína Ativadora1

Fluído do Lavado Broncoalveolar

Acetiltransferase

Transportador de Colina de Alta Afinidade

Capacidade Residual Funcional

Capacidade Vital Forçada

Comissão de Ética no Uso de Animais

Doença Pulmonar Obstrutiva Crônica

Fator de Crescimento Epidérmico

Espécies Reativas de Oxigênio

Global Initiative for Chronic Obstructive Lung

Resistência Tecidual

Agonista Seletivo de $\alpha 7 n A C h R$

Animais que Receberam Instilação de Sal e tratados com VE

Animais que Receberam Instilação de Elastase e tratados com VE

Animais que Receberam Instilação de Elastase e tratados com PNU-282987

Animais que Receberam Instilação de Elastase e tratados com PNU-282987

Animais que Receberam Instilação de Elastase e tratados com MLA e PNU-282987

Peróxido de Hidrogênio

Elastância do Tecido

Corticoide inalatório 
I-KB

IFN-Y

IL

JAK2

LABA

LAMA

LBA

LM

MAPK

MCP-1

MEC

MIP-2

MLA

MMPs

mAChR

nAChR

NF-kB

NMD

NTS

$\mathrm{O}_{2}{ }^{-}$

$\mathrm{OH}^{-}$

ONOO-

PNU-282987

Raw

RNS

ROS

SDRA

SNC
Inibidor do Fator Nuclear kappa B

Interferon-Gama

Interleucinas

Tirosina Quinase 2

$\beta_{2}$ Agonista de Ação Prolongada

Muscarínicos Antagonista de Ação Prolongada

Lavado Broncoalveolar

Intercepto Linear Médio

Proteína quinase Ativada por Mitógenos

Proteína Quimiotática de Monócitos

Matriz Extracelular

Proteína 2 Macrofágica Inflamatória

Metillicaconitine

Metaloproteinase de matriz

Receptores Muscarínicos

Receptores Nicotínicos

Fator Nuclear kappa B

Núcleo Motor Dorsal

Núcleo do Trato Solitário

Anion Superóxido

Radical de Hidroxila

Peroxinitrito

Agonista Seletivo de $\alpha 7 \mathrm{nAChR}$

Resistência das Vias Aéreas

Espécies Reativas de Nitrogênio

Espécies Reativas de Oxigênio

Síndrome do Desconforto Respiratório Agudo

Sistema Nervoso Central 
SNP

SNS

SOCS3

STAT3

TGF- $\beta$

Tc1

Tc2

TIMP

TNF- $\alpha$

VAChT

VEF $_{1}$
Sistema Nervoso Parassimpático

Sistema Nervoso Simpático

Supressor de Citoxinas de Sinalização 3

Transdutor e Ativação de Transcrição de sinal 3

Fator de Crescimento Transformador

Células Citotóxicas do Tipo 1

Células Citotóxicas do Tipo 2

Inibidores Teciduais de Metaloproteinases

Fator de Necrose tumoral

Transportador Vesicular de Acetilcolina

Fluxo Expiratório Forçado no Primeiro Segundo 


\section{LISTA DE FIGURAS}

Figura 1. Ferramentas refinadas da avaliação $A B C D$................... 5

Figura 2. Fisiopatologia do enfisema pulmonar............................ 9

Figura 3. Estresse oxidativo................................................. 16

Figura 4. Arco reflexo da inflamação........................................... 19

Figura 5. Mecanismos envolvidos na resposta colinérgica antiinflamatória.............................................................. 25

Figura 6. Protocolo experimental............................................. 35

Figura 7. Efeito do tratamento com PNU- 282987 nas células positivas de $\alpha 7$ no parênquima pulmonar....................... 48

Figura 8. Efeito do tratamento com PNU-282987 na destruição alveolar (Lm) .................................................. 50

Figura 9. Efeito do tratamento com PNU-282987 nas células inflamatórias no LBA............................................... 52

Figura 10. Efeito do tratamento com PNU-282987 nas células inflamatórias no parênquima pulmonar......................... 54

Figura 11. Efeito do tratamento com PNU-282987 nas fibras colágeno e elástica no parênquima pulmonar.............. 57

Figura 12. Efeito do tratamento com PNU-282987 nas células positivas de MMP-9 no parênquima pulmonar............... 60

Figura 13. Efeito do tratamento com PNU-282987 nas células positivas de TIMP-1 no parênquima pulmonar............... 61

Figura 14. Efeito do tratamento com PNU-282987 na fração de volume de isoprostano 8 -iso-PGF-2 $\alpha$ no parênquima pulmonar................................................................. 62

Figura 15. Efeito do tratamento com PNU-282987 nos níveis de citocinas II-6, IL-1 $\beta$, IL-17, TNF- $\alpha$ e IL-10 no homogenato pulmonar............................................ 65

Figura 16. Efeito do tratamento com PNU-282987 na expressão proteica do p-STAT3/STA3........................................................ 67

Figura 17. Efeito do tratamento com PNU-282987 na expressão proteica da SOCS3............................................... 68

Figura 18. Efeito do antagonista de $\alpha 7$ revertendo os efeitos do PNU na resposta inflamatória..................................... 70

Figura 19. Efeito do tratamento com PNU-282987 na função pulmonar. 


\section{LISTA DE TABELAS}

Tabela 1. Classificação DPOC........................................................ 4

Tabela 2. Citocinas e seus efeitos na DPOC............................... 11

Tabela 3. Randomização dos grupos e metodologia......................... 33 
RESUMO 
Banzato R. Papel do receptor nicotínico alfa-7 nas alterações pulmonares em modelo experimental de enfisema pulmonar induzido por elastase

[Tese]. São Paulo: Faculdade de Medicina, Universidade de São Paulo; 2021.

Introdução: $O$ enfisema pulmonar é o principal componente da doença pulmonar obstrutiva crônica (DPOC) e é caracterizado por limitação do fluxo aéreo, decorrentes das alterações das vias aéreas e/ou alveolares. Os receptores nicotínicos, particularmente 0 subtipo $\alpha 7 \quad(\alpha 7 n A C h R)$, estão envolvidos nas respostas anti-inflamatórias colinérgicas. A ativação farmacológica in vivo do $\alpha 7 n A C h R$ reduziu a inflamação pulmonar em vários modelos experimentais e com isso formulamos a hipótese de que o $\alpha 7 n A C h R$ pode ser um alvo a ser explorado no enfisema pulmonar. Objetivo: $O$ objetivo deste estudo foi avaliar o papel do receptor $\alpha 7 \mathrm{nAChR}$ na modulação da resposta inflamatória, alterações da mecânica e remodelação pulmonar em um modelo experimental de enfisema pulmonar. Metodologia: $O$ enfisema foi induzido em camundongos machos (C57BL/6) por instilação nasal de elastase pancreática suína (PPE). O tratamento com PNU-282987 (2,0 mg / kg, ip) foi avaliado em duas abordagens diferentes: i) Pré: iniciou junto com a instilação de elastase e repetidos nos dias 0, 7, 14, 21 e 28; ii) Pós-tratamento: iniciou no dia 21 e seguiu diariamente, $1 \mathrm{x} / \mathrm{dia}$, até o dia 28 . No dia 28 , os animais foram anestesiados e avaliou-se a função pulmonar. Após a eutanásia, os pulmões foram retirados para avaliação da resposta inflamatória e de remodelamento pulmonar além da expressão de MMP-9, TIMP-1, a7nAChR e 8-isoprostano por imunhistoquímica. A expressão de STAT3 e SOCS3 foram avaliadas no pulmão por Wester Blotting. Os níveis de citocinas foram avaliados no lavado broncoalveolar por Elisa. Resultados: A elastase aumentou o número de células positivas para $\alpha 7 \mathrm{nAChR}$ no tecido pulmonar e os tratamentos com PNU reduziram esta resposta. Ambos os tratamentos com PNU (Pré e Pós) reduziram o número de macrófagos recuperados no lavado broncoalveolar, os níveis de IL-6 e IL-1 $1 \beta$, a deposição de fibras colágenas e elásticas e evitaram a fosforilação de STAT3 e a redução da proteína SOCS3 que foram induzidas pela instilação de PPE no pulmão. Curiosamente, os níveis de IL-17 e TNF- $\alpha$, as células polimorfonucleares recrutadas para o tecido do parênquima pulmonar e a destruição do tecido alveolar (enfisema) foram reduzidas apenas pelo tratamento com PNU pós. O MLA, um antagonista do a7nAChR, quando administrado previamente ao PNU, restaurou os efeitos do PNU em alguns parâmetros inflamatórios importantes. Conclusão: Tomados em conjunto, esses dados mostram claramente os efeitos protetores do a7nAChR contra o enfisema induzido pela elastase e fornecem fortes evidências para estudos adicionais sobre a ativação do $\alpha 7 \mathrm{nAChR}$ como uma terapêutica de grande importância na mitigação do enfisema pulmonar.

DESCRITORES: Enfisema pulmonar; Acetilcolina; Inflamação; Receptor nicotínico de acetilcolina alfa7; PNU282987; Modelos animais; Camundongos. 
Banzato R. Role of the alpha-7 nicotinic receptor in pulmonary changes in an experimental model of pulmonary emphysema induced by elastase

[Thesis]. São Paulo: "Faculdade de Medicina, Universidade de São Paulo"; 2021.

Banckground: Pulmonary emphysema is the major component of chronic obstructive pulmonary disease (COPD), and is characterized by airflow limitation, resulting from changes in the airways and / or alveolar airways. The nicotinic receptors, particularly of the $\alpha 7$ subtype ( $\alpha 7 \mathrm{nAChR})$, are involved in the anti-inflammatory cholinergic responses. The in vivo pharmacological activation of $\alpha 7 \mathrm{nAChR}$ reduced pulmonary inflammation in several experimental models and then we hypothesized that $\alpha 7 \mathrm{nAChR}$ can be a target to be explored in pulmonary emphysema. Aim: The aim of the present study was to evaluate the role of $\alpha 7 n A C h R$ in the modulation of inflammatory response, lung mechanics alterations and lung remodeling in an experiment model of pulmonary emphysema. Methods: Emphysema was induced in male mice (C57BL/6) by nasal instillation of porcine pancreatic elastase (PPE). The treatment with PNU282987 (2.0 mg / kg, ip) was evaluated in two different approaches; i) Pre which consist in the administration of PNU together with the PPE, and then repeated on days $0,7,14,21$ and 28; ii) Post-treatment: began on day 21 and then was repeated every day until the day 28 . On day $28^{\text {th }}$, animals were anesthetized, and lung mechanics was evaluated. Then after euthanasia, lungs were removed to evaluate the inflammatory response and lung remodeling as well as the lung expression of MMP-9, TIMP-1, $\alpha 7 \mathrm{nAChR}$ and 8-isoprostane by immunohistochemistry. The lung expression of STAT3 and SOCS3 were evaluated by Western blotting. The levels of cytokines were evaluated in bronchoalveolar lavage by Elisa. Results: The elastase increased the number of positive cells $\alpha 7 \mathrm{nAChR}$ expression in lung tissue and both PNU-treated groups showed reduction in this response. Both PNU treatment (Pre and Post approach) reduced the macrophages recovered on bronchoalveolar lavage, the levels of IL- 6 and IL-1 $\beta$, the deposition of collagen and elastic fibers and avoided the STAT3 phosphorylation and the reduction of SOCS3 protein that was induced by PPE instillation on lung. Interestingly, the levels of IL-17 and TNF- $\alpha$, the density of polymorphonuclear cells recruited to lung parenchyma tissue and the alveolar diameter (emphysema) was reduced only in the posttreatment group. The MLA, an antagonist of $\alpha 7 \mathrm{nAChR}$, when administered before PNU, restored the effects of PNU in some important inflammatory parameters. Conclusion: Taken together, these data clearly show the protective effects of $\alpha 7 \mathrm{nAChR}$ against elastase-induced emphysema and provide strong evidence for further studies on $\alpha 7 \mathrm{nAChR}$ activation as a therapeutic of great importance in the mitigation of pulmonary emphysema.

DESCRIPTORS: Pulmonary emphysema; Acetylcholine; Inflammation; Nicotinic acetylcholine alfa7 receptor; PNU282987; Animal models; Mice. 


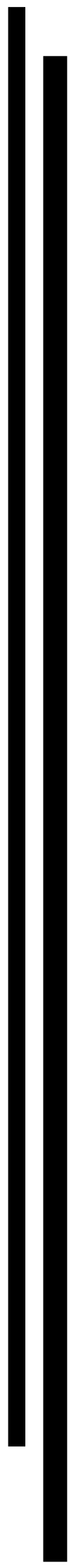

1.INTRODUÇÃO 


\subsection{Doença Pulmonar Obstrutiva Crônica}

\subsubsection{Definição e classificação}

A Doença Pulmonar obstrutiva Crônica (DPOC), conforme definição Global Initiative for Chronic Obstructive Lung Disease (GOLD), é uma doença evitável e tratável caracterizada por persistência de sintomas respiratórios e limitação do fluxo aéreo, decorrentes das alterações das vias aéreas e/ou alveolares, geralmente causada por exposição significativa de partículas nocivas. As exacerbações e as comorbidades contribuem para a gravidade dos pacientes [1]. A limitação ao fluxo aéreo característica da DPOC é causada por um conjunto de alterações entre doenças pulmonares das vias aéreas (bronquiolite obstrutiva) e a destruição do parênquima pulmonar (enfisema) [1, 2]. A limitação do fluxo aéreo caracteriza-se pela redução do fluxo expiratório detectada pela espirometria, com redução irreversível de fluxo expiratório forçado no primeiro segundo $\left(V_{E F}\right)$ e da relação $V E F_{1} / C V F$ (capacidade vital forçada). Segundo o GOLD, a limitação ao fluxo aéreo ocorre quando a relação $V_{E F} / C V F$ é $<70 \%$ (pós broncodilatador).

A DPOC se manifesta por dois tipos clínicos, a bronquite e o enfisema. A bronquite é clinicamente definida por tosse produtiva por no mínimo três meses nos últimos dois anos consecutivos [3]. O enfisema é caracterizado por uma inflamação crônica que causa a destruição das paredes alveolares, resultando no alargamento dos espaços aéreos distais e bronquíolos terminais, ocasionando a perda da superfície respiratória e de irrigação sanguínea, diminuição do recolhimento elástico e hiperinsuflação pulmonar [1]. 
No enfisema pulmonar a sintomatologia é caracterizada por dispneia, tosse, expiração prolongada, inatividade física, uso da músculos respiratórios acessórios e hiperinsuflação pulmonar, ocasionando diminuição do murmúrio vesicular respiratório, podendo os ruídos adventícios, como sibilos expiratórios e estertores, não serem frequentes [4]. Esses pacientes enfisematosos podem evoluir com falência pulmonar, onde se observa a diminuição da oxigenação arterial, aumento do dióxido de carbono e hipoxemia grave. Nesse estágio pode ocorrer hipertensão pulmonar, hipertrofia ventricular direita e Cor Pulmonale agravando o prognóstico [5].

O fumo (o tabaco e cigarro eletrônico) continua sendo o principal fator de risco para o desenvolvimento da DPOC, mas não podemos negligenciar outros fatores desencadeantes como: poluição do ar, exposição ocupacional prolongada, envelhecimento e o componente genético [6]. Apesar do fumo ser a principal causa da DPOC, a interrupção à exposição ao cigarro não resulta em resolução da resposta inflamatória nas vias aéreas [7]. Isto sugere que há mecanismos que perpetuem o processo inflamatório crônico, após este estar estabelecido. Esses mecanismos podem ser responsáveis pela sintomatologia da DPOC em pacientes que já pararam de fumar. Entretanto, os mecanismos de persistência da doença ainda não são totalmente conhecidos [8].

O diagnóstico clínico da DPOC é baseado na exposição aos fatores de riscos, nos sintomas e na espirometria [1]. Os pacientes podem apresentar piora dos sintomas, caracterizada por exarcebações, que podem ocorrer em média três vezes ao ano em pacientes com DPOC moderada ou grave [9]. 
Nessas exarcebações observa-se piora da dispneia, aumento da secreção purulenta expectorada, geralmente são eventos agudos ocasionado por infecções do trato respiratório por vírus ou bactérias, que toda vez que se manifesta pode ocasionar um declínio na qualidade de vida [10].

Segundo a atualização do GOLD 2020, a espirometria continua sendo considerada uma forma simples, não invasiva para mensurar a limitação ao fluxo aéreo e classificar a DPOC (Tabela 1). O documento ainda destaca que a avaliação do paciente com DPOC deve incluir avaliação dos sintomas, da limitação ao fluxo aéreo pós-broncodilatador, histórias de exacerbações e comorbidades. Essa avaliação complexa divide os pacientes em quatro categorias A, B, C e D (Figura 1).

Tabela 1 : Classificação da DPOC (Adaptado GOLD 2020)

\begin{tabular}{|c|c|c|}
\hline & Classificação & VEF1 previsto \\
\hline GOLD 1 & LEVE & $\geq 80$ \\
\hline GOLD 2 & MODERADA & $50-79$ \\
\hline GOLD 3 & GRAVE & $30-49$ \\
\hline GOLD 4 & MUITO GRAVE & $<30$ \\
\hline
\end{tabular}




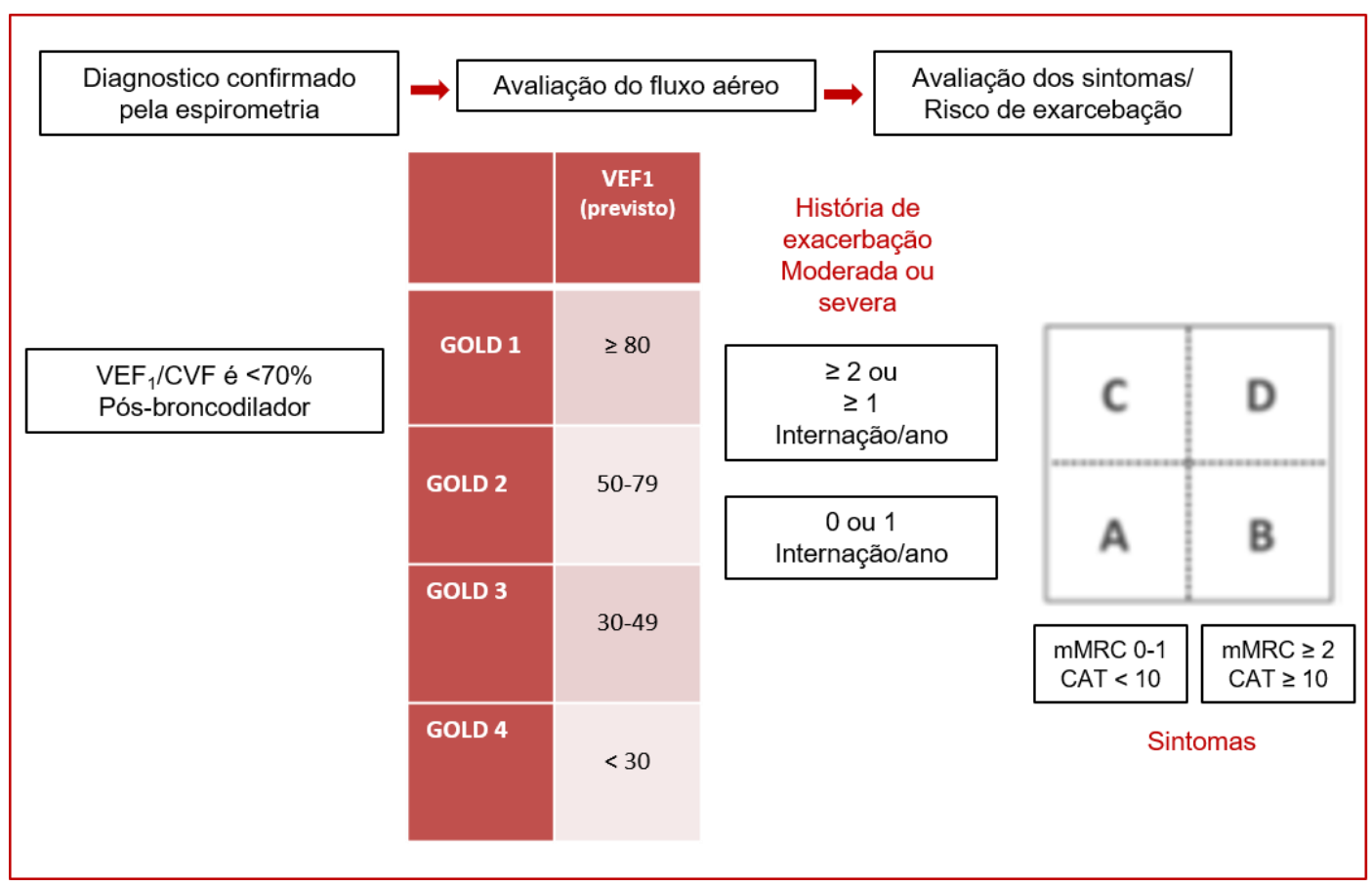

Figura 1. Ferramentas refinadas da avaliação $A B C D$ (Adaptado GOLD 2020).

A classificação da DPOC está relacionada a sintomatologia, grau da limitação ao fluxo aéreo, comorbidades e riscos de exacerbações [1]. Com base nessa classificação o tratamento inicial é inespecífico [11] e controverso [12] , mas o uso com antagonistas muscarínicos de ação prolongada (LAMA) em combinação com $\beta 2$-agonista de ação prolongada (LABA) e a associação LABA com corticoides inalatórios (ICS), estão sendo cada vez mais utilizado no tratamento da DPOC, essas combinações proporcionam melhora da sintomatologia, na função pulmonar, tolerância ao exercício e melhora na qualidade de vida [13]. Mandal et al. [13] concluíram que apesar do uso do LAMA mostrar um efeito importante na limitação do fluxo aéreo, nas exacerbações, na melhora da qualidade de vida, esse tipo de tratamento pode 
ser ineficaz em relação a inflamação em pacientes com DPOC moderada a grave. Suissa et al [12] observaram em seu estudo, diferentemente dos estudos IMPACTO [14] e FLAME [15], que os pacientes tratados com LABA/LAMA e LABA/ICS tiveram incidências semelhantes de exacerbações, mas observaram que a incidência de pneumonia foi maior nos pacientes usando a combinação de LABA/LAMA.

\subsubsection{Epidemiologia}

A DPOC é um problema grave de saúde pública, é considerada uma das cinco causas de incapacitação em todo mundo [16] e em 2030 será a terceira causa de morte mundial, podendo haver mais de 4,4 milhões de mortes anuais até 2040 [16, 17]. A prevalência de morbidade e a taxa de mortalidade, devido a DPOC, variam nos diferentes países e em diferentes grupos de pessoas e estão relacionadas à prevalência de fumantes na população e a inalação de gases tóxicos. Estima-se que a exposição prolongada aos fatores de risco e o aumento do envelhecimento na população induzem maior prevalência e contribuem com o maior impacto sócio econômico dessa patologia, tornando-se um desafio para a saúde mundial nas próximas décadas [1]. Embora tradicionalmente a DPOC tenha sido considerada uma doença que afete homens, atualmente tem se observado em alguns países, um aumento da prevalência e da mortalidade mais altas entre as mulheres do que entre os homens [18]. 
Existe uma relação forte das exacerbações e a gravidade do DPOC com os custos de atendimento. Nos Estados Unidos, os custos diretos com a DPOC são de 29,5 bilhões e os custos indiretos é da ordem de 20,4 bilhões. Na União Europeia os custos diretos representam 56\% destes gastos (38,6 bilhões de euros) [19].

Santos L et al. [20], realizaram um estudo descritivo avaliando o perfil de internação e mortalidade da DPOC nas regiões brasileiras entre 2016 e 2018. Esses autores observaram que houve 345.527 internações, sendo que os pacientes permaneceram internados em média seis dias, com gastos hospitalares de $\mathrm{R} \$ 287.168 .494,88$ e uma taxa de mortalidade de 7,63 por mil habitantes nas regiões sudeste e sul do Brasil em comparação com as demais regiões [20]. Esses dados maiores nessas regiões, podem estar associados ao seu desenvolvimento econômico e industrial, ocasionando a exposição maior aos poluentes ambientais.

Mesmo já mencionado acima que a DPOC é um problema grave de saúde pública, acometendo uma população economicamente ativa e prejudicando a qualidade de vida desses pacientes, esta patologia ainda é subdiagnosticada. O Projeto Latino-Americano de Investigação de Enfermidade Obstrutiva (Platino) [21] estudou a prevalência da limitação ao fluxo aéreo pósbroncodilatador, em pessoas com mais de 40 anos na América Latina em diferentes países (Brasil, Chile, México, Uruguai e Venezuela). No Brasil, São Paulo foi a cidade escolhida e segundo os dados espirométricos apresentou uma prevalência de 15,8\% de DPOC. Em 2014, após um seguimento de 9 
anos, os autores responsáveis pelo estudo Platino concluíram que a taxa de sub diagnóstico nos novos casos da doença na fase de seguimento em São Paulo foi de $70 \%$ [22]. Essa taxa alta de sub diagnóstico da DPOC reforça a necessidade de maior divulgação e ampliação do uso da espirometria em fase inicial da doença.

\subsubsection{Fisiopatogênese}

As mudanças fisiopatológicas na DPOC são decorrentes de alterações patológicas observadas nas vias aéreas centrais, nas vias aéreas periféricas e nos vasos pulmonares resultando em uma resposta inflamatória crônica [23] que aumenta ainda mais durante as exacerbações agudas decorrente de infecções bacterianas ou virais [24].

O padrão característico inflamatório observado na DPOC é resultado do influxo de diferentes células inflamatórias aumentado no lúmen das vias aéreas, incluindo macrófagos, neutrófilos, células T helper (Th1) e Th17, linfócitos T (especialmente CD8+). Observa-se nesses pacientes com DPOC respostas inflamatórias imunes inatas (inflamação neutrofilica) e adaptativas (células T citotóxicas) que são ativadas por células dendríticas [24, 25]. Uma vez essas células ativadas, há liberação de diferentes mediadores inflamatórios tais como: proteases, citocinas e espécie reativas de oxigênio (EROs), que degradam a elastina e consequentemente destruição da parede alveolar (enfisema pulmonar) [26]. 


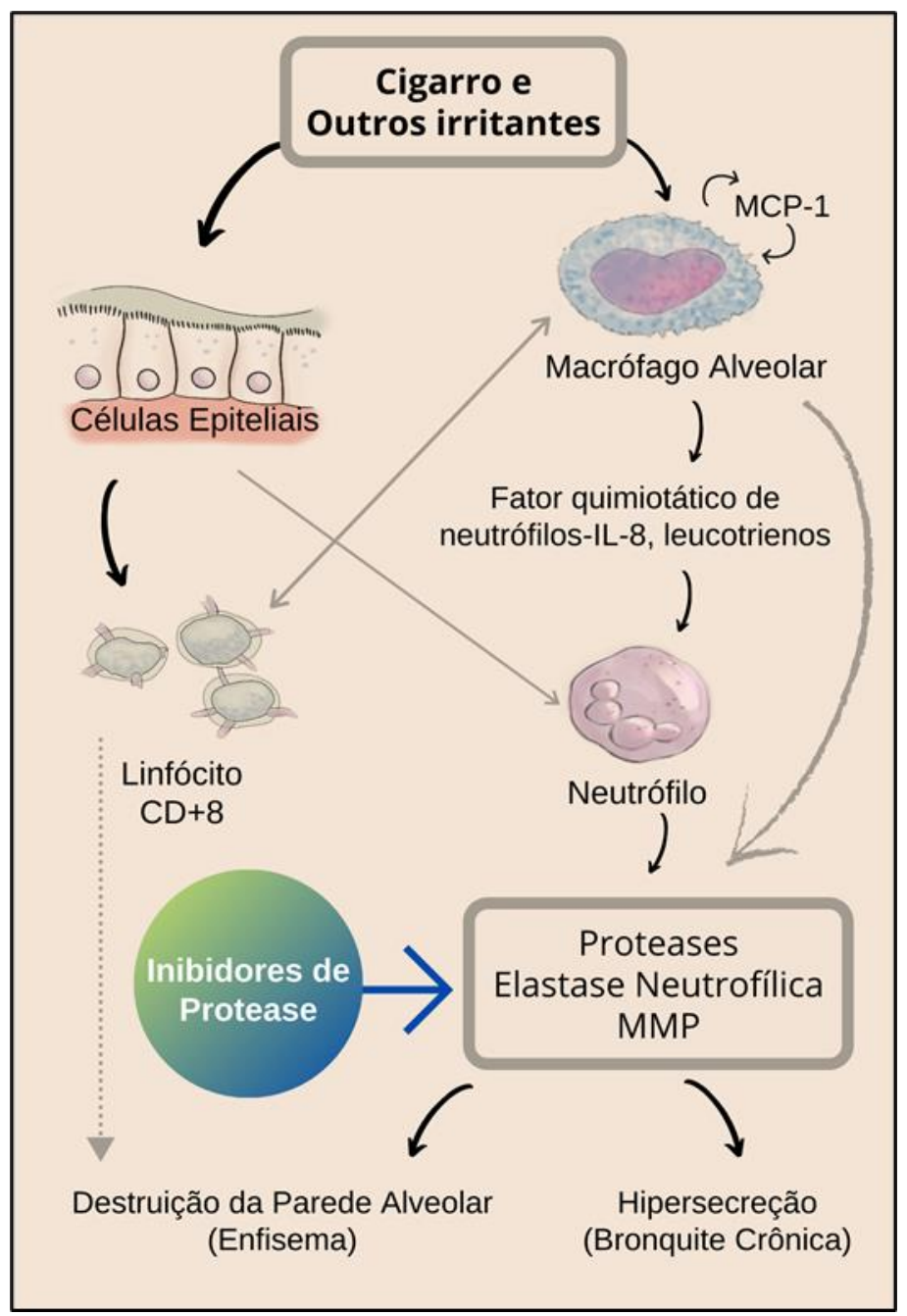

Figura 2. Fisiopatologia do enfisema pulmonar: Fatores irritantes, como a fumaça do cigarro, ativam macrófagos e células epiteliais no trato respiratório, causando a liberação de fatores quimiotáticos de neutrófilos, incluindo IL-8 e leucotrienos B4, que ativam os neutrófilos. Os macrófagos e neutrófilos atuam sobre as proteases que degradam o tecido conjuntivo no parênquima pulmonar, ocasionando a destruição da parede alveolar (enfisema pulmonar) e estimula da hipersecreção de muco (bronquite crônica). As proteases são neutralizadas por inibidores de protease, como: $\alpha$-1-antripsina e os TIMPs. As células T citotóxicas CD8+ (linfócitos) podem também estar envolvidos na cascata infamatória e podem induzir a destruição alveolar. (Modificado de Barnes PJ, 2004) [27].

A fumaça do cigarro e outros irritantes inalados ativam as células epiteliais produzindo mediadores inflamatórios incluindo fator de necrose tumoral (TNF- $\alpha$ ), interleucina-1 $\beta$ (IL-1 $\beta$ ), interleucina-6 (IL-6), CXCL8 (IL-8) e o fator de crescimento epidérmico (EGF). As células epiteliais ainda expressam fator de crescimento 
transformador (TGF- $\beta$ ) nas pequenas vias aéreas o que causa a fibrose local, podendo ocorrer perda de pequenas vias aéreas, mesmo em doença leve [24, 28]. A obstrução das vias aéreas na DPOC é irreversível e progressiva ao longo dos anos [28]. Em resposta a fumaça do cigarro, os monócitos se acumulam nos pulmões e provavelmente ativem a liberação de quimiocinas, como a proteína quimiotática de monócito (MCP-1) no pulmão e no sangue periférico [25] . (Figura 2). As principais classes de citocinas estão descritas na tabela 2. 
Tabela 2: Citocinas e seus efeitos na DPOC. Modificado de Chung 2001 [29].

\begin{tabular}{|c|c|c|c|}
\hline Classe & Mediadores & Fonte & $\begin{array}{c}\text { Efeitos celulares e } \\
\text { mediadores } \\
\text { importantes }\end{array}$ \\
\hline $\begin{array}{l}\text { Citocina pró- } \\
\text { inflamatória }\end{array}$ & TNF- $\alpha$ & Macrófagos ativados & $\begin{array}{c}\text { Ativa epitélio, } \\
\text { endotélio, células } \\
\text { apresentadoras de } \\
\text { antígenos, monócitos / } \\
\text { macrófagos }\end{array}$ \\
\hline $\begin{array}{l}\text { Citocina pró- } \\
\text { inflamatória }\end{array}$ & IL-1 $\beta$ & $\begin{array}{c}\text { Monócitos, Macrófagos } \\
\text { ativados, células } \\
\text { endoteliais }\end{array}$ & $\begin{array}{c}\text { Ativação de } \\
\text { macrófagos e células } \\
\text { T. }\end{array}$ \\
\hline $\begin{array}{l}\text { Citocina pró- } \\
\text { inflamatória }\end{array}$ & IL-6 & Macrófagos, Monócitos & $\begin{array}{c}\text { Fator de crescimento } \\
\text { de células } T .\end{array}$ \\
\hline $\begin{array}{l}\text { Citocina pró- } \\
\text { inflamatória }\end{array}$ & IL-17 & Células T CD4 + & $\begin{array}{l}\text { Proliferação de células } \\
\text { T, Induz a liberação } \\
\text { de IL - } 6, \\
\text { IL - 8, } \\
\text { ativador de neutrófilos }\end{array}$ \\
\hline $\begin{array}{l}\text { Citocina anti- } \\
\text { inflamatória }\end{array}$ & IL-10 & Monócitos e Macrófagos & $\begin{array}{c}\text { Redução da ativação } \\
\text { de macrófagos e } \\
\text { redução Th1 e Th2 }\end{array}$ \\
\hline
\end{tabular}


A perpetuação da inflamação é uma característica importante da lesão do tecido pulmonar, estando associado ao aumento de muco, metaplasia do epitélio das vias respiratórias, alteração dos vasos sanguíneos e da matriz extracelular (MEC), com consequência da destruição do parênquima pulmonar e obstrução das vias aéreas menores [30] A principal citocina anti-inflamatória presente na DPOC é a interleucina 10 (IL-10) liberada por monócitos e macrófagos [24] O processo de remodelamento dessas vias aéreas menores está relacionado ao grau e a gravidade de obstrução ao fluxo aéreo [31]. O remodelamento das vias aéreas é sem dúvida um dos problemas mais difíceis na DPOC, uma vez que leva a perda irreversível da função pulmonar [32]. O desequilíbrio protease-antiprotease (as metaloproteinases e seus inibidores teciduais de metaloproteinases de matriz) e o estresse oxidativo têm sido relacionados a patogênese do enfisema pulmonar (decorrente do aumento ERO) e contribuem também com a perpetuação do quadro [33, 34].

Como já mencionado, é observado nos pacientes com a DPOC respostas imunes e adaptativas. Na resposta imune adaptativa em pacientes fumantes, temos aumento de células dendríticas, $\mathrm{T} \mathrm{CD4}^{+}$e $\mathrm{T} \mathrm{CD8}{ }^{+}$nas vias aéreas levando a liberação de TNF- $\alpha$, perpetuando a inflamação e a lesão pulmonar [35]. As células $\mathrm{T} \mathrm{CD8}^{+}$levam a degradação da $\mathrm{MEC}$ e do remodelamento, consequentemente piora do fluxo aéreo e do enfisema pulmonar [36]. Em relação as células $\mathrm{T} \mathrm{CD4}^{+}$, de acordo com as citocinas, podem ser divididas em células Th1, Th2, Th17 e T regulatórias (T reg) [37]. 
Apesar do tabagismo ser a principal causa da DPOC, a interrupção à exposição ao cigarro não resulta em resolução da resposta inflamatória nas vias aéreas [7], o que sugere que há mecanismos que perpetuem o processo inflamatório crônico, após este estar estabelecido. Os subtipos das células T $\mathrm{CD}^{+}$, Th17 e T reg tem um papel importante na progressão da DPOC [38, 39]. Entre essas, a Th 17 está caracterizada pela produção de IL-17 A, IL-17F [40] e podem ativar as células $T$ e o acumulo de neutrófilos nas vais aéreas já inflamadas. Doe et al. [40] demostraram que as concentrações de IL-17 estão aumentadas na submucosa brônquica de pacientes com DPOC que param de fumar. O aumento da concentração de IL-17 pode levar o acumulo de macrófagos, recrutamento de neutrófilos, aumento de secreção de muco e ao remodelamento da vias aéreas [41]. Há evidencias que a IL-17 contribui com a patogênese da DOPC [42] e para a sua gravidade [43].

\subsubsection{Papel das proteases e antiproteases}

O desequilíbrio de protease e antiprotease tem um papel importante na patogenia do enfisema, isso porque esse desequilíbrio ocasiona a destruição da parede alveolar decorrente da ação enzimáticas proteolíticas que degradam a MEC, afetando as fibras colágenas e elásticas. As proteases são divididas em três classes, serina protease, metaloproteinase da matriz (MMPs) e cisteína protease, que são responsáveis pela quebra do tecido conjuntivo no 
parênquima pulmonar especialmente a elastina, ocasionando o enfisema [33, 44].

A MMP pertence a uma família de enzimas que degradam e degeneram os componentes proteicos da MEC e tem um papel importante no desenvolvimento, remodelação e reparação de tecidos [44]. No enfisema pulmonar pode-se citar três MMPs relacionadas a essa doença: MMP-2, MMP9 e MMP-12. O principal inibidor das MMPs é o inibidor de tecido da família das metaloproteases (TIMPs). A família TIMP compreende quatro membros, TIMP$1,2,3$ e 4 [45].

A fumaça do cigarro ativa macrófagos, que expressam MMP-9 e MMP12, que decompõe a elastina em fragmentos que são quimiotáxicos, aumentando consequentemente o processo inflamatório e a destruição do parênquima pulmonar. Esse aumento das MMPs são neutralizadas pelas TIMPs, necessárias para o controle dessa destruição do parênquima [45].

Em um estudo Li et al. [46] observaram que os níveis elevados de

proteínas MMP-9 e TIMP-1 além de estarem correlacionados com a patogênese da DPOC, podem representar importantes marcadores biológicos para o diagnóstico precoce da DPOC.

\subsubsection{Papel do estresse oxidativo}

Como já mencionado acima, o estresse oxidativo também está envolvido na patogênese e progressão da DPOC e tem grande importância no início da inflamação [47]. O tabagismo causa um desequilíbrio de enzimas oxidantes e 
antioxidantes levando ao estresse oxidativo no pulmão e também a nível sistêmico. Os oxidantes oriundos da fumaça do cigarro (tanto da fase do alcatrão como da fase gasosa) atuam diretamente sobre o tecido, causando destruição de células, inativação do mecanismo de defesa, início da inflamação, resultando ainda mais estresse oxidativo [48].

Os radicais livres de oxigênio (aníons superóxido, peroxido de hidrogênio e hidroxila) podem ser formados a partir da fumaça de cigarro [48], ou após ativação de diferentes células inflamatórias (macrófagos, neutrófilos e eosinófilos) [34]. A exposição à diferentes tipos de partículas, além da fumaça do cigarro, como queima de biomassa e partículas de poluição do ar ou mesmo situações nas quais os sistemas antioxidantes do organismo estão diminuídos, ocorre aumento dos níveis de espécies reativas de oxigênio (ROS) e espécies reativas de nitrogênio (RNS), que são responsáveis por diferentes efeitos que prejudicam as vias aéreas, causando diversas condições patológicas [34, 48].

Durante as exarcebações da DPOC há aumento da concentração de peróxido de hidrogênio exalado pelos pacientes, também se observa aumento da concentração de 8-isoprostano, que é um marcador do estresse oxidativo no sangue, na urina e condensado da respiração $[48,49]$. 


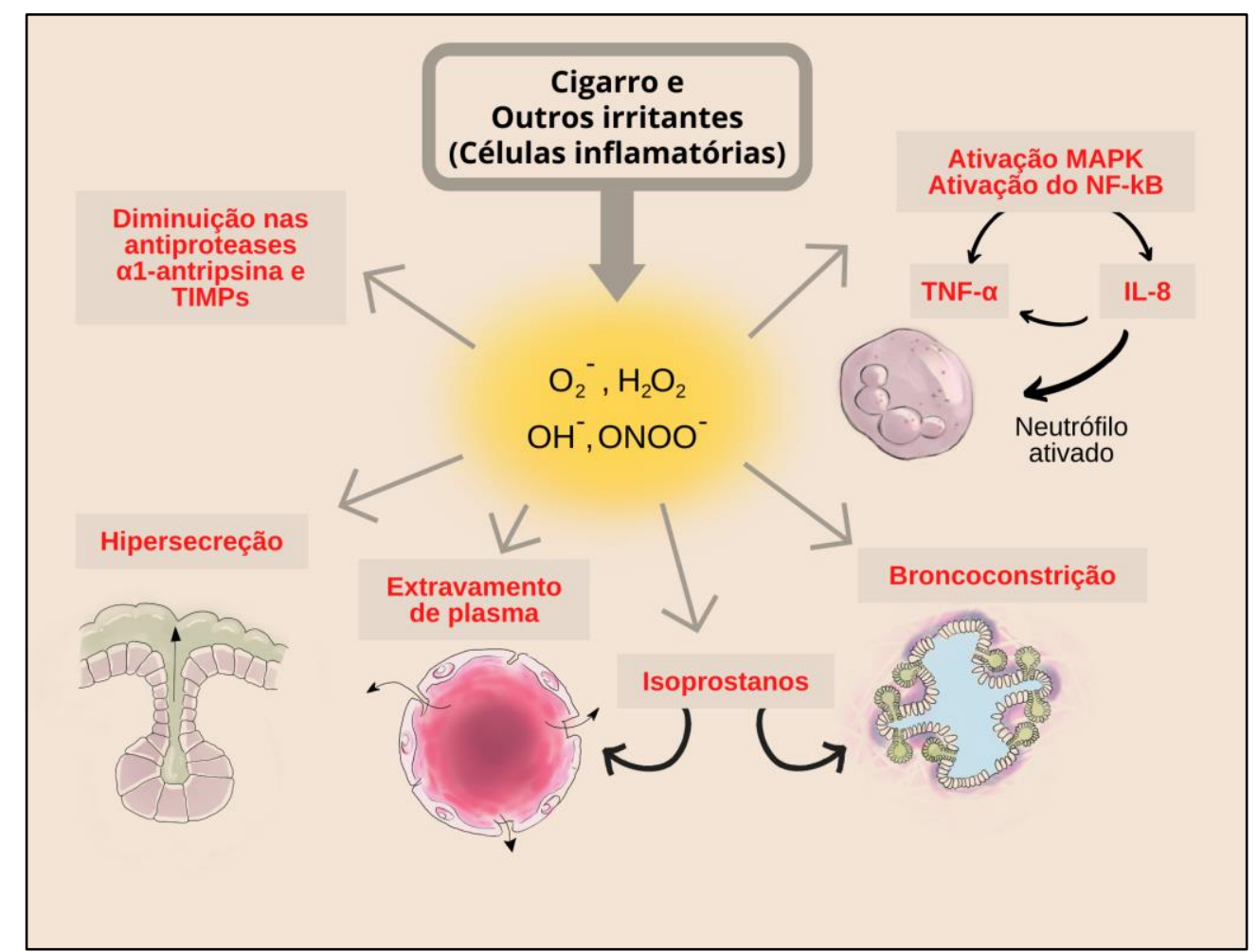

Figura 3. Fisiopatologia do enfisema pulmonar - Estresse oxidativo: As espécies reativas de oxigênio decorrente da fumaça do cigarro e outros irritantes podem causar diferentes efeitos prejudiciais no pulmão como: a redução de antiprotease, a ativação de MAPK e ativação do NF-KB, resultando no aumento de citocinas pró-inflamatórias IL-8 e TNF- $\alpha$. O aumento do isoprostano induz a broncoconstrição e extravasamento de plasma. Além disso, as espécies reativas de oxigênio podem levar o aumento de muco. (Modificado de Barnes PJ, 2004) [27].

\subsubsection{Papel de JAK/STATS e SOCS}

As citocinas são mediadores extracelulares responsáveis em transmitir sinais entre as células e consequentemente são responsáveis na manutenção da homeostase inflamatória [49]. Esses sinais podem ser recebidos por diferente receptores, como pode ocorrer com as proteínas Janus quinases (JAKs) que uma vez acionada, ativa STAT (Transdutor e Ativação de Transcrição de Sinal) [50]. Para manter essa homeostase existem as proteínas 
supressoras da sinalização JAK/STAT conhecidas como SOCS (Supressor de sinalização de Citocinas de Sinalização) [51].

Considerando o papel da STAT na perpetuação dos processos inflamatórios, incluindo os envolvidos na progressão da DPOC, Maritano et al. [52] demonstraram aumento das proteínas fosforilação de STAT1 e STAT3 em indivíduos fumantes com ou sem obstrução pulmonar.

A IL-6 no pulmão pode ser produzida por diferentes fontes, como células epiteliais, macrófagos e outras células inflamatórias. Após sua ligação ao receptor gp130, IL-6 ativa JAK que fosforiza STAT3, induzindo sua translocação para o núcleo e com isso ocorre a liberação de diferentes citocinas pró-inflamatórias causando uma ação pró-inflamatório no pulmão [53]. Uma vez que o STAT3 está ativado, este regula SOCS3 que aumenta a expressão de proteínas anti-inflamatórias através da sua ligação ao receptor gp130 que irá inibir atividade da JAK [49]. Apesar de poucos estudos relatarem o papel da SOCS na progressão da DPOC [54], Springer et al sugeriram que o desequilíbrio dos supressores de citocinas (SOCS) e da liberação de citocinas inflamatórias desempenham um importante papel na progressão da DPOC, uma vez que foi observado uma diminuição da expressão da SOCS3 em tecidos de biopsia pulmonar em pacientes com DPOC [55]. 


\subsection{Sistema colinérgico na resposta inflamatória}

A inflamação é uma resposta que o organismo dispõe para localizar, neutralizar e eliminar um agressor, promovendo dessa forma a homeostase. No entanto, esse restabelecimento pode não ser atingido, devido a uma quantidade excessiva de mediadores pró-inflamatórios na circulação, resultando em uma inflamação sistêmica, falha do sistema e até a morte [56]. O nervo vago tem um papel importante nesses processos regulatórios, isto porque possuem fibras que transportam sinais sensoriais ascendente para 0 Sistema Nervoso Central (SNC) e sinais motores descendentes para outros órgãos [57]. A resposta da inflamação é controlada e autorregulada pela interação do sistema SNC e imune que são fundamentais para a modulação da resposta imune inata no processo inflamatório [58].

Há exatamente 21 anos, Borovikova et al. [59] descreveram pela primeira vez o arco reflexo da inflamação com a descoberta da via colinérgica anti-inflamatória. O sistema colinérgico anti-inflamatório é um mecanismo neural que suprime a resposta inflamatória inata e controla a inflamação por inibição da liberação de citocinas pró-inflamatórias, como o TNF- $\alpha$. A interação do sistema nervoso e imunológico na tentativa de regular a inflamação através das fibras sensitivas do nervo vago, iniciam o reflexo da inflamação. O foco inflamatório libera mediadores químicos, estes estímulos são transmitidos por via de fibras aferentes vagais ao núcleo do trato solitário e ativam os neurônios vagais eferentes [60] liberando seu principal neurotransmissor, acetilcolina (ACh). A ACh interage, neste caso principalmente, com os receptores 
nicotínicos a7 ( $\alpha 7 \mathrm{nAChR}$ ) (do inglês, $\alpha 7$ nicotinic acetycholine receptor, receptor nicotínico $\alpha 7$ de acetilcolina), expressos principalmente em macrófagos, para suprimir a liberação de TNF-a e outras citocinas próinflamatórias, como as interleucinas (IL1 $\beta$ e IL6) na tentativa de controlar a resposta inflamatória (Figura 4).

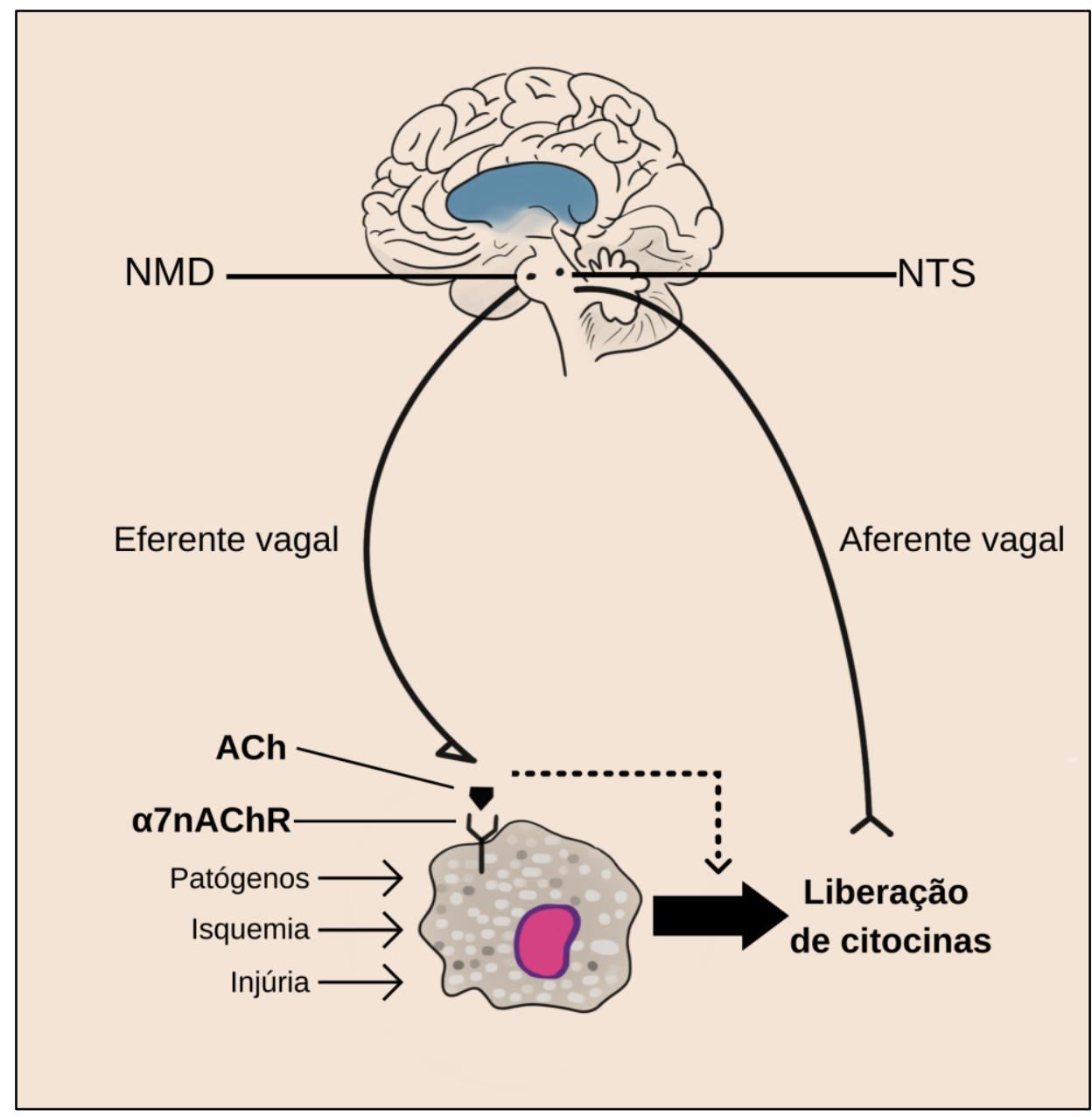

Figura 4. Arco reflexo da inflamação: Patógenos, isquemia e outras lesões induzem a resposta inflamatória, levando a liberação de citocinas pelo sistema imunológico que serão detectadas pelo nervo vago aferente. Estas informações são transmitidas ao núcleo do trato solitário (NTS) que faz sinapse com núcleo motor dorsal (NMD), resultando em ativação do nervo vago eferente (denominado via colinérgica anti-inflamatória). A atividade do nervo vago eferente estimula a liberação do seu principal neurotransmissor, acetilcolina (ACh), que inibe a produção de citocinas pró-inflamatórias, provavelmente via ativação $\alpha 7 n A c h R$ localizado principalmente em macrófagos e em outras células do sistema imunológico (Adaptado de Johnston e Webster, 2009) [61]. 
O sistema nervoso colinérgico está envolvido em diversas funções fisiológicas do organismo. No sistema respiratório, a via descendente vagal inerva a laringe, traqueia, porção condutora dos brônquios e as fibras não mielinizadas inervam também glândulas e a musculatura lisa das vias aéreas [62]. A estimulação nervosa parassimpática induz a liberação de ACh que induz a contração da musculatura lisa traqueobrônquica e aumento da secreção de muco. Por outro lado, a via simpática que também libera ACh pelas fibras préganglionares, tem como neurotransmissor pós-ganglionar a noradrenalina, que atua no pulmão relaxando a musculatura lisa $[63,64]$.

A ACh é um éster de ácido acético e colina, que possui um papel importante no controle das funções fisiológicas do SNC e periférico (SNP) [65]. A Colina-O-acetil-Transferase (ChAT) é a enzima responsável pela síntese da ACh a partir do substrato de acetil-CoA e colina [66]. Uma vez sintetizada, a ACh é transportada para o interior das vesículas sinápticas pelo transportador vesicular de acetilcolina (VAChT) e posteriormente as vesículas liberam ACh na fenda sináptica $[67,68]$. Após ser liberada, a ACh interage com receptores colinérgicos muscarínicos (mAChR) e nicotínicos (nAChR) tanto em órgãos alvos quanto em neurônios, presentes na membrana pós- sináptica [60, 65, 69, 70]. A ação da ACh cessa, quando essa é hidrolisada em acetato e colina pela enzima acetilcolinesterase (AChE), presente na fenda sináptica [71]. A colina retorna ao terminal nervoso através do transportador de colina de alta afinidade (CHT1) e um novo ciclo da síntese da ACh reinicia [68, 72]. 


\subsubsection{Receptores muscarínicos}

Os mAChR pertencem à família de receptores acoplados a proteína $\mathrm{G}$ e são cinco os subtipos de receptores muscarínicos (M1 - M5) [73], sendo que os subtipos M1, M2 e M3 são os de maior papel fisiológico no pulmão e os subtipos M2 e o M3 estão mais presentes na musculatura lisa da via aérea na proporção de 4:1. O M3 é o mais envolvido na contração da musculatura brônquica e traqueal, no recrutamento de células inflamatórias e aumento da secreção brônquica [74]. O aumento da secreção de muco é uma característica patológica observada na DPOC, contribuindo para a limitação do fluxo aéreo [75].

Os receptores M1, M2 e M3 foram estudados no escarro de pessoas saudáveis, fumantes e em pacientes portadores de DPOC e estes receptores foram observados em macrófagos e neutrófilos, sendo que o receptor M3 apresentou-se aumentando significativamente nos pacientes com DPOC [76].

A ACh age como um potente bronconstritor ao se ligar aos mAChR, o que explica a utilização dos anticolinérgicos como broncodiladores, principalmente os antagonistas muscarínicos, no tratamento das doenças respiratórias. O efeito mais importante parece ocorrer com o bloqueio dos receptores M2 e M3, por meio dos anticolinérgicos de curta e LAMA [77]. 


\subsubsection{Receptores nicotínicos}

Os nAChRs estão localizados nas membranas plasmáticas das células do músculo esquelético, neurônios e células não neuronais e são do tipo canais iônicos regulados por ligantes e podem ser compostos pela combinação de 17 diferentes tipos de subunidades ( $\alpha 1-10, \beta 1-4, \delta, \varepsilon, \gamma)[78,79]$ e sua ativação, gera abertura do canal permitindo a entrada de sódio e cálcio e saída de potássio [79]. Em contraste aos efeitos deletérios da ACh no pulmão quando atua via receptores muscarínicos, o papel da ACh em receptores nicotínicos na resposta inflamatória pulmonar parece ter um efeito benéfico, confirmando a importância deste receptor possa estar envolvido no sistema colinérgico antiinflamatório [80].

Com a descoberta da via colinérgica anti-inflamatória, vários estudos têm sido descritos com diferentes modelos de inflamação animal e de ativação ou inibição dessa via como: a estimulação elétrica ou inibição do nervo vago [81, 82], vagotomia [83, 84], uso de fármacos que inibam a AChE [85] e o uso de fármaco agonista ou antagonista de receptores específicos [86, 87].

Em 2007, Huston et al. [81], mostraram em modelo experimental de endotoxemia, que a estimulação elétrica no nervo vago eferente diminuiu a produção de citocinas pró-inflamatórias, inibindo a resposta inflamatória aguda no choque hipovolêmico e diminuição da inflamação intestinal. Já Hofer et al. [88], administraram fisostigmina ou neostigmina (inibidor da AChE) e observaram aumento da sobrevida de camundongos com sepses experimental. Ainda $\mathrm{Li}$ et al. [83], observaram que com a vagotomia induziu aumento da 
expressão de TNF-a, IL-6 e a proteína do grupo de alta mobilidade 1 (HMGB1) detectados por ELISA ou por imunohistoquímica em modelo de artrite em camundongos, e em modelo de peritonite séptica aumentou citocinas próinflamatórias e o influxo de células inflamatórias [84].

Os efeitos do sistema colinérgico anti-inflamatório nas doenças pulmonares foram poucos estudados até o momento, e os efeitos da ACh dependerá do tipo de receptor em que atue, como citado acima. Recentemente nosso grupo estudou a deficiência de VAChT (transportador vesicular de ACh) em modelo animal com redução de VAChT e lesão pulmonar induzida por LPS e observou aumento das células inflamatórias, demonstrando que o sistema colinérgico anti-inflamatório está envolvido no controle da resposta inflamatória pulmonar [89]. Demonstramos ainda que a redução de VAChT aumenta a resposta inflamatória em modelo de asma [90] e de inflamação pulmonar induzida pela poluição atmosférica [91]. Mais recentemente, demonstramos ainda que a redução de VAChT piora a inflação pulmonar induzida por elastase (dados ainda não publicados).

Jeremias et al. [92] ao estudarem um modelo de sepse induzido por ligadura cecal em animais com deficiência de VAChT, observaram diminuição das células T helper e citotóxica e aumento de células Th17 além de aumento nas citocinas IL-1 $1 \beta$, IL-6 e TNF- $\alpha$, concluindo que a ACh modula a resposta inflamatória durante a sepses pela via de IL-17. Ainda, recentemente demonstramos que fêmeas com redução de VAChT, não conseguem produzir 
citocinas e morrem após indução de lesão pulmonar aguda devido a isquemia e reperfusão intestinal [93].

Johnston et al. [61] demostraram que $\alpha 7 n A C h R$ é essencial para o efeito anti-inflamatório da ACh em diversos órgãos. O a7nAChR está expresso em células do sistema imune como macrófagos, linfócitos $T$ e $B$, células dendríticas, inclusive em células epiteliais alveolares [86, 94, 95]. Wang et al. [95] estudaram a importância do $\alpha 7 n A C h R$ na via anti-inflamatória em animais Knockout para $\alpha 7 n A C h R$ e foi observado aumento de citocinas (TNF- $\alpha$, IL-1, IL6, IL-8 e HMGB1) no baço, no fígado e em macrófagos. Contudo a maioria dos estudos no pulmão foram realizados em modelos de lesão aguda [94, 96, 97], deixando uma lacuna nos modelos de enfisema pulmonar.

Muitas pesquisas têm tentado explicar os mecanismos envolvidos no controle da inflamação pelo $\alpha 7 n A C h R$, atualmente tem sido descrito duas principais vias: a) As citocinas pró-inflamatórias como TNF- $\alpha$ e as interleucinas, através do arco reflexo, estimulam o nervo vago a liberar ACh que interage com a7NAChR e inibe a translocação do NF-אB para o núcleo, inibindo a cascata inflamatória [96]; b) na segunda hipótese, a ativação do a7 recruta a JAK2 que promove a fosforilação e ativação de STAT3. Essa via JAK2/STAT3 induz a expressão de citocinas anti-inflamatórias como a SOCS3 [56, 94]. Também se observou um aumento da SOCS3 com ativação do STAT3 [94], em células epiteliais no cólon em patologias intestinais [98] e na artrite reumatoide em modelos experimentais [99]. Pinheiro et al. [100] mostraram que animais 
com deficiência colinérgica apresentam inflamação pulmonar com aumento da expressão de NF-KB e redução da via JAK2-STAT3-SOCS3.

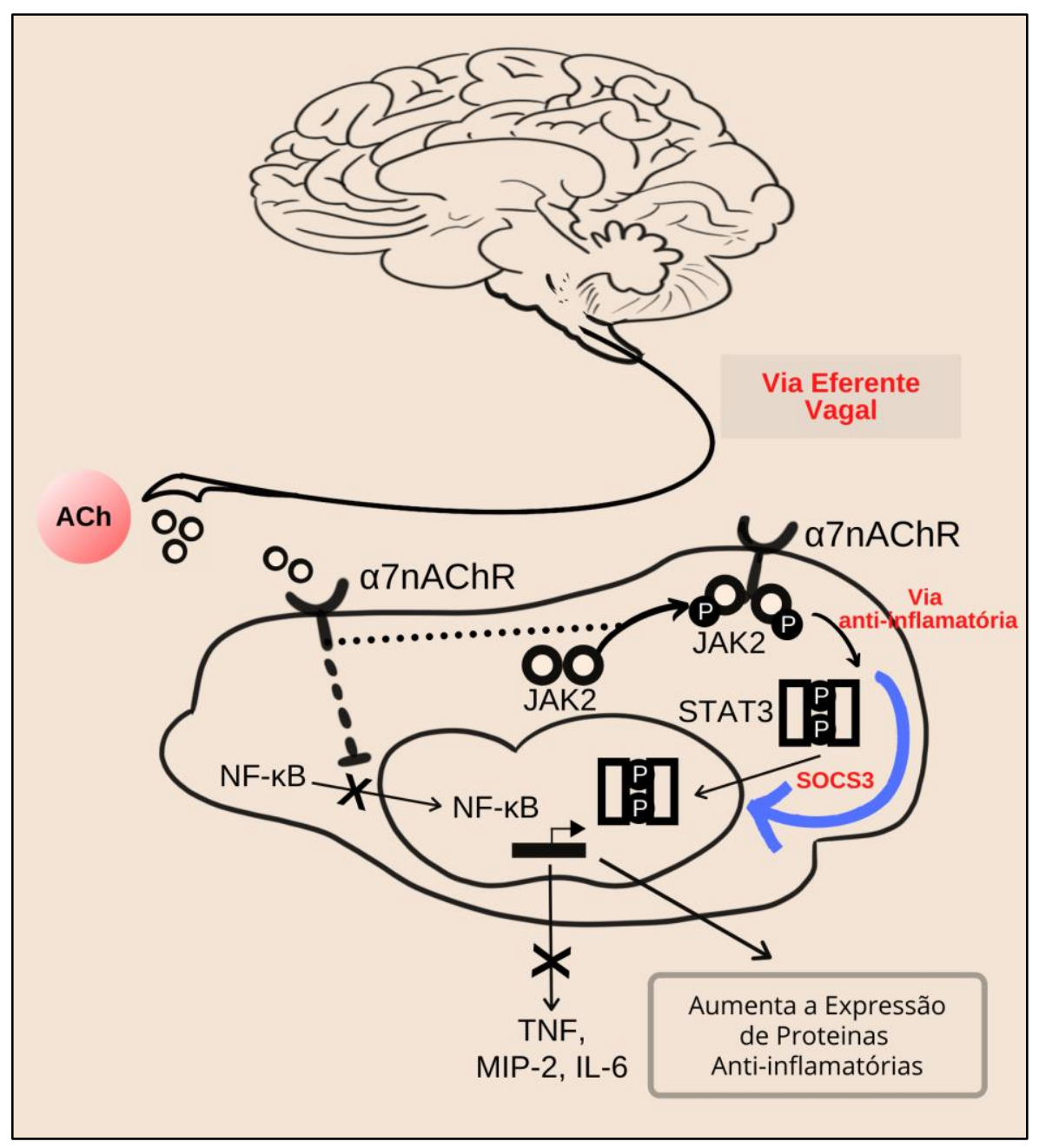

Figura 5. Mecanismos envolvidos na resposta colinérgica anti-inflamatória: Durante uma inflamação tecidual, há liberação de mediadores químicos que ativam as fibras sensitivas do nervo vago iniciando o arco reflexo aferente da inflamação, que ativa o tronco cerebral. Em seguida os neurônios vagais eferentes liberam ACh que ativa o $\alpha 7 n A C h R$ inibindo a

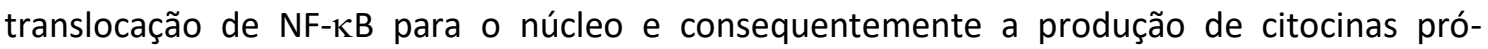
inflamatórias. A ativação do $\alpha 7 n A C h R$ também atua sobre via JAK2/STAT3, que desempenha um papel na sinalização de citocinas anti-inflamatórias. SOCS-3 levará à inibição da ativação das células imunes e de supressão de TNF- $\alpha$, a síntese da proteína inflamatória-2 (MIP-2) e IL-6 de macrófagos. (Modificado de Gallowitsch-Puerta, e Pavlov, 2007) [58]. 
Em relação a estudar $\alpha 7 n A C h R$ no controle da inflamação, alguns trabalhos utilizam animais knock-out ou tratamento com agonistas inespecíficos como a nicotínica ou agonistas mais específicos. Blanchet et al. [101] utilizaram um agonista nicotínico não seletivo em modelo experimental de asma, e observaram a diminuição do influxo total de células inflamatórias e a eosinofilia pulmonar. Já Giebelen et al. [102] utilizaram um agonista seletivo do a7nAChR, GTS-21, em modelo experimental de inflamação pulmonar induzida por instilação de LPS e observaram a diminuição dos níveis TNF-a. Ainda Douaoui et al. [103] utilizaram o agonista seletivo GTS-21 em células oriundas do plasma de pacientes com DPOC (estáveis e em exacerbação) e puderam observar uma diminuição significativa dos níveis de IL-6 e NO, sugerindo que que ativação das vias pró-inflamatórias na células de pacientes com DPOC são sensíveis ao GTS-21, agonista seletivo do $\alpha 7 \mathrm{nAChR}$.

Neste sentido, o PNU-282987 [N-[(3R)-1-azabiciclo[2.2.2]oct-3-yl]-4clorobenzamida hidrocloridrato] tem sido descrito como um potente e seletivo agonista do a7nAChR [104] e com pouca interação com os outros tipos de nAChR [105]. Como temos observado na literatura, o $\alpha 7 n A C h R$ possui um papel importante na regulação da resposta anti-inflamatória e a ativação da sinalização de $\alpha 7 n A C h R$ pelo PNU-282987 tem sido utilizado em vários estudos como por exemplo em cefaleia crônica [106], na isquemia hepática [107], hemorragia subaraquinoideo [108], distúrbios de comportamento [105], 
em modelo de lesão pulmonar aguda [86] e na prevenção da lesão pulmonar induzida pela ventilação mecânica [109].

O PNU-282987 tem alta afinidade ao $\alpha 7 \mathrm{nAChR}$ e seu tempo de meia vida in vitro é de 0,120 minutos, mas não temos o conhecimento da meia vida em camundongos após injeções intraperitoneais. Para determinar se os efeitos da ativação dos nAChR são diretamente relacionados ao subtipo $\alpha 7$, estudos têm sido realizados com antagonista específico metillicaconitine (0 3-metil-2,5dioxopirrole) (MLA) [110]. A meia vida do MLA é de aproximadamente 20 minutos, após o uso de injeção intraperitoneal em camundongos [111].

\subsection{Justificativa do estudo}

É certo que ACh tem um papel modulador na inflamação pulmonar e recentemente demonstramos, utilizando animais geneticamente modificados com redução da ACh, que os animais com deficiência colinérgica submetidos ao protocolo de enfisema pulmonar apresentaram piora da resposta inflamatória aumentando o número de macrófagos e das citocinas (principalmente de MCP-1), sugerindo assim que o sistema nervoso colinérgico desempenha um papel importante para limitar a inflamação. Considerando o papel antagônico da ACh na modulação da resposta inflamatória pulmonar, estudos que elucidem os efeitos dos receptores nicotínicos no controle do enfisema pulmonar são de extrema relevância. 
Considerando que a estimulação farmacológica com agonistas do a 7 a7nAChR tem sido benéfica em diversos modelos de inflamação aguda [112], acreditamos que este receptor seja um importante alvo terapêutico no manejo do enfisema. Para esta estimulação farmacológica, utilizamos o PNU-282987 descrito como um potente e seletivo agonista do $\alpha 7 \mathrm{nAChR}$ [104]. 
2.OBJETIVOS 


\subsection{Geral}

Avaliar se a estimulação farmacológica com um agonista do receptor a7nAChR, PNU-282987, interfere com nas alterações pulmonares observadas em modelo experimental de enfisema pulmonar induzida pela elastase em camundongos.

\subsection{Específico}

Avaliar se o tratamento com agonista do receptor $\alpha 7 \mathrm{nAChR}$, PNU282987, interfere nos seguintes aspectos:

- Na mecânica pulmonar,

- No diâmetro alveolar médio;

- Na inflamação pulmonar (células e citocinas)

- No remodelamento pulmonar

- No estresse oxidativo

- Na sinalização celular (STAT3 e SOCS3). 
3.MATERIAL E MÉTODOS 
Este estudo foi aprovado pela Comissão de Ética no Uso de Animais (CEUA) do Hospital das Clínicas da Faculdade de Medicina da Universidade de São Paulo, protocolo número SPF 111/16. Os animais foram manejados de acordo com o Guia Brasil de produção manutenção de animais em atividades de ensino ou pesquisa científica (CONCEA) de 2019 [113], e foram mantidos num ciclo de 12 horas de luz/escuro, em uma sala com temperatura controlada de 21 a $23^{\circ} \mathrm{C}$, com livre acesso a água e comida.

Foram utilizados camundongos C57BL/6, machos, peso médio 25g, idade entre 6 e 8 semanas, provenientes do Biotério Central da Faculdade de Medicina da Universidade de São Paulo. Estes animais foram mantidos no biotério conjunto de manutenção dos Laboratórios de Investigação Médica LIM- 20.

\subsection{Grupos Experimentais}

Os animais foram divididos aleatoriamente nos seguintes grupos, conforme descrito na Tabela 3. 
Tabela 3: Randomização dos grupos e metodologia

\begin{tabular}{|c|c|c|c|}
\hline Grupos & Metodologia & $\begin{array}{l}\text { Mecânica e Análise } \\
\text { Morfométrica }\end{array}$ & $\begin{array}{l}\text { Analise } \\
\text { WB/Elisa }\end{array}$ \\
\hline CONTROLE & $\begin{array}{l}\text { Instilação de Sal e VE } \\
(2 \mathrm{mg} / \mathrm{kg}) \text { intraperitoneal }(0, \\
\left.7,14,21 \text { e } 28^{\circ}\right)\end{array}$ & $n=8$ & $n=6$ \\
\hline SAL+PNU & $\begin{array}{l}\text { Instilação de Sal e PNU } \\
(2 \mathrm{mg} / \mathrm{kg}) \text { intraperitoneal }(21 \text {, } \\
22,23,24,25,26,27 \mathrm{e} \\
\left.28^{\circ}\right) .\end{array}$ & $n=4$ & $n=0$ \\
\hline PPE & $\begin{array}{l}\text { Instilação de Elastase no } \\
\text { primeiro dia e VE }(2 \mathrm{mg} / \mathrm{kg}) \\
\text { intraperitoneal }(0,7,14,21 \\
\left.\text { e } 28^{\circ}\right) \text {. }\end{array}$ & $n=8$ & $n=7$ \\
\hline PPE-PRÉ & $\begin{array}{l}\text { Instilação de Elastase no } \\
\text { primeiro dia e PNU } \\
(2 \mathrm{mg} / \mathrm{kg}) \text { intraperitoneal }(0 \text {, } \\
\left.7,14,21 \text { e } 28^{\circ}\right)\end{array}$ & $n=8$ & $\mathrm{n}=7$ \\
\hline PPE-PÓS & $\begin{array}{l}\text { Instilação de Elastase no } \\
\text { primeiro dia e PNU } \\
\text { ( } 2 \mathrm{mg} / \mathrm{kg} \text { ) intraperitoneal }(21 \text {, } \\
22,23,24,25,26,27 \text { e } \\
\left.28^{\circ}\right) .\end{array}$ & $n=7$ & $n=10$ \\
\hline MLA & $\begin{array}{l}\text { Instilação de Elastase no } \\
\text { primeiro dia. Instilação de } \\
\text { MLA (2mg/kg) } \\
\text { intraperitoneal } 30 \text { min antes } \\
\text { do PNU }(2 \mathrm{mg} / \mathrm{kg}) \\
\text { intraperitoneal }(21,22,23 \text {, } \\
\left.24,25,26,27 \text { e } 28^{\circ}\right) \text {. }\end{array}$ & $n=5$ & $n=4$ \\
\hline
\end{tabular}

\subsubsection{Protocolo de indução do enfisema pulmonar}

Para induzir o enfisema, os animais foram anestesiados com xilazina $(5 \mathrm{mg} / \mathrm{kg})$ e ketamina $(40 \mathrm{mg} / \mathrm{kg})$ e em seguida receberam uma instilação

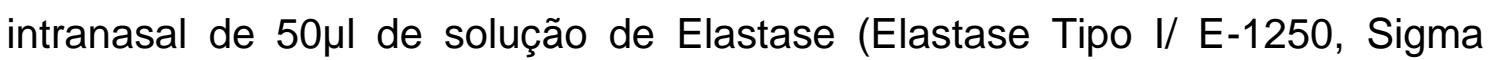
Aldrich) $(0,667 \mathrm{IU})$. O grupo controle recebeu a instilação intranasal de solução 
salina no mesmo volume. Todos os animais foram avaliados após 28 dias da instilação de elastase ou solução salina [114]. Este protocolo também já foi utilizado por nosso grupo [115].

\subsubsection{Tratamento com PNU-282987 e pré-tratamento com metillicaconitine (MLA) \\ O agonista seletivo (PNU 282987) do $\alpha 7 n A C h R$, foi administrado} injeções intraperitoneais de $2 \mathrm{mg} / \mathrm{kg}$ diluídas em solução salina de $100 \mu \mathrm{l}$ [86] 30 minutos após instilação de elastase ou salina, e também receberam a mesma dosagem do PNU-282987 no sétimo, decimo quarto e vigésimo primeiro dia (grupo PPE-Pré). No dia 28 foi administrado a mesma dosagem de PNU28298730 minutos antes de iniciar a mecânica.

Ainda um outro grupo foi tratado com a mesma dose de 2,0mg/Kg de PNU282987, somente a partir do dia 21 (momento que o enfisema já está instalado) até o $28^{\circ}$ dia, diariamente (grupo PPE-Pós), na mesma concentração.

O tratamento com metillicaconitine (MLA), um antagonista seletivo do a7nAChR, foi administrado em parte dos animais na dose de $2 \mathrm{mg} / \mathrm{kg}[96,116]$ 30 minutos antes do tratamento com PNU-282987 a partir do dia 21 (diariamente) até o $28^{\circ}$ dia, a fim de observar se os efeitos de PNU-282987 eram realmente dependentes do $\alpha 7 \mathrm{nAChR}$. Os animais controles e PPE foram submetidos ao tratamento com veículo (salina) (Figura 6).

Os animais dos grupos controles e PPE foram submetidos ao tratamento com veículo (salina). 


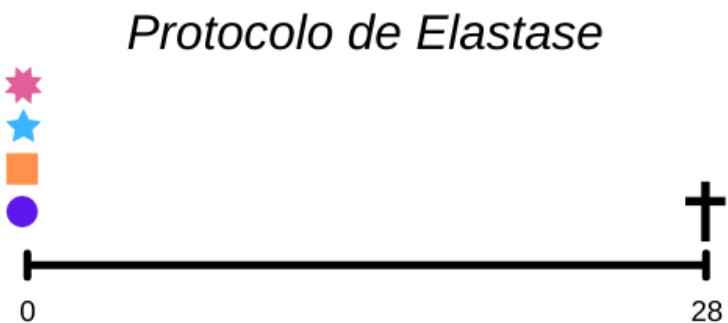

Instilação intranasal de elastase no dia 0: Grupos PPE; PPE-Pré, PPE-Pós e MLA

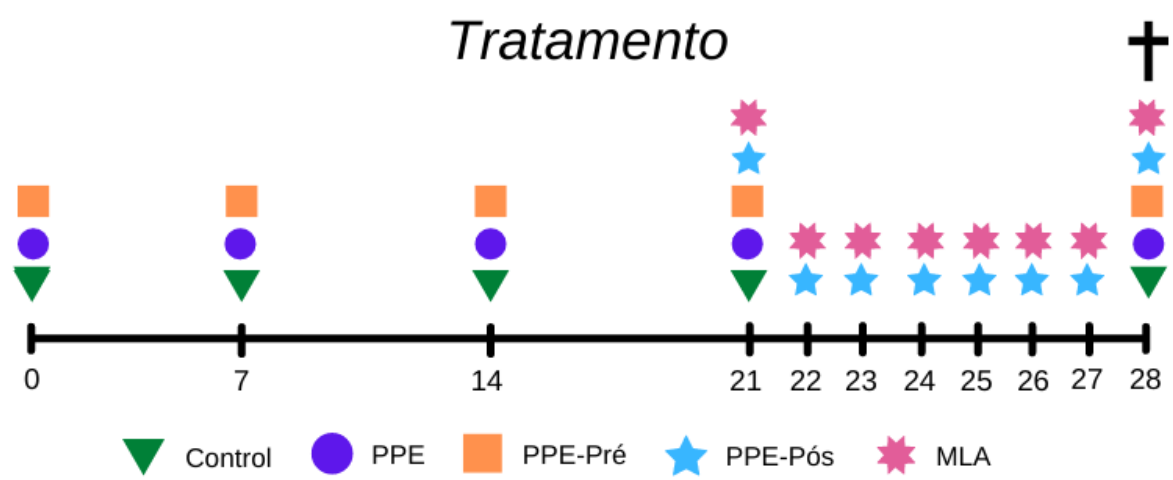

- CONTROL: instilação de salina e veículo intraperitoneal (0, 7, 14, 21 e 28).

- PPE: Instilação de elastase no dia 0 e veículo como tratamento (salina) $(0,7$, 14, 21 e 28)

- PPE-Pré: Instilação de elastase no dia 0 e tratamento intraperitoneal com PNU282987 (0, 7, 14, 21 e 28);

- PPE-Pós: Instilação de elastase no dia 0 e tratamento intraperitoneal com PNU-282987 (21, 22, 23, 24, 25, 26, 27 e 28)

- MLA: Instilação de elastase no dia 0 e tratamento com MLA 30 minutos depois do tratamento intraperitoneal com PNU-282987 (21, 22, 23, 24, 25, 26, 27 e 28)

Figura 6. Protocolo experimental: Exemplificação do protocolo de indução da elastase e o protocolo de tratamento com salina, PNU-282987 e MLA. 


\subsection{Avaliação da mecânica do sistema respiratório}

Após 28 dias do protocolo de elastase ou solução salina, os animais foram anestesiados 30 minutos após receberem a última dose $(2,0 \mathrm{mg} / \mathrm{Kg})$ de PNU, com uma injeção intraperitoneal de Tiopental $(70 \mathrm{mg} / \mathrm{kg})$, foram pesados, traqueostomizados e conectados a um respirador para pequenos animais (Flexivent, Scireq, Montreal, CA) com volume corrente de $10 \mathrm{~mL} / \mathrm{kg}$ e 150ciclos/min. Os dados de oscilação forçada foram obtidos após os animais serem paralisados com uma injeção de brometo de pancrônio $(0,2 \mathrm{mg} / \mathrm{kg})$.

Para o cálculo dos dados foram feitas correções, considerando as perdas devido à compressibilidade dos gases [117] $\mathrm{V}_{c y l}$ foi corrigido a fim de obter o volume que efetivamente chega ao animal (V) e $\mathrm{P}_{\text {cyl }}$ foi corrigido, nos dando o valor de $\mathrm{P}_{a o}$, pressão de abertura das vias aéreas. Através da derivação no tempo de $\mathrm{V}$, obtivemos o fluxo (V'). E para análise das impedâncias, foi utilizado o modelo de fase constante, descrito por Hantos et al. $Z(f)=R_{a w}+i \cdot 2 \cdot \pi \cdot f \cdot I_{a w}+\frac{G-i \cdot H}{(2 \cdot \pi \cdot f)^{\alpha}}$

Onde Raw é a resistência de vias aéreas, law é a inertância, Gtis caracteriza a dissipação de energia nos tecidos pulmonares, Htis a energia acumulada no tecido do pulmão, $i$ é a unidade imaginária, $f$ é a frequência e $\alpha=\frac{2}{\pi} \cdot \arctan \left(\frac{H}{G}\right)$.

Esse modelo fase-constante considera o sistema pulmonar de forma multicompartimental, permitindo a obtenção de dados de diferentes compartimentos do pulmão: resistência das vias aéreas (Raw) onde podemos 
analisar as vias aéreas sem a interferência tecidual; resistência tecidual (Gtis) e elastância do tecido ( Htis).

\subsection{Lavado broncoalveolar (LBA)}

Ao final da avaliação mecânica, os animais foram exanguinados via secção da aorta abdominal e o LBA foi coletado [118] por meio da infusão de $0,5 \mathrm{~mL}$ de solução salina por 3 vezes consecutivas (volume total de $1,5 \mathrm{~mL}$ ). $\mathrm{O}$

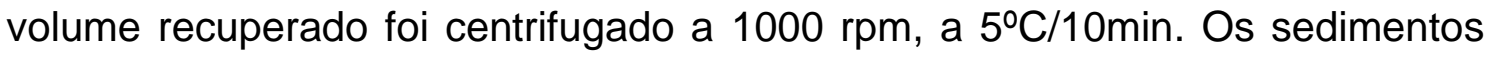
das células foram ressuspensos em $0,2 \mathrm{~mL}$ de solução salina estéril. A contagem total de células foi realizada por microscopia óptica com auxílio de hemocitômetro de Neubauer no aumento de 400x.

Para a contagem do diferencial celular, 100 $\mu \mathrm{L}$ do BALF foi citocentrifugado a $450 \mathrm{rpm} / 6 \mathrm{~min}$ (Cytospin, Chehire, UK) e após secar as lâminas, estas foram coradas pela técnica de Diff-Quick (Biochemical Sciences INC, Swedesboro, NJ). Pelo menos 300 células foram contadas seguindo critérios hemocitológicos para diferenciação de neutrófilos, eosinófilos, linfócitos e macrófagos com auxílio de um microscópio óptico com objetiva de imersão (aumento de 1000x) [100]. Os resultados foram expressos em células por $m L$ de LBA.

\subsection{Estudo morfométrico}

Após a coleta do LBA, os pulmões foram removidos em bloco e fixados com formaldeído a $4 \%$ durante 24 horas a uma pressão constante de 20 $\mathrm{cmH}_{2} \mathrm{O}$. Os pulmões, em seguida, foram transferidos para uma solução de 
etanol a $70 \%$ e submetidos às técnicas habituais com parafina, para obtenção de cortes de $4 \mu \mathrm{m}$ de espessura.

Para morfometria convencional, foi utilizado um retículo de 100 pontos e 50 retas, acoplado à ocular de um microscópio óptico convencional ou pela quantificação no analisador de imagens, sendo que o pesquisador desconhecia a que grupo pertencia o animal.

\subsubsection{Medidas do Intercepto linear médio (Lm)}

O Lm é um índice do diâmetro dos espaços aéreos distais. Foram contados 15 campos por lâmina, por meio de um microscópio óptico $(\mathrm{CH} 30$, Olympus, Japão) com aumento de 200x, utilizando o retículo sobreposto ao parênquima pulmonar nas regiões distais. Foi contado o número de vezes que o intercepto cruzava a parede dos alvéolos [67, 118].

Foi feita a média dos quinzes campos para cada lâmina e calculado o Lm através da seguinte equação:

$$
\operatorname{Lm}=\frac{2500 \mu m}{\begin{array}{l}
\text { média do número de vezes } \\
\text { que o intercepto cruzou a } \\
\text { parede dos alvéolos. }
\end{array}}
$$




\subsubsection{Remodelamento pulmonar}

Para obtenção da medida das fibras de colágeno, foi realizada a coloração para a contagem das fibras colágenas no parênquima pulmonar usando Sirius-Red (Direct Red 80, C> I 35780, Aldrich, EUA). Os cortes foram desparafinados e levados à água. Foram corados por 1 hora no picro-sírius à temperatura ambiente e posteriormente lavada em água corrente por 5 minutos. Após esta etapa, os cortes foram corados pela Hematoxilina de Harris por 6 minutos e posteriormente lavados em água corrente por 10 minutos. Por fim, as lâminas foram montadas [67].

Já para a obtenção das medidas das fibras elásticas, foi utilizado para sua coloração a Resorcina-Fucsina de Weigert Oxidada. Para tanto, os cortes foram desparafinados e hidratados em água. Sobre eles, foi gotejada uma solução aquosa de OXONA $10 \%$ e ficaram oxidando por 40 minutos. Foram então lavados em água corrente por 5 minutos e após foram submersos no

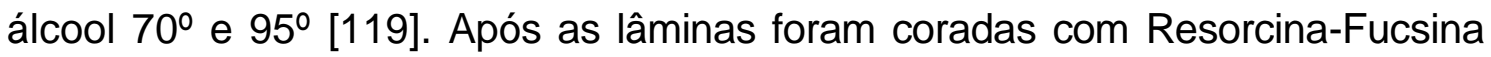
[67].

A quantificação de fibras colágenas e elásticas no pulmão foi realizada no analisador de imagens (Image ProPlus 4.5.029), por meio da densidade óptica. As imagens foram capturadas (aumento de 400x) por uma câmera modelo DFC420 (Leica, Wetzlar, Alemanha) acoplada a um microscópio óptico trinocular DM2500 (Leica), e enviadas ao computador onde foram processadas pelo programa Qwin Plus (Leica). Após a captura das imagens, para cada coloração, um filtro de cores que foi aplicado em todas as leituras de todos os grupos experimentais. As análises foram realizadas por meio do Software Image PróPlus (Image Pro Plus, 4.5.0.29, Cibernética Media, Inc., Bethesda, MD). 


\subsubsection{Avaliação de células inflamatórias no parênquima pulmonar}

A avaliação das células inflamatórias (mononucleares e polimorfonucleares) foi realizada na coloração de Hematoxilina e Eosina. As quantificações foram realizadas pela técnica de contagem de pontos e retas [120] por meio de um microscópio óptico (CH30, Olympus, Japão) e com o auxílio de um retículo de 100 pontos e 50 retas com área conhecida em um aumento de 1000x.

A quantificadas das células positivas, após o reticulo ser fixado na base do epitélio, foi dada pela razão entre o número de células em determinada área. Os resultados das células foram expressos em célula por unidade de área $\left(10^{4} \mu \mathrm{m}^{2}\right)$. Para todas as análises foram avaliados 10 aéreas randomicamente selecionados por corte [67].

\subsection{Imunohistoquimica para a detecção de MMP-9, TIMP-1, a7nAChR e isoprostano}

A imunohistoquímica para MMP-9, TIMP-1 e a7nAChR foi realizada pelo método Biotina-estreptavidina peroxidase. Para tanto, cortes histológicos de $3 \mu \mathrm{m}$ de espessura foram realizados em lâminas silanizadas (3-Aminopropil-tri etoxisilano-Sigma, Aldrich, St. Louis, MO, USA). As lâminas foram desparafinizadas e hidratadas (Xilol 1, 2 e 3; Etanol Absoluto 1 e 2, Etanol 96\% e Etanol 70). Após foi realizada a recuperação antigênica pela exposição de 1 minuto a temperatura de $125^{\circ} \mathrm{C}$ ao vapor de uma panela de pressão (Decloaking Chamber, Bio-core medical, Califórnia, EUA) onde as lâminas estavam imersas em solução tampão (Target Retrieval Solution, DAKO, Califórnia, EUA). Foi então realizado o bloqueio das peroxidases endógena por meio de 7 lavagens de 5 minutos com água 
oxigenada (H2O2) volume 10. Após, foi realizado o bloqueio para ligações inespecíficas em solução de caseína (5 min). Foi então realizada a incubação com Anticorpo Primário anti-MMP-9 (1:600, Santa Cruz Biotechonology, Inc., Texas, EUA); anti-TIMP1 (1:200, Santa Cruz Biotechonology., Texas, EUA) e $\alpha 7$ (1:100, Santa Cruz Biotechonology., Texas, EUA), diluídos em solução de BSA $5 \%$ (do inglês bovine serum albumin) e deixados overnight em uma câmera úmida em geladeira à $4^{\circ} \mathrm{C}$. Após 18 horas da incubação com o anticorpo primário, foram incubadas por 1 hora em estufa à $37^{\circ} \mathrm{com}$ o anticorpo secundário. A revelação foi realizada com o cromógeno 3,3 Diaminobenzidine (DAB, Sigma Aldrich, St. Louis, MO, USA) e as lâminas foram então contra-coradas com Hematoxilina de Harris (Merck, Darmstadt, Alemanha). Para a detecção da expressão de células positivas para MMP-9, TIMP-1 e $\alpha 7$ no parênquima pulmonar foi utilizada a metodologia de pontos e retas que consiste na leitura de células positivas com o auxílio de um retículo de 50 retas e 100 pontos que foi acoplado a uma ocular do microscópio óptico comum e que possui uma área conhecida (10.000 $\mu \mathrm{m} 2$ no aumento de 1000x). A razão do número de células positivas e dos pontos que coincidiam com o tecido pulmonar resultam em um número de células positivas por área $10^{4} \mu \mathrm{m}^{2}[100]$.

Para detecção do isoprostano, foi realizada a imunohistoquímica com anticorpo Anti-8-epi-PGF2 $\alpha$ (Oxford Biomedical Reserch, Rochester Hills, MI, USA) na diluição de 1:10000 [121]. A quantificação de isoprostano foi realizada no parênquima pulmonar realizada de forma semelhante ao descrito acima e foram quantificados pontos que coincidiam com o tecido e pontos coincidentes com a áreas positivas, tendo assim o resultado expresso por 
porcentagem (\%) de área positiva. Foram analisados 10 campos no parênquima pulmonar, selecionados de forma randômica.

\subsection{Extração de proteína}

Os pulmões foram homogeneizados com um polytron PTA 205 (Brinkmann Instruments modelo PT 10/35) em 1,5 mL de tampão contendo 100 $\mathrm{mM}$ Trisma (pH 7,5), $10 \mathrm{mM}$ EDTA, $17 \mathrm{mM}$ pirofosfato de sódio, $100 \mathrm{mM}$ fluoreto de sódio, $10 \mathrm{mM}$ ortovanadato de sódio, $2 \mathrm{mM}$ PMSF e $8 \mu \mathrm{L} / \mathrm{mL}$ de aprotinina. As amostras foram colocadas em um tubo para microcentrífuga e foram centrifugadas a $12.000 \mathrm{rpm}$ a $4^{\circ} \mathrm{C}$ por 15 minutos para a remoção do material insolúvel. Após a centrifugação, parte do sobrenadante foi utilizada para determinação do conteúdo proteico por espectrofotometria pelo método de Bradford (Protein Assay, Bio-rad, EUA) na titulação de 1:5. Foi utilizado o espectrofotômetro de placa (Epoch - Bioteck) e o programa GEN 5.1.1.1 com leitura em densidade óptica a $550 \mathrm{~nm}$.

\subsection{Western blotting para detecção da expressão proteica de STAT3 total e fosforilado e SOCS3 no homogenato de pulmão}

Foram utilizados os pulmões congelados a $-70^{\circ} \mathrm{C}$ (os mesmos que foram utilizados para detecção de citocinas).

A técnica de Western Blotting foi utilizada para identificar expressão proteica de STAT3 total/fosforilada 1:100, \#9139 e \#9131 respectivamente, Cell Signaling, EUA) e de SOCS3 (1:100, \#2923, Cell Signalling, EUA). Para análise foi utilizada a porcentagem de aumento em relação à média do grupo controle, depois que os valores das proteínas foram corrigidos pela proteína constitutiva 
$\beta$-actina (1:5000, A5316, Sigma-Aldrich, EUA), exceto o anticorpo p-STAT3 que foram corrigidos pela respectiva proteína total [100].

O sobrenadante do homogenato das amostras de pulmão foi tratado com tampão de Laemmli (1970) contendo DTT (Dithiothreitol, Bio-Rad, EUA) $200 \mathrm{mM}$ e aquecido em banho seco a $96^{\circ} \mathrm{C}$ por 5 minutos. As amostras, contendo $30 \mu \mathrm{g}$ de proteína cada, foram adicionadas em gel de poliacrilamida (SDS-PAGE 10\%) e então submetidas à eletroforese em no aparelho para minigel (Mini-Protean, Bio-Rad, EUA). Em cada gel foi utilizado como padrão um marcador de peso molecular com valores estabelecidos (Precision Plus Protein Standards - Dual Color, Bio-Rad, EUA).

A transferência das proteínas separadas no gel foi realizada eletricamente para uma membrana de nitrocelulose, através de transferência semi-seca (Trans-Blot Turbo Transfer System, Bio-Rad, EUA) por 10 minutos a 25 volts. A ligação inespecífica de proteínas na membrana de nitrocelulose foi diminuída pela incubação desta com uma solução bloqueadora (leite desnatado $5 \%$ em TBS-T) por 2 horas em temperatura ambiente. As membranas foram lavadas com TBS-T $3 x$ de 5 minutos, para então receberem 0 anticorpo primário específico diluído em TBS-T com $5 \%$ de BSA, overnight à $4^{\circ} \mathrm{C}$. No dia seguinte, as membranas foram novamente lavadas com TBS-T 3x de 5 minutos e incubadas por 1 hora em temperatura ambiente com anticorpo secundário conjugado à peroxidase (Anti-mouse ou anti-rabbit, Cell Signalling, EUA). Para a revelação e posterior quantificação das proteínas, a membrana foi incubada por 1 minuto em uma solução contendo: luminol (2,5 mM), ácido p-cumárico (450 uM); Tris pH 8,5 (100 uM), $\mathrm{H}_{2} \mathrm{O}_{2}(5,4 \mathrm{mM})$, podendo assim ser detectado 
por quimioluminescência pelo fotodocumentador (Alliance 4.7, Uvitec, Cambridge, Reino Unido). A intensidade das bandas foi quantificada pelo programa Uviband (Uvitec, Reino Unido)e os valores foram corrigidos conforme descrito acima.

\subsection{Análise de citocinas no homogenato pulmonar pelo método “Enzyme- Linked Immunosorbent Assay" (ELISA) de IL-6, IL-1 $\beta$, IL- 10, IL-17 e TNF- $\alpha$}

Resumidamente, placas de 96 poços com alta sensibilidade foram sensibilizadas com cada anticorpo específico para citocina de interesse. Após esta sensibilização, as placas foram lavadas e bloqueadas para ligações inespecíficas. As amostras foram distribuídas e incubadas para que em seguida fossem adicionados anticorpos conjugados à biotina específicos para a diferenciação. A revelação foi realizada com conjugado enzimático de estreptavidina-peroxidase, substrato e cromógeno (R\&D Systems), cuja reação foi interrompida a adição de uma solução ácida (H2SO4 - 2N). Para a quantificação das citocinas, foi utilizado o espectrofotômetro de placa (Epoch Bioteck) e o programa GEN 5.1.1.1 com leitura em densidade óptica a $450 \mathrm{~nm}$. A correção foi realizada pela proteína total quantificada e os valores foram expressos por pg/mg de proteína.

O ensaio imunoenzimático foi realizado no homogenato pulmonar para citocinas IL-6, IL-1 1 , IL-10, IL-17 e TNF- $\alpha$ utilizando o kit Duo-Set para camundongos (R\&D Systems, Minneapolis, MN, EUA) seguindo as instruções do fabricante. As citocinas foram expressas em picograma por micrograma de proteína total. A quantificação das proteínas foi realizada no espectrofotômetro 


\subsection{Análise estatística}

A análise estatística foi realizada usando o programa Sigma Stat (SPSS Inc., Califórnia, EUA). Todos os dados foram analisados pelo método One Way ANOVA seguidos pelo método de Student-Newman-Keuls e pelo método t-test. Os dados foram expressos em média \pm SEM. O nível de significância foi ajustado para $5 \%$. 
4.RESULTADOS 


\subsection{Efeito do tratamento com PNU-282987 nas células positivas de $\alpha 7$ no parênquima pulmonar}

Na Figura 7A está representado o número de células positivas de $\alpha 7$ no parênquima pulmonar. Pode-se observar que as células positivas $\alpha 7$ estão aumentadas no grupo submetido ao protocolo de elastase (PPE: 14,686 \pm 1,137) em comparação com o grupo salina (Controle: 6,455 $\pm 1,483),(P<0,001)$.

O tratamento com PNU atenuou essa resposta nos grupos (PPE-Pré: 5,758 \pm 0,248) e no grupo (PPE-Pós: $5,979 \pm 0,722$ ) em relação ao grupo PPE, $(\mathrm{P}<0,001)$.

Em relação as fotomicrografias representativas de células positivas para a7 (Figura 8B a E), podemos observar aumento no grupo PPE (painel B) em relação ao grupo Controle (painel C). Nos painéis D e E podemos observar a diminuição das células positivas de $\alpha 7$ pelo tratamento com PNU em relação ao grupo PPE. 


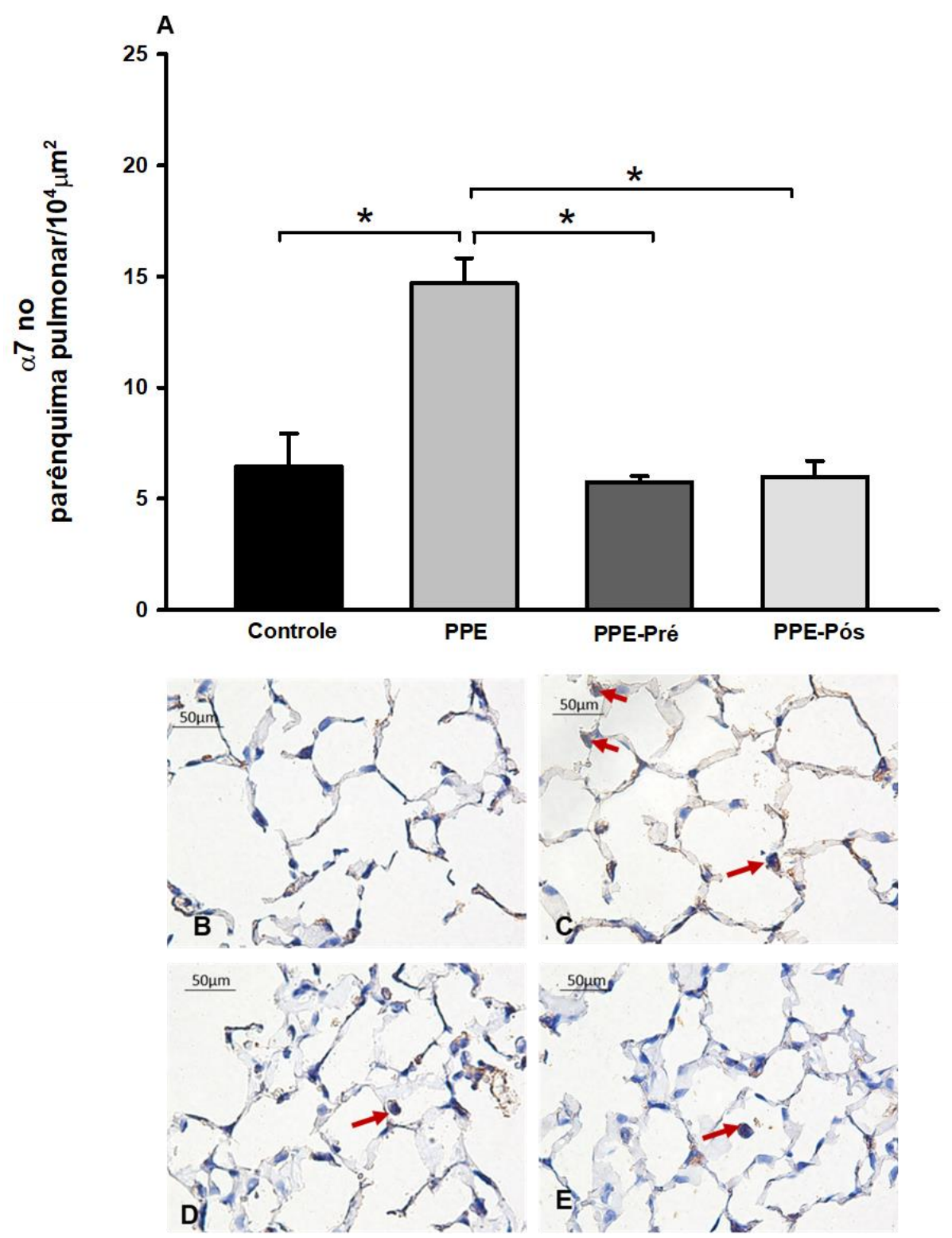

Figura 7: Efeito do tratamento com PNU-282987 nas células positivas de $\alpha 7$ no parênquima pulmonar: Foram avaliadas células positivas de $\alpha 7$ no parênquima pulmonar submetidos ao protocolo de elastase e tratados com veículo, PNU concomitante a elastase. As fotomicrografias representativas do parênquima pulmonar ( $\mathrm{B}$ a $E$ ) foram analisadas por imuno-histoquímica e quantificadas através da metodologia de pontos e retas em aumento de $1000 \mathrm{x}$, em animais submetido ao protocolo de elastase, tratados com veículo e com PNU $\left(0,7,14,21\right.$ e $28^{\circ}$ dia) e tratado com PNU $\left(21,22,23,24,25,26,27\right.$ e $\left.28^{\circ} \mathrm{dia}\right)$. Os gráficos representam a média \pm erro padrão de $6-8$ animais por grupo. $* \mathrm{P}<0,001$. 


\subsection{Efeito do tratamento com PNU-282987 na destruição alveolar (Lm)}

Pode-se observar na Figura 8A que o Lm está aumentado no grupo submetido ao protocolo de elastase (PPE: $81,37 \pm 7,83$ ) e aquele que recebeu o PNU como tratamento preventivo (PPE-Pré: $75,05 \pm 4,71$ ) em comparação com o grupo salina (Controle: $49,31 \pm 0,97), P<0,001$ ). $O$ tratamento com PNU terapêutico após 21 dias (PPE-Pós: 53,04 $\pm 1,64$ ) reduziu o Lm em relação ao grupo PPE $(P<0,01)$. Nas fotomicrografias representativa $(8 B, C, D$ e $E)$, podemos observar que o pulmão dos animais que foram submetidos ao protocolo de elastase (Figura $8 \mathrm{C}$ ), apresenta um aumento do espaço alveolar com áreas hiperinsufladas e com ruptura do tecido (setas) quando comparado ao pulmão de animais que receberam veículo (B). Podemos observar que pouca alteração se observa na $8 \mathrm{C}$ dos animais pré tratados e que na fotomicrografia (Figura $8 \mathrm{E}$ ) uma redução das áreas hiperinsufladas e da ruptura do tecido em relação ao grupo tratado com salina. 

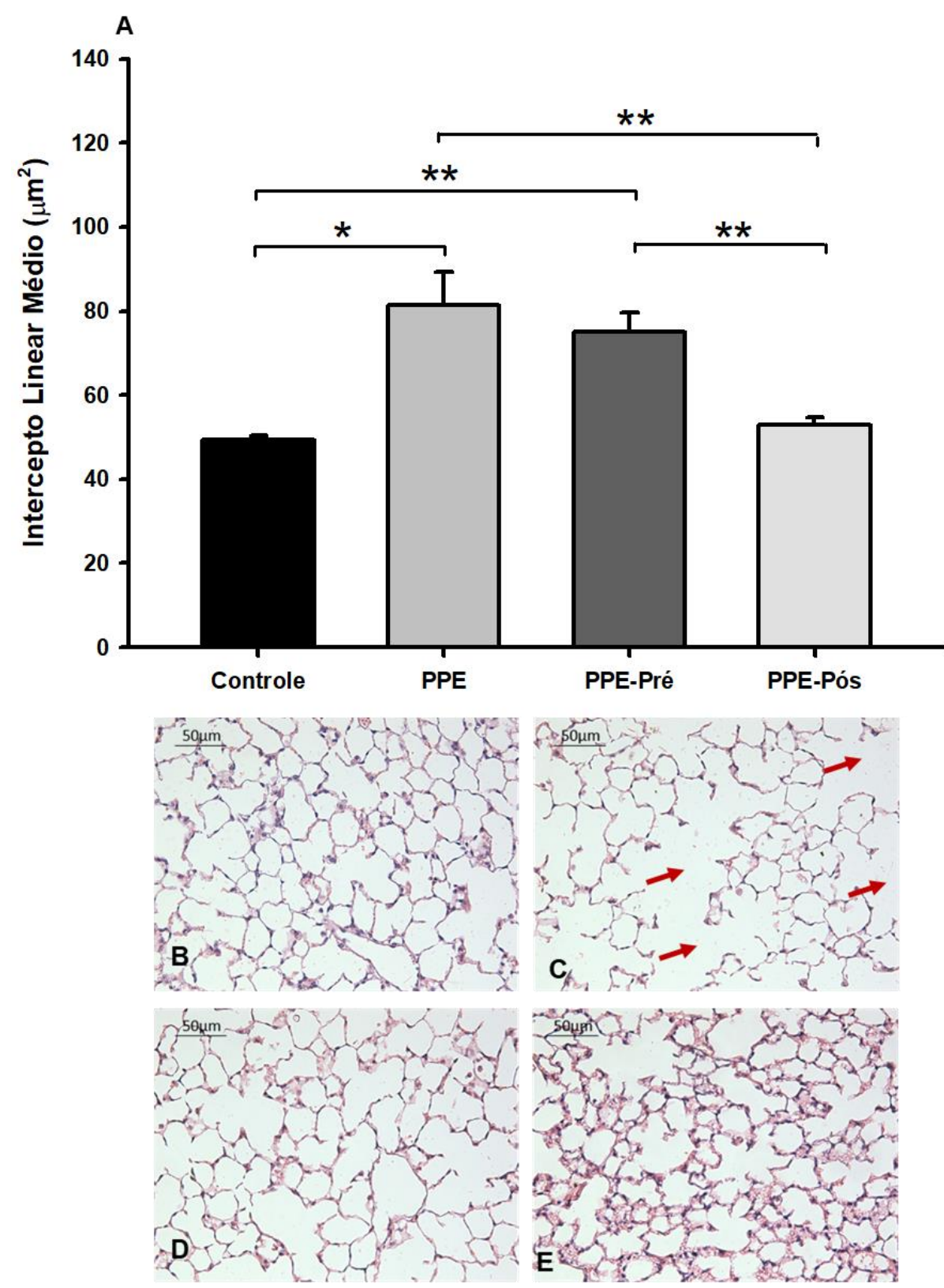

Figura 8: Efeito do tratamento com PNU-282987 na destruição alveolar ( Lm). Foram avaliados os números de interceptos que cruzavam com o septo alveolar no pulmão de animais submetidos ao protocolo de elastase e tratados com veículo, PNU concomitante a elastase ou após 21 dias. Animais controle receberam salina e foram tratados com veículo. Podemos observar na fotomicrografia representativa o pulmão de um animal controle (B), o pulmão do animal que foi submetido ao protocolo de elastase (C), com aumento do espaço alveolar com áreas hiperinsufladas e com ruptura do tecido (setas) e pode-se ainda observar na fotomiografia (E) uma redução das áreas hiperinsufladas e da ruptura do tecido no pulmão de um animal tratado com PNU. O tratamento prévio com PNU não atenuou esta lesão (D) de forma significativa. Dados representam média e erro padrão de 6-8 animais por grupo. ${ }^{*} \mathrm{P}<0,001 ;{ }^{*} \mathrm{P}<0,01$. 


\subsection{Efeito do tratamento com PNU-282987 na inflamação pulmonar}

\subsubsection{No lavado broncoalveolar (LBA)}

Na Figura 9 observamos os valores de contagem total e do diferencial de células quantificadas no LBA. Podemos observar que houve aumento das células totais (Figura 9A) nos animais submetidos ao protocolo de elastase (PPE: 3,02 \pm 0,42) em comparação com o grupo salina (Controle: 1,42 $\pm 0,30$ ), $(P<0,01)$. Os animais submetidos ao protocolo de elastase e tratados com PNU [(PPE-Pré: 1,57 \pm 0,14), (PPE-Pós: 1,81 \pm 0,23)] apresentam redução das células totais no LBA em relação ao grupo PPE $(P<0,01)$.

O número de macrófagos (Figura 9B) aumentou no grupo submetido ao protocolo de elastase (PPE: 2,69 \pm 0,40 em comparação com o grupo salina Controle: $1,39 \pm 0,30),(P<0,05)$. Os animais submetidos ao protocolo de elastase e tratados com PNU [(PPE-Pré: 1,52 \pm 0,13), (PPE-Pós: 1,76 \pm 0,23)] apresentaram redução do número de macrófagos recuperados no LBA em relação ao grupo PPE $(P<0,05)$. Não houve diferença entre os grupos estudados em relação a neutrófilos, linfócitos e eosinófilos (Figuras 9C, D e E, respectivamente). 

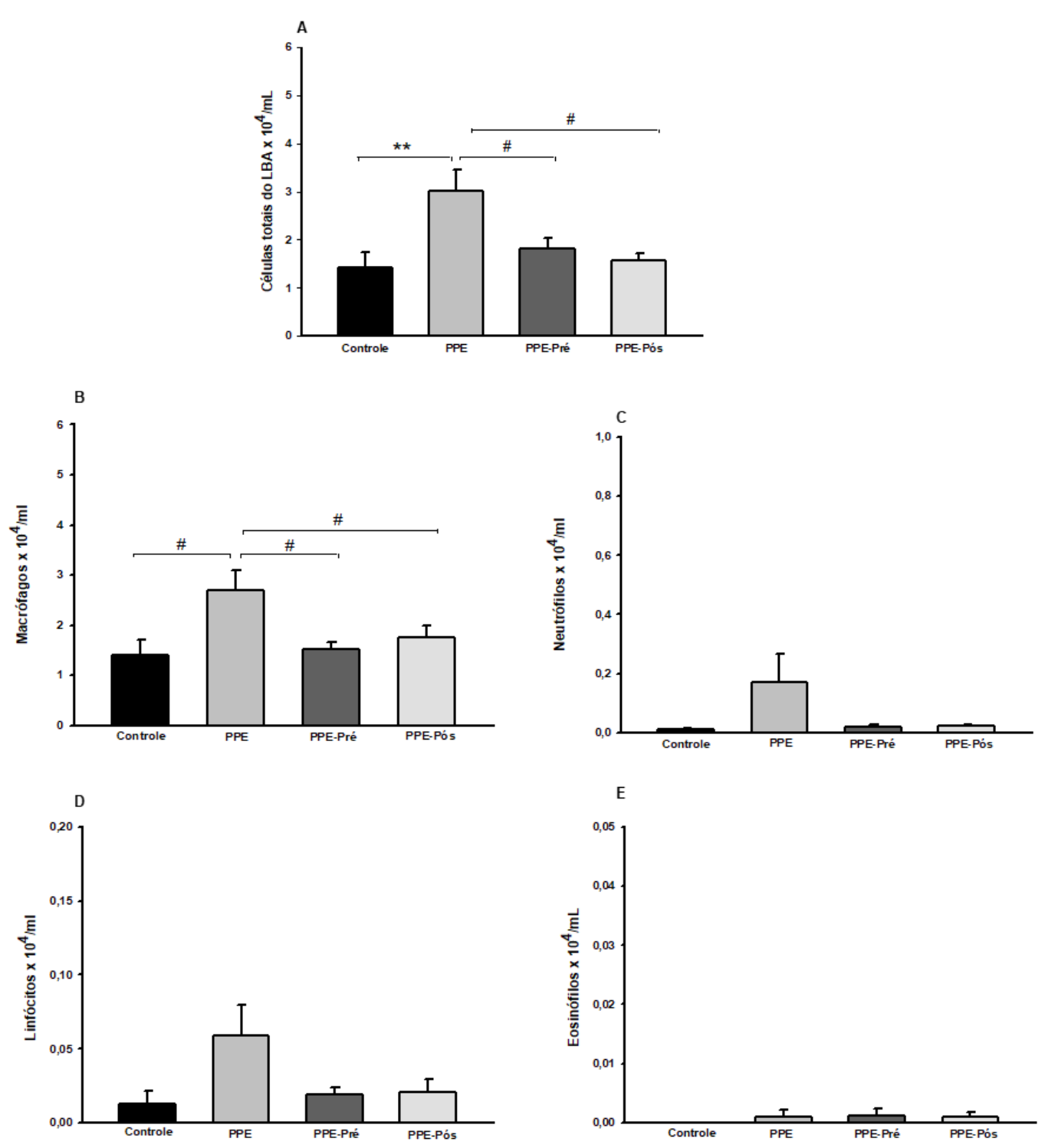

Figura 9: Efeito do tratamento com PNU-282987 nas Células inflamatórias no LBA: Foi avaliado as células totais e diferencial em animais submetido ao protocolo de elastase, tratados com veículo e com PNU $\left(0,7,14,21\right.$ e $28^{\circ}$ dia) e tratado com PNU $(21,22,23,24,25$, 26,27 e $\left.28^{\circ} \mathrm{dia}\right)$. Os gráficos representam a média \pm erro padrão de 5-9 animais por grupo. **P $<0,01$ e ${ }^{\#} \mathrm{P}<0,05$ 


\subsubsection{Células inflamatórias no parênquima pulmonar}

Podemos observar na Figura 10 que tanto o número de células mononucleares (PPE: 32,95 $\pm 2,899$ ) (Figura 10A) e de polimorfonucleares (PPE: $3,77 \pm 0,62)$, PPE-Pré $(4,79 \pm 0,97, \quad \mathrm{P}<0,05)$, (Figura 10B) está aumentado no grupo submetido ao protocolo de elastase em comparação com o grupo salina [mononucleares: (Controle: 10,05 $\pm 1,05, \quad P<0,001$ ); polimorfonucleares: (Controle: $1,08 \pm 0,30$ ), $\mathrm{P}<0,05$ e $\mathrm{P}<0,01$ respectivamente]. Os grupos PPE-Pré $[(20,65 \pm 3,27), P<0,01]$ e o PPE-Pós $[(14,76 \pm 1,84$, $\mathrm{P}<0,001)]$ apresentaram redução do número de mononucleares em relação ao grupo PPE. Já em relação as células polimorfonucleares (B), o grupo PPE-Post $[(1,78 \pm 0,43, P<0,05)]$ apresentou redução em relação ao grupo PPE e em relação ao grupo PPE-Pré $[(4,79 \pm 0,97, \quad \mathrm{P}<0,05)]$. Fotomicrografias representativas de lâminas de tecido pulmonar coradas com H\&E para análise das células inflamatórias mononucleares (setas vermelhas) e polimorfonucleares (setas pretas) dos grupos Controle, PPE, PPE-Pré e PPEPós estão representadas na Figura 10 C, D, E e F respectivamente. Podemos observar o aumento das células inflamatórias mononucleares e polimorfonucleares no pulmão de animal submetido ao protocolo de elastase (painel D, setas vermelhas e pretas respectivamente) em relação ao animal controle (Controle). Também observamos a diminuição das células inflamatórias mononucleares nos grupos tratados com PNU (Figura $10 \mathrm{E}, \mathrm{F}$; setas vermelhas) em relação ao grupo que recebeu elastase. 

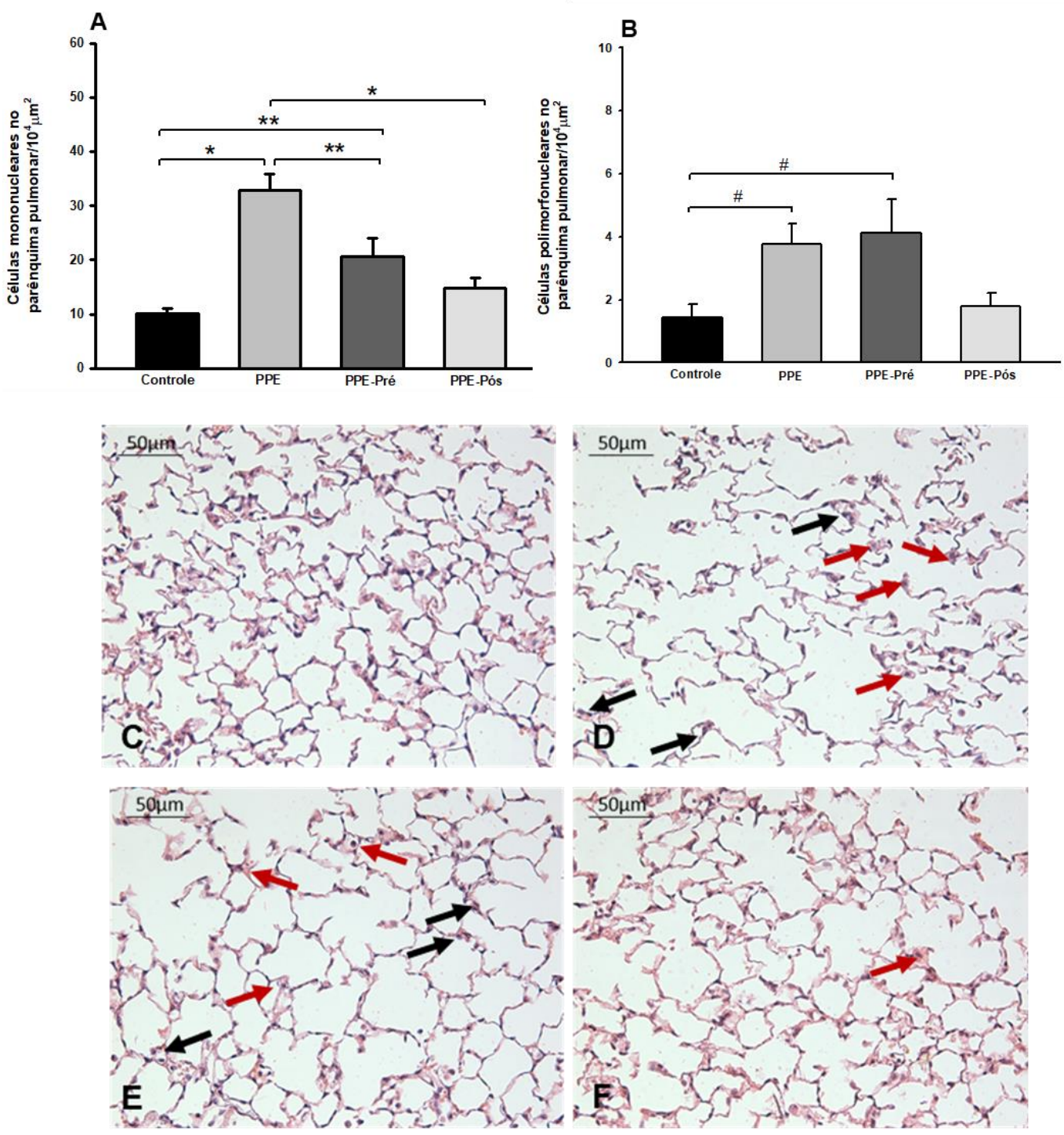

Figura 10: Efeito do tratamento com PNU-282987 nas Células inflamatórias no parênquima pulmonar: Foram avaliadas as células mononucleares e polimorfonucleares no parênquima pulmonar de animais submetidos ao protocolo de elastase e tratados com veículo, PNU concomitante a elastase. As fotomicrografias ( $C$ a $\mathrm{F}$ ) representativas da área do parênquima pulmonar foram quantificadas por morfometria, técnica de contagem de pontos e retas, em pulmão corados com H\&E retirados em animais submetido ao protocolo de elastase, tratados com veículo e com PNU $\left(0,7,14,21\right.$ e $28^{\circ}$ dia) e tratado com PNU $(21,22,23,24,25$, 26,27 e $\left.28^{\circ} \mathrm{dia}\right)$. Os gráficos representam a média \pm erro padrão de 6-8 animais por grupo. ${ }^{*} \mathrm{P}<0,001,{ }^{*} \mathrm{P}<0,01$ e ${ }^{\#} \mathrm{P}<0,05$. Setas vermelhas: células mononucleares; setas pretas: polimorfonucleares. 


\subsection{Efeito do tratamento com PNU-282987 no remodelamento pulmonar}

\subsubsection{Nas fibras colágenas}

$\mathrm{Na}$ Figura $11 \mathrm{~A}$ está representado o valor de fibras colágenas quantificadas no parênquima pulmonar. Podemos observar que houve aumento da porcentagem de fibras colágenas no grupo dos animais submetidos ao protocolo de elastase (PPE: $5,80 \pm 0,29$ ) em comparação com o grupo salina (Controle: $3,64 \pm 0,53),(P<0,001)$. Os animais submetidos ao tratamento de PNU [(PPE-Pré: $3,29 \pm 0,40)$, (PPE-Pós: $3,33 \pm 0,14)]$ apresentam redução da porcentagem de fibras colágenas em relação ao grupo PPE $(P<0,01)$.

As fotomicrografias representativas de lâminas de tecido pulmonar para análise das fibras colágenas podem ser observadas nos painéis $C, D, E$ e F. Nota-se aumento da deposição de fibras colágenas no tecido pulmonar de animais submetido ao protocolo de elastase (painel D) em relação aos animais controle (Controle) (painel C). Também observamos a diminuição das fibras colágenas no tecido pulmonar nos grupos tratados com PNU (painel E e F) em relação ao grupo que recebeu elastase.

\subsubsection{Nas fibras elásticas}

Na Figura 11B observamos que houve aumento das fibras elásticas no grupo dos animais submetidos ao protocolo de elastase (PPE: 6,04 $\pm 1,24$ ) em comparação com o grupo salina (Controle: 1,69 $\pm 0,38)$, $(P<0,001)$. Os animais tratados com PNU (PPE-Pré: 1,90 \pm 0,24), P<0,001); (PPE-Pós: 2,41 \pm 0,55), $(P<0,01)$, apresentam redução das fibras elásticas em relação ao grupo PPE. 
As fotomicrografias representativas de lâminas de tecido pulmonar para análise das fibras elásticas podem ser observadas nos painéis $\mathrm{G}, \mathrm{H}, \mathrm{I}$ e J. Podemos observar o aumento das fibras elásticas no tecido pulmonar de animais submetido ao protocolo de elastase (Figura $11 \mathrm{H}$ ) em relação aos animais controle (Controle). Também observamos a diminuição das fibras elásticas no tecido pulmonar nos grupos tratados com PNU (Figura 11 I e J) em relação ao grupo que recebeu elastase. 

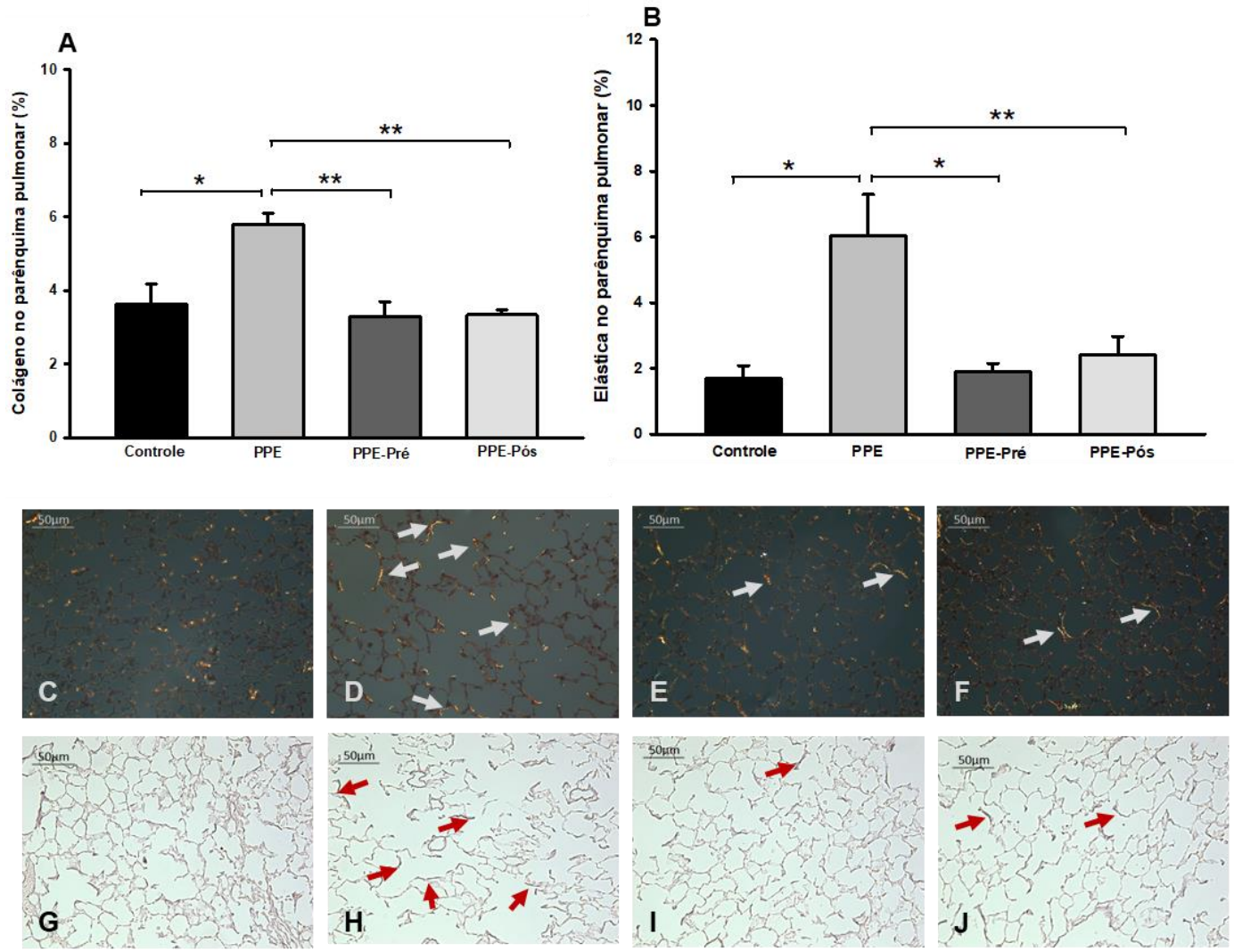

Figura 11: Efeito do tratamento com PNU-282987 nas fibras colágenas e elásticas no parênquima pulmonar. Foram avaliadas as fibras colágenas no parênquima pulmonar de animais submetidos ao protocolo de elastase e tratados com veículo e PNU concomitante a elastase. As fotomicrografias (C a F) (imunofluorescência) representativas do tecido pulmonar foram quantificadas por meio do analisador imagem em aumento de 400x e corados com Picro-Sirus. Já as fibras elásticas estão representadas nas fotomicrografias ( $G$ a J) e foram quantificadas por meio do analisador imagem em aumento de 400x e corados com Resorcina-fucsina em animais submetido ao protocolo de elastase. Todos os animais foram tratados com veículo e com PNU $(0,7,14,21$ e $28^{\circ}$ dia) e tratado com PNU $\left(21,22,23,24,25,26,27\right.$ e $28^{\circ}$ dia). Os gráficos representam a média \pm erro padrão de 6-8 animais por grupo. ${ }^{*} P<0,001 \mathrm{e}^{* *} \mathrm{P}<0,01$. 


\subsection{Efeito do tratamento com PNU-282987 na detecção de MMP-9, TIMP-1 e isoprostano 8-iso-PGF-2a}

O número de células positivas para MMP-9 no parênquima pulmonar está representado na Figura 13A. Houve um aumento no número de células positivas para MMP-9 no grupo PPE (PPE: $23,15 \pm 1,49$ ) em comparação com o grupo salina (Controle: $13,25 \pm 0,77),(P<0,01)$. O tratamento com PNU atenuou essa resposta apenas no grupo PPE-Pré: 16,18 $\pm 2,66$ ) em relação ao grupo PPE, $(P<0,05)$. Não houve diferença no grupo PPE-Pós.

Em relação as fotomicrografias representativas de células positivas para MMP-9 (Figura 13B a E), podemos observar aumento no grupo PPE (painel B) em relação ao grupo Controle (painel C). No painel D (PPE-Pré) podemos observar a diminuição das células positivas de MMP-9 em relação ao grupo PPE.

Não houve diferença em relação ao número de células positivas para TIMP-1 entre os grupos experimentais estudados (Figura 14).

A fração de volume de isoprostano 8-iso-PGF-2a nas vias aéreas está mostrado na Figura 15. Houve um aumento na fração de volume no grupo no grupo PPE (PPE: $24,18 \pm 1,26)$ em comparação com o grupo salina (Controle: $16,10 \pm 1,00),(P<0,001)(15 \mathrm{~A}) . \mathrm{O}$ tratamento com PNU atenuou essa resposta no grupo PPE-Pré: $(17,28 \pm 1,25)$ e no grupo PPE-Pós $(15,62 \pm 1,80)$ em relação ao grupo $\mathrm{PPE},(\mathrm{P}<0,001)$.

Na Figura 15B, C, D e E pode-se observar fotomicrografias com a área positiva de isoprostano 8-iso-PGF-2a no parênquima pulmonar nos quatro 
grupos experimentais. Pode-se observado o aumento da área positiva para isoprostano 8-iso-PGF-2a no grupo PPE (C) em relação ao grupo Controle. No painel $\mathrm{D}$ e $\mathrm{E}$ pode ser observado uma diminuição da área positiva para isoprostano 8-iso-PGF-2 $\alpha$ em relação ao grupo PPE. 

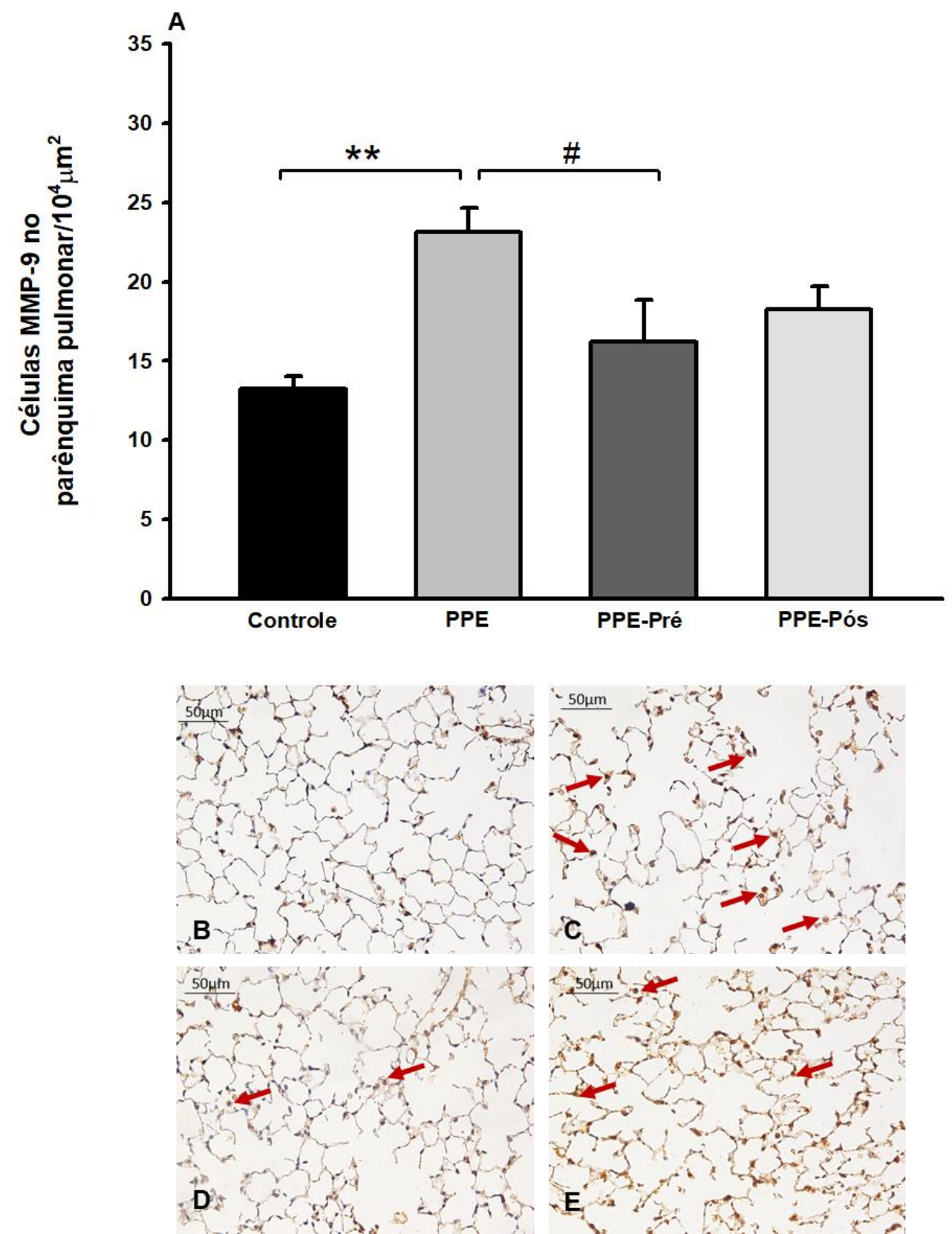

Figura 12: Efeito do tratamento com PNU-282987 nas células positivas de MMP-9 no parênquima pulmonar: Foram avaliadas células positivas de MMP-9 no parênquima pulmonar submetidos ao protocolo de elastase e tratados com veículo, PNU concomitante a elastase. As fotomicrografias representativas do parênquima pulmonar ( $B$ a $E$ ) foram analisadas por imunohistoquímica e quantificadas através da metodologia de pontos e retas em aumento de 1000x, em animais submetido ao protocolo de elastase, tratados com veículo e com PNU $\left(0,7,14,21\right.$ e $28^{\circ}$ dia) e tratado com PNU $\left(21,22,23,24,25,26,27\right.$ e $28^{\circ}$ dia). Os gráficos representam a média \pm erro padrão de 6-8 animais por grupo. ${ }^{* *} \mathrm{P}<0,01 \mathrm{e}{ }^{\#} \mathrm{P}<0,05$. 


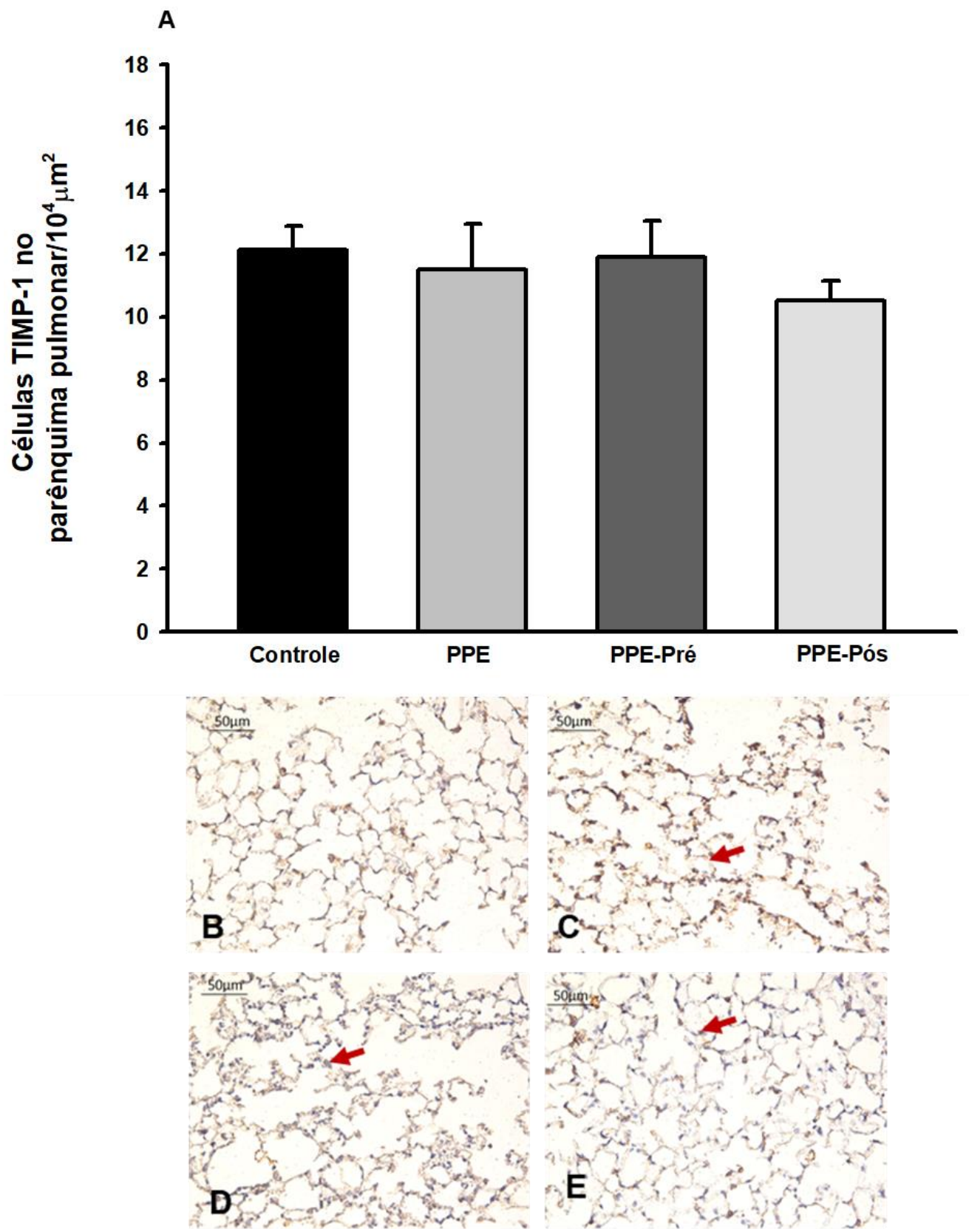

Figura 13: Efeito do tratamento com PNU-282987 nas células positivas TIMP-1 no parênquima pulmonar. Foram avaliadas as células positivas TIMP-1 no parênquima pulmonar submetidos, em animais submetido ao protocolo de elastase, tratados com veículo e com PNU (0, $7,14,21$ e $28^{\circ}$ dia) e tratado com PNU $\left(21,22,23,24,25,26,27\right.$ e $28^{\circ}$ dia). Não houve diferença estatística entre os grupos estudados. 


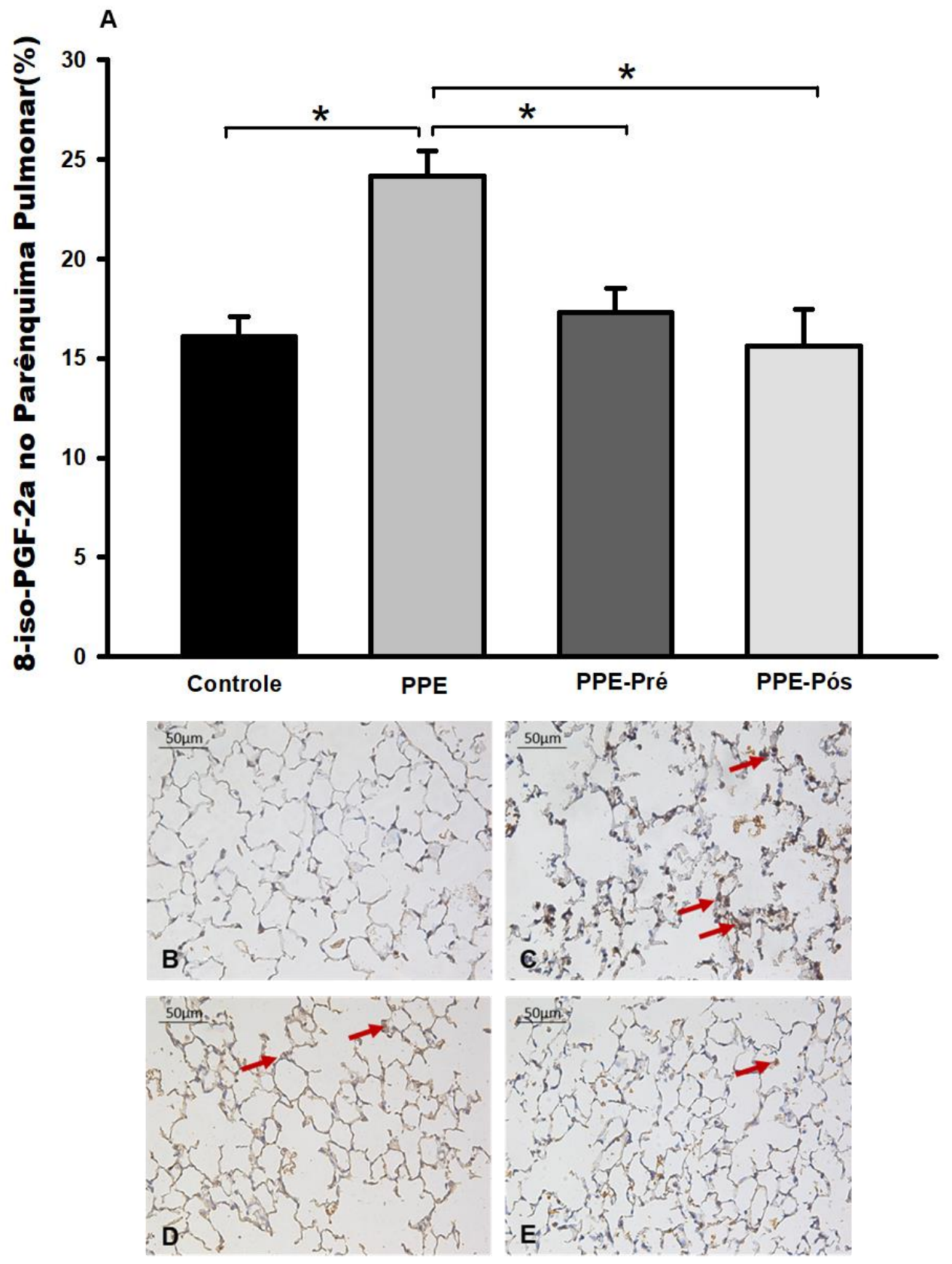

Figura 14: : Efeito do tratamento com PNU-282987 na fração de volume de isoprostano 8iso-PGF-2 $\alpha$ no parênquima pulmonar: Foi avaliada a fração de volume de isoprostano 8 -iso-PGF-2 $\alpha$ no parênquima pulmonar de animais submetidos ao protocolo de elastase e tratados com veículo e com PNU (0, 7, 14, 21 e $28^{\circ}$ dia) e tratado com PNU (21, 22, 23, 24, 25, 26, 27 e 28 dia). Os gráficos representam a média \pm erro padrão de 6-8 animais por grupo. ${ }^{*} \mathrm{P}<0,001$ 


\subsection{Efeito do tratamento com PNU-282987 nos níveis de citocinas IL-6, IL-1 $\beta$, IL-17, TNF- $\alpha$ e IL-10 no homogenato de pulmão}

Para investigar se a estimulação do agonista do $\alpha 7 \mathrm{nAChR}$ modula as citocinas pró-inflamatórias quantificamos os níveis de IL-6, IL-1 $\beta$, IL-17, TNF- $\alpha$ e IL-10 (anti-inflamatória) (Figura 16) no homogenato pulmonar.

Podemos observar que a instilação de elastase aumentou os níveis de IL-1 $\beta$ [(PPE: $56,18 \pm 1,86)]$ e de IL-6 [(PPE: : 39,47 $\pm 2,56)]$ em comparação com o grupo controle [IL-1 $\beta$ (Controle: $41,17 \pm 3,61, \mathrm{P}<0,05$ ); IL-6 (Controle: $26,72 \pm 1,83)(P<0,05$ e $P<0,01$ respectivamente)]. Nos grupos tratados com PNU houve uma redução tanto de IL-1 $\beta$ [(PPE-Pré: 28,61 \pm 5,53),(PPE-Pós: 38,75 \pm 3,27)] quanto de IL-6 [(PPE-Pré: 20,05 \pm 3,04),( PPE-Pós: 28,10 \pm 2,56)] em relação grupo submetido ao protocolo de elastase e tratado com veículo ( $\mathrm{P}<0,001$ para PPE-Pré e $\mathrm{P}<0,01$ para $\mathrm{PPE}-\mathrm{Pós})$. Não houve diferença entre os grupos tratados com PNU em relação aos níveis dessas citocinas.

Em relação IL-17 a instilação de elastase aumentou os níveis desta citocina no grupo (PPE: $3800,48 \pm 372,54$ ) em comparação com o grupo controle (Controle: $2348,17 \pm 252,12, \mathrm{P}<0,01$ ). Nos grupos tratados com PNU houve uma redução de IL-17 [(PPE-Pré: 3634,31 I 446,17),(PPE-Pós: 525,74 \pm 43,74)] em relação grupo submetido ao grupo controle $(P<0,01, P<0,001$ respectivamente) e redução do grupo PPE-Pós em relação ao grupo PPE, $P<0,001$. Também houve diferença entre os grupos tratados com $P N U$, $P<0,001$. Não houve diferença entre os grupos PPE e PPE-Pré em relação a essa citocina.

Embora a instilação de elastase não tenha aumentado os níveis de TNFa no pulmão dos animais do grupo (PPE: $34539,33 \pm 3125,95)$ em comparação 
com o grupo controle (Controle: $20363,17 \pm 2985,27$ ), os animais tratados com PNU apresentaram uma redução dos níveis de TNF-a (PPE-Pós: 10984,12 \pm 2263,00 ) em relação grupo submetido ao protocolo de elastase e tratado com veículo $\mathrm{P}<0,01$ para PPE. Também houve diferença entre os grupos tratados com PNU em relação aos níveis dessa citocina, $P<0,01$. Não houve diferença entre os grupos PPE e PPE-Pré em relação a essa citocina.

Ao avaliar o efeito do estímulo do agonista do $\alpha 7 \mathrm{nAChR}$ no controle da citocinas anti-inflamatórias IL-10, foi observado o aumento dos níveis no grupo tratado com PNU (PPE-Pré: $4462,13 \pm 873,06$ ) em relação ao grupo submetido ao protocolo de elastase (PPE: $1375,44 \pm 518,05, \mathrm{P}<0,01$ ). Houve diferença entre os grupos pré e pós tratados com PNU (PPE-Pós: 1251,87 $\pm 305,81$ $\mathrm{P}<0,01)$. 

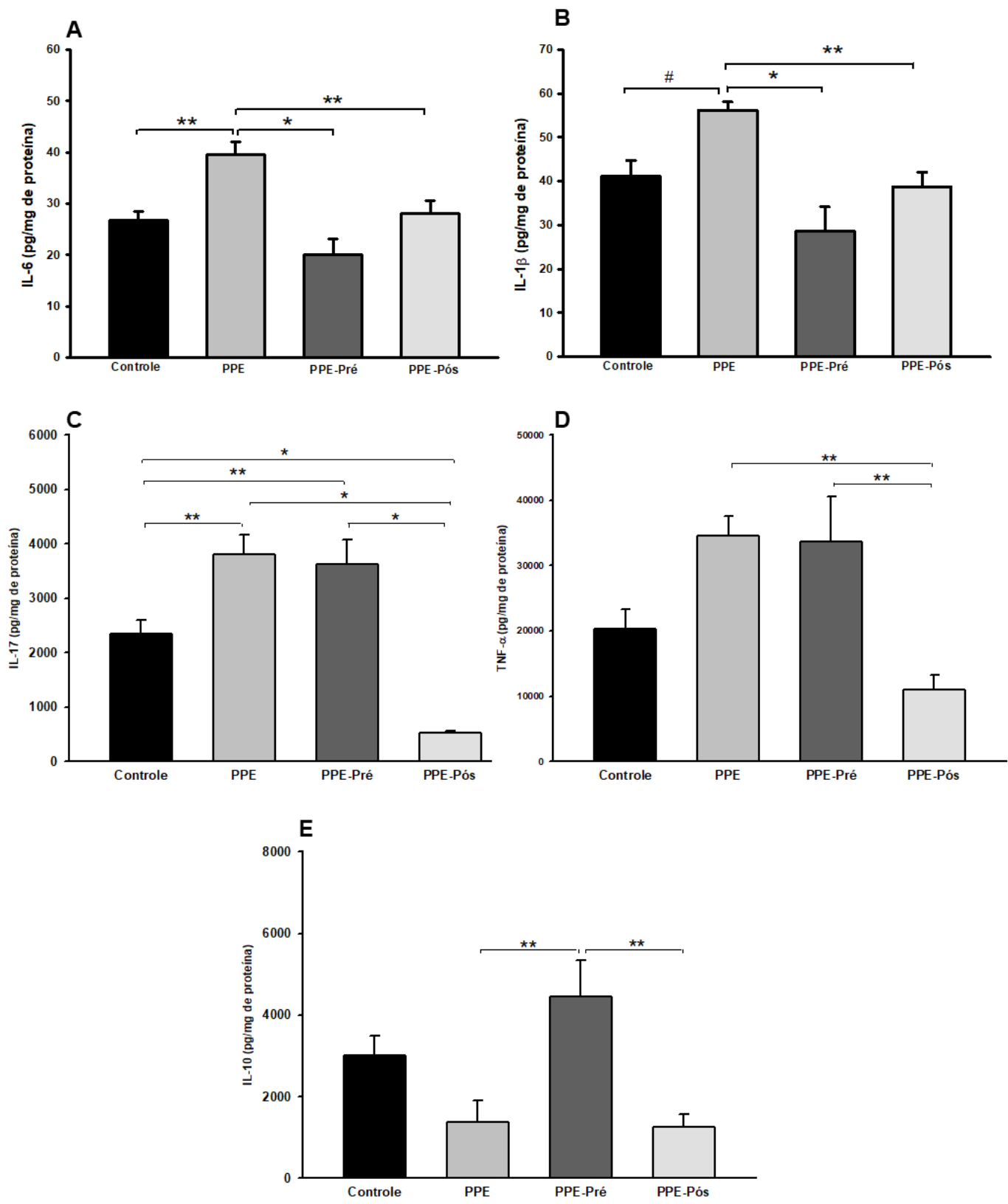

Figura 15: Efeito do tratamento com PNU-282987 nos níveis de citocinas IL-6, IL-16, IL-17, TNF- $\alpha$ e II-10 no homogenato de pulmão. Os níveis de IL-6 (A) e IL-1 $\beta$ (B) IL-17 (C), TNF- $\alpha$ (D)e II-10 (E) no homogenato pulmonar foram quantificados por ELISA nos animais submetidos ao protocolo de elastase, tratados com veículo e pré tratados com PNU $\left(0,7,14,21\right.$ e $28^{\circ}$ dia) ou pós tratados com PNU $\left(21,22,23,24,25,26,27\right.$ e $28^{\circ}$ dia). Os gráficos representam a média \pm erro padrão de 6 animais por grupo. ${ }^{*} \mathrm{P}<0,001,{ }^{*} \mathrm{P}<0,01$ e ${ }^{\#} \mathrm{P}<0,05$. 


\subsection{Efeito do tratamento com PNU-282987 na expressão proteica do pSTAT3/ STAT3 total e SOCS3.}

Foram avaliados em homogenato pulmonar a expressão das proteínas: STAT-3 total, pSTAT-3, SOCS-3 e $\beta$-actina (Figuras 17 e 18 respectivamente).

Não houve diferença entre os grupos experimentais em relação a expressão de STAT3 total no pulmão. Encontrou-se um aumento da fosforilação de STAT3 e uma redução na expressão de SOCS-3 (Figura 18) nos animais que receberam elastase [(pSTAT3/STAT3: PPE 191,22 \pm 28,05); (SOCS3/ $\beta$-actina: PPE: $57,85 \pm 6,76)$ ] em relação ao grupo controle [(pSTAT3/STAT3: Controle: 100,00 \pm 11,94); (SOCS3/ $\beta$-actina: Controle: $100,00 \pm 3,59)]$. Os tratamentos com PNU não foram efetivos na redução da fosforilação de STAT3 e a redução de SOCS3, entretanto os tratamentos evitaram o aumento na fosforilação de STAT3 e a redução de SOCS3 nos animais tratados, uma vez que os grupos PPE-Pré e PPE-Pós apresentaram valores semelhantes tanto ao grupo PPE quanto ao grupo Controle. 


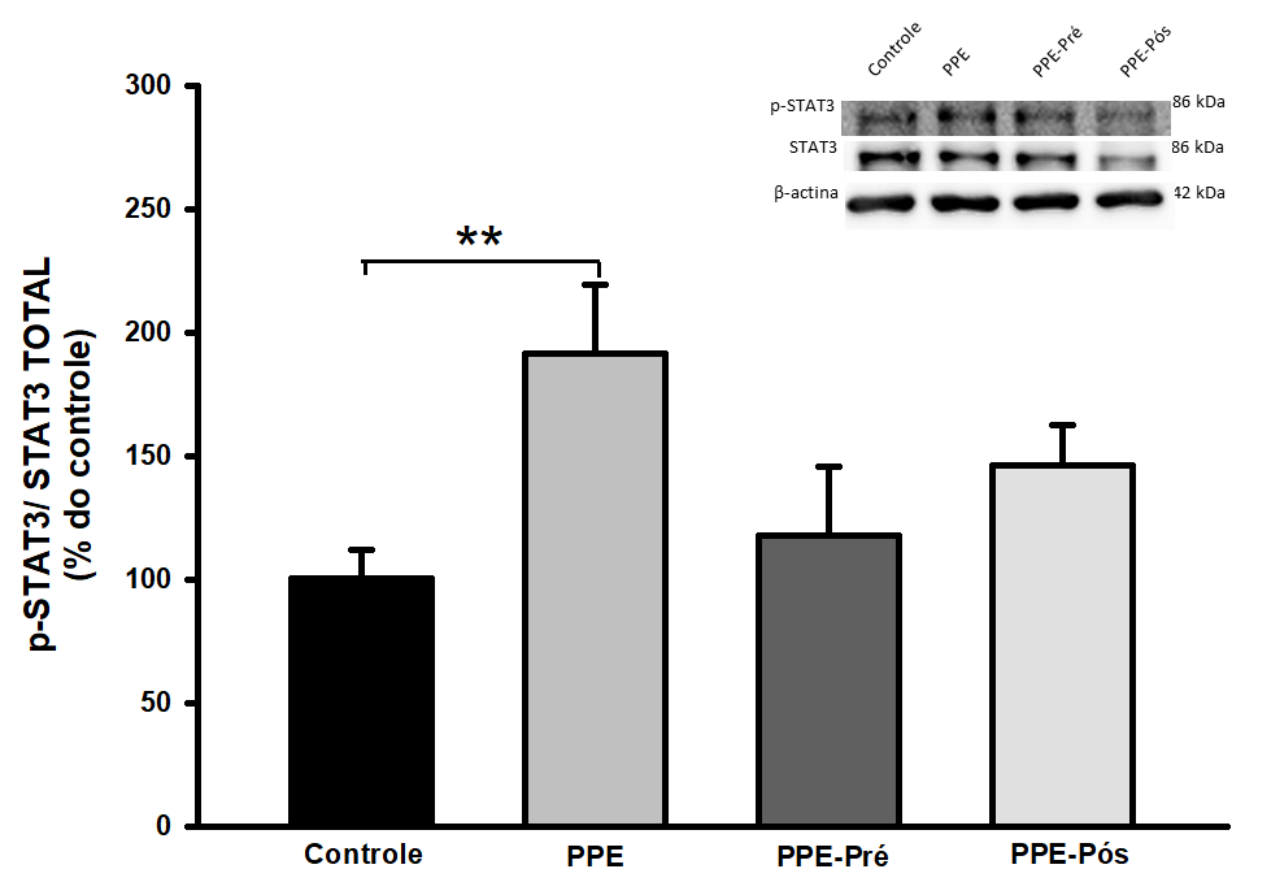

Figura 16-: Efeito do tratamento com PNU-282987 na expressão proteica do p-STAT3/ STAT3 Total: A expressão de STAT3 total e fosforilada foram medidos por Western Blotting em homogenato do pulmão de animais submetido ao protocolo de elastase, tratados com veículo e com PNU $\left(0,7,14,21\right.$ e $28^{\circ}$ dia) e tratado com PNU $\left(21,22,23,24,25,26,27\right.$ e $28^{\circ}$ dia). 0 gráfico representa a média \pm erro padrão de 6 animais por grupo. ${ }^{* *} P<0,01$. $O$ gel é representativo a média \pm erro e a STAT total foi normalizada pela $\beta$-actina, enquanto STAT3 fosforilada foi normalizada pelo total. 


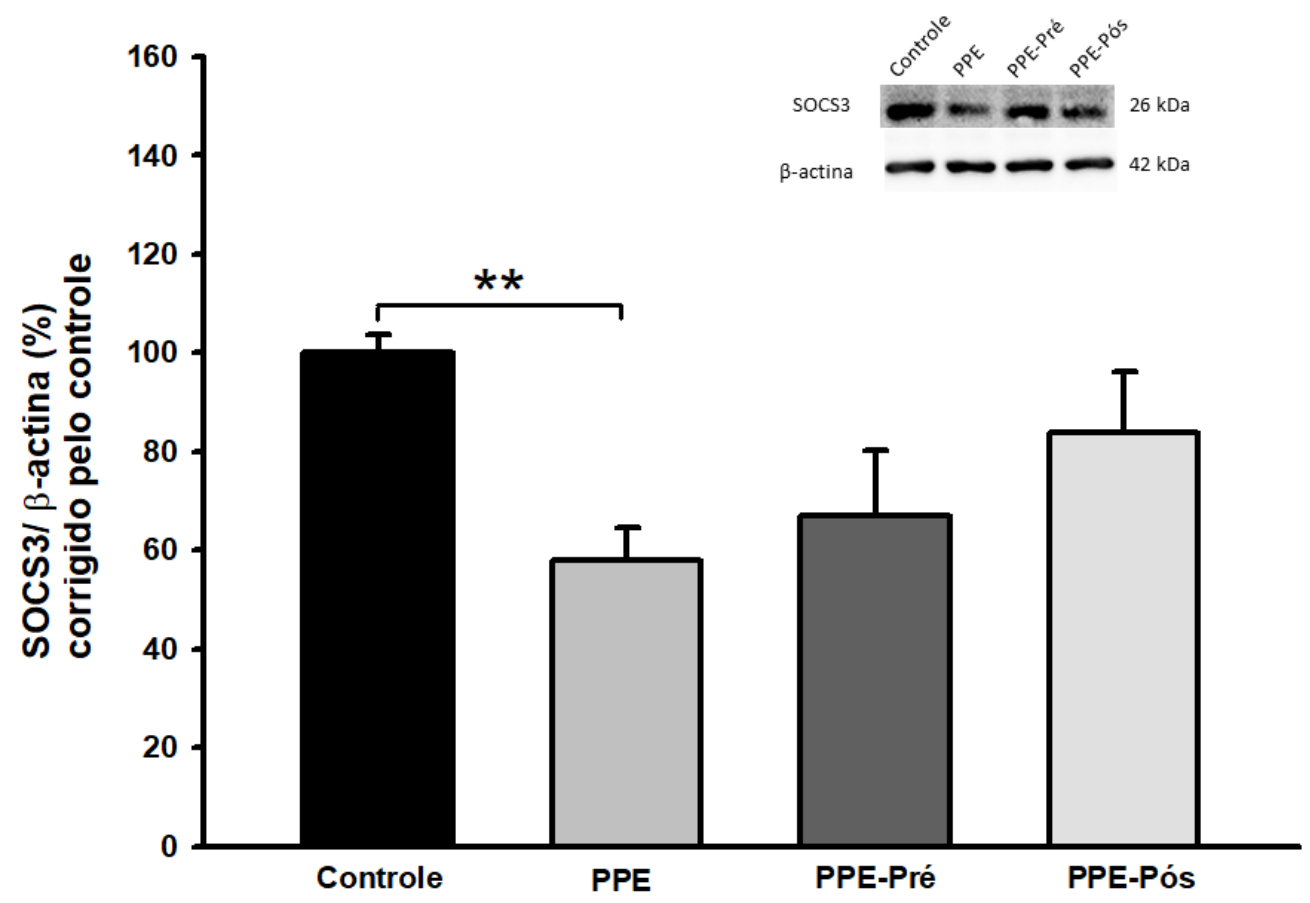

Figura 17: Efeito do tratamento com PNU-282987 na expressão proteica do SOCS3: A expressão de SOCS-3 foi avaliada por Western Blotting em homogenato do pulmão de animais a submetido ao protocolo de elastase, tratados com veículo e com PNU $\left(0,7,14,21\right.$ e $28^{\circ}$ dia) e tratado com PNU $\left(21,22,23,24,25,26,27\right.$ e $28^{\circ}$ dia). 0 gráfico representa a média \pm erro padrão de 6 animais por grupo. ${ }^{* *} \mathrm{P}<0,01$. O gel é representativo da média \pm erro e a SOCS3 foi normalizada pela $\beta$-actina. 


\subsection{Efeito do antagonista de a7 (MLA) revertendo os efeitos do PNU- 282987 na resposta inflamatória}

Ao avaliar o efeito do estímulo antagonista do $\alpha 7 \mathrm{nAChR}$ revertendo o efeito do PNU-282987 (Figura 19), avaliamos a resposta das células positivas de $\alpha 7$ no parênquima pulmonar, a contagem total e do diferencial de células quantificadas no LBA.

Na Figura 19A (células positivas de $\alpha 7$ ) foi observado o aumento dos níveis no grupo tratado com MLA (MLA: $10,39 \pm 1,24$ ) em relação ao grupo PPE-Pós (PPE-Pós: 5,97 \pm 0,72; P<0,01). No caso das citocinas de IL-17, figura 19B, observou-se o aumento dos níveis destas citocinas no grupo tratado com MLA (MLA: 7522,93 $\pm 1051,34)$ em relação ao grupo PPE-Pós (PPE-Pós: $525,743 \pm 43,74 ; P<0,05)$. Em relação as células totais (Figura 19C), foi observado o aumento dos níveis no grupo tratado com MLA (MLA: 3,46 $\pm 0,47$ ) em relação ao grupo PPE-Pós (PPE-Pós: $1,81 \pm 0,23 ; \mathrm{P}<0,01$ ) $\mathrm{O}$ número de macrófagos (Figura 19D) aumentou no grupo tratado com (MLA: $3,81 \pm 0,61$ ) em relação ao grupo PPE-Pós (PPE-Pós: 1,76 \0,23; P<0,05). 

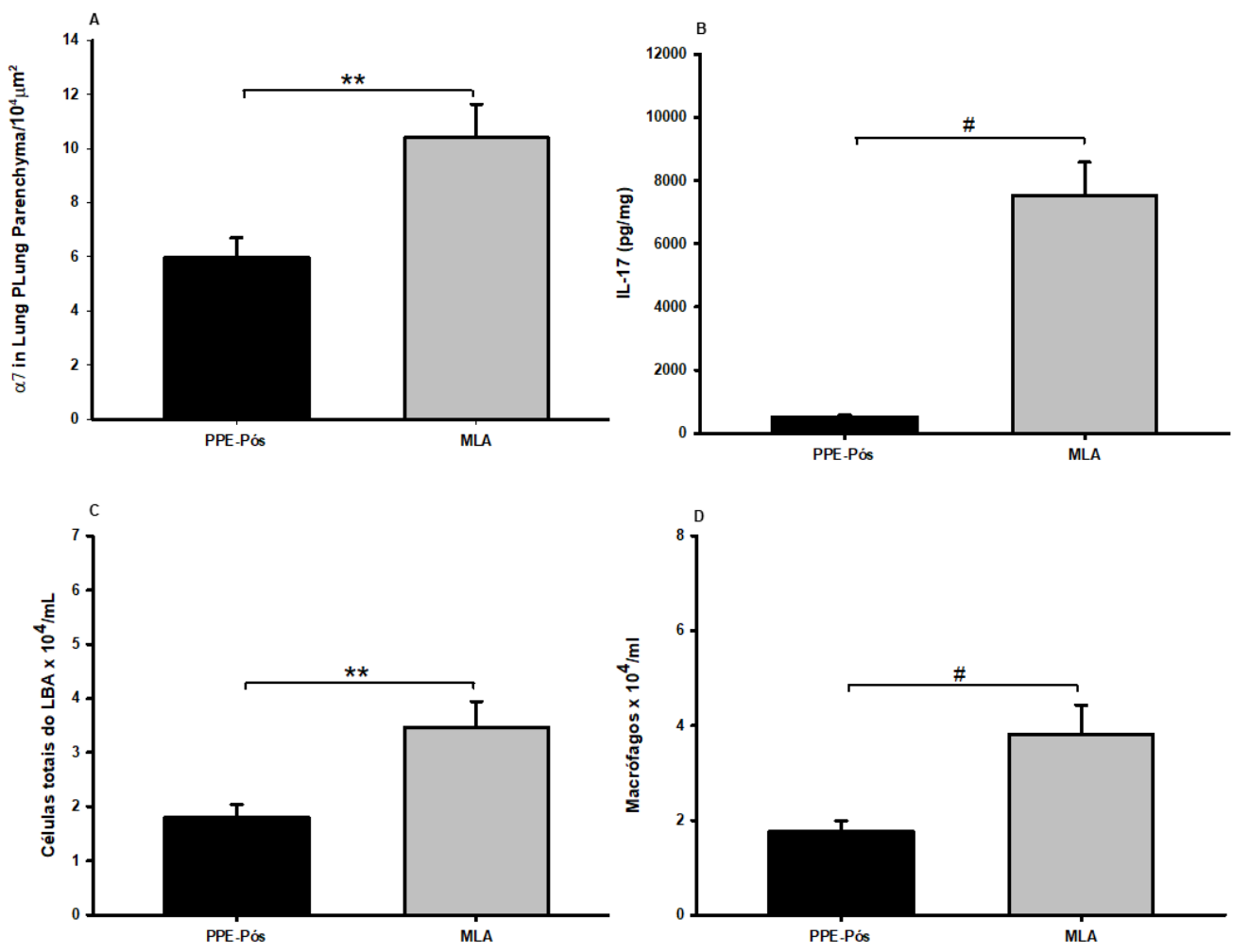

Figura 18. Efeito do antagonista de $\alpha 7$ revertendo os efeitos do PNU-282987 na resposta inflamatória: Foram avaliadas as células positivas de $\alpha 7$ no parênquima pulmonar, citocinas IL-17, as células totais e os macrófagos no LBA de animais submetidos ao protocolo de elastase e tratados com PNU e MLA $\left(21,22,23,24,25,26,27\right.$ e $28^{\circ}$ dia). Os gráficos representam a média \pm erro padrão de 6-8 animais por grupo. ${ }^{* *} \mathrm{P}<0,01 \mathrm{e}^{\#} \mathrm{P}<0,05$. 


\subsection{Efeito do tratamento com PNU-282987 na função pulmonar}

Na Figura 20 pode-se observar os dados de mecânica pulmonar. Não houve diferença significativa na função pulmonar (Htis e Gtis) entre os grupos estudados.
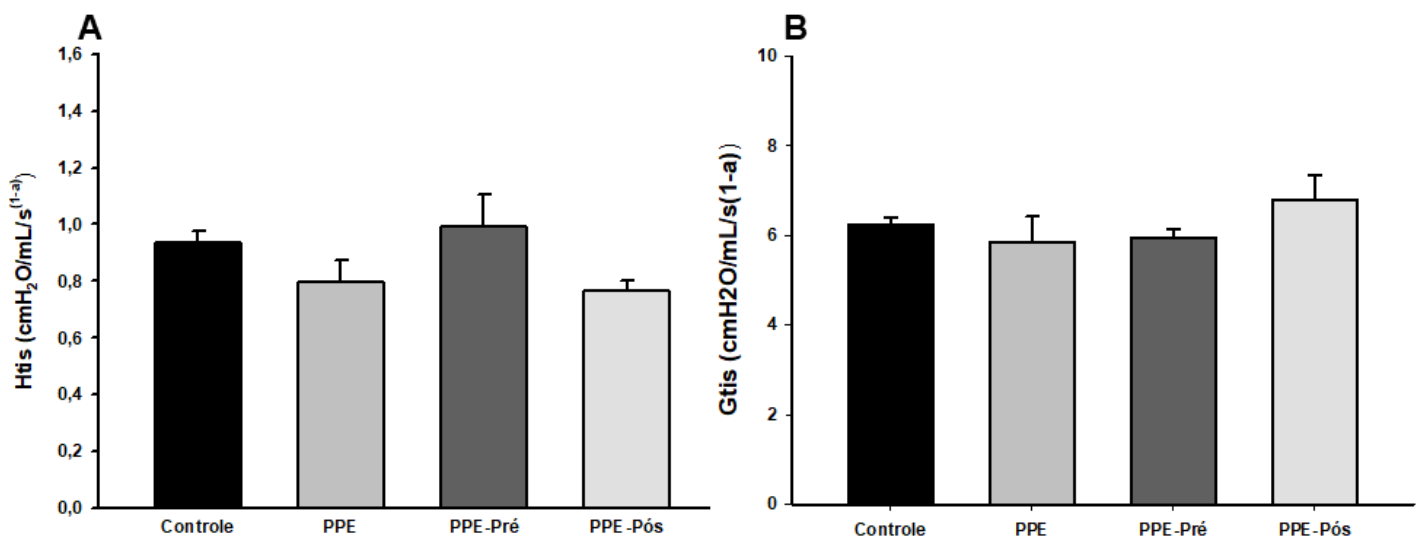

Figura 19. Efeito do tratamento com PNU-282987 na função pulmonar (Htis e Gtis). Não houve diferença significativa entre os grupos estudados 
5.DISCUSSÃO 
No presente estudo mostramos que o enfisema aumentou a expressão de células positivas para $\alpha 7 \mathrm{nACh}$ no pulmão em camundongos com enfisema pulmonar. Além disso, mostramos que o tratamento com PNU-282987, um agonista seletivo de $\alpha 7 n A C h R$, tem o potencial de reduzir a inflamação pulmonar e o enfisema induzidos pela elastase. Componentes colinérgicos, como receptores muscarínicos, VAChT e AChE, estão aumentados em neutrófilos de pacientes com DPOC [122] sugerindo uma participação do sistema colinérgico na fisiopatologia da DPOC. O papel do receptor nicotínico na DPOC é pouco estudado e controverso, uma vez que o receptor nicotínico está envolvido nos efeitos da nicotina no câncer de pulmão [123]. No entanto, os receptores nicotínicos, especialmente $\alpha 7 \mathrm{nAChR}$, são os receptores finais envolvidos nos efeitos anti-inflamatórios do sistema colinérgico e são expressos por células neuronais e não neuronais, incluindo as células imunes [124].

Para induzir o enfisema pulmonar, utilizamos um modelo de instilação de PPE onde uma única dose de instilação intranasal de elastase em camundongos induziu um aumento significativo na destruição alveolar, avaliada pelo diâmetro alveolar médio. Esse índice é aceito para inferir a destruição do tecido alveolar, denominado de enfisema [125]. Embora a instilação de elastase em animais não seja a forma mais fisiológica de induzir o enfisema semelhante ao que ocorre em pacientes, onde o fator de risco mais importante para o seu desenvolvimento é o tabagismo, nesse modelo ocorre a inflamação pulmonar, a destruição alveolar, o remodelamento o que reproduz de forma análoga semelhanças observadas no pulmão de pacientes com DPOC [126, 
127]. Nesse modelo, além de aumentar a o número de células positivas para a expressão de $\alpha 7 n A C h R$ no pulmão, o PPE induziu destruição alveolar com aumento de macrófagos e infiltração de neutrófilos no tecido pulmonar associada ao aumento dos níveis de IL-6, IL-1ß e IL-17. Esse estímulo inflamatório levou à remodelação do tecido pulmonar com deposição de fibras colágenas e elástica e aumento de células positivas para a expressão de MMP9. A maioria dessas características foi descrita em modelos de enfisema induzido por PPE por nosso grupo 7 e por outros [128], exceto o aumento da expressão de $\alpha 7 n A C h R$, que no nosso conhecimento é a primeira vez que ocorre essa descrição em modelos de enfisema induzido por elastase in vivo.

O sistema colinérgico anti-inflamatório foi descoberto em 2000 por Borovikova [59] e sugere que a ACh tenha um papel anti-inflamatório, particularmente quando se liga em nACh descritos inicialmente em macrófagos. Desde então, vários trabalhos vêm sendo realizados utilizando diferentes tipos de modelos experimentais ativando ou inibindo a via colinérgica antiinflamatória, por estimulação elétrica, inibição do nervo vago por vagotomia [88, 112], pelo uso de fármacos que inibam a AChE ou ainda pelo o uso de agonistas ou antagonistas específicos dos receptores colinérgicos [86].

No pulmão, a ACh apresenta um papel antagônico dependendo dos receptores que atua. É bastante conhecido que anticolinérgicos muscarínicos como o tiotrópio, (LAMA), tem um efeito de broncodilatador e anti-inflamatório [129]. Além disso, o tratamento com LAMA melhora a sintomatologia e diminuiu as exacerbações ligadas as internações em pacientes com DPOC [1]. Embora haja uma variedade de medicamentos comerciais usados no tratamento da 
DPOC, 65 milhões de pessoas têm DPOC moderada a grave [130], o que coloca em xeque a eficácia de muitos anti-inflamatórios existentes em pacientes com DPOC [7]. Nesse sentido, o sistema anti-inflamatório colinérgico e os receptores nicotínicos têm sido relatados como anti-inflamatórios em outros modelos de inflamação pulmonar, como asma, lesão pulmonar aguda entre outros [11, 131]. Curiosamente, a vareniclina, um agonista parcial dos receptores nicotínicos utilizado como farmacoterapia para cessar de fumar, melhorou significativamente a expansão alveolar e a resposta inflamatória avaliada no fluido de lavagem bronco alveolar em camundongos que receberam PPE [131].

Vários trabalhos ao longo dos anos têm sido realizados utilizando agonista seletivos ou agonista não seletivos do $\alpha 7 \mathrm{nAChR}$ na tentativa de suprimir a resposta inflamatória em diferentes tipos de modelos de inflamação sistêmica. No pulmão algumas evidências sugerem que a estimulação do a7nAChR também reduz a inflamação [86, 96, 109]. O PNU-282987, até onde saibamos, nunca foi utilizado em modelos experimentais de enfisema pulmonar.

A patogênese da DPOC é multifatorial e envolve a interação da inflamação, desequilíbrio protease-antiprotease e o estresse oxidativo, promovendo a perda progressiva do tecido pulmonar e da função pulmonar. As citocinas são consideradas importante no desencadeamento da resposta inflamatória e na persistência da mesma em várias doenças inflamatória, como a DPOC [52]. 
O presente estudo fornece novas evidências da relevância dos receptores nicotínicos para a DPOC. Primeiro mostramos que é expresso em células inflamatórias no parênquima pulmonar e é aumentado pela instalação de elastase. Outros modelos da DPOC mostraram o aumento $\alpha 7 \mathrm{nAChR}$ no pulmão induzido pela fumaça do cigarro [96]. A fim de verificar os efeitos do a7nAChR no desenvolvimento do enfisema e como possível alvo no tratamento de pacientes com enfisema, testamos duas abordagens diferentes de tratamento com PNU-282987, um agonista de $\alpha 7 n A C h R$, aqueles em que o tratamento começou junto com a instilação de elastase e a segunda abordagem em que o tratamento começou no dia 21 , momento que sabemos que o enfisema (destruição alveolar) está instalado neste modelo [132].

A destruição alveolar é o principal problema no enfisema, e embora o uso de corticosteroides e broncodilatadores reduzam a dispneia e a inflamação, não reverteram a destruição alveolar 31 que pode piorar progressivamente a função pulmonar [2]. Interessante que apenas o PNU-282987 administrado após $021^{\circ}$ dia foi capaz de reduzir a destruição alveolar, o que nos faz hipotetizar que este efeito do PNU-282987 na destruição alveolar pode ser devido a uma redução da inflamação.

Consistente com isso, o PNU-282987 foi capaz de reduzir as células inflamatórias obtidas no LBA, principalmente o número de macrófagos. O papel do macrófago no enfisema é bem relatado [1] e esta é a célula imune mais bem documentada para expressar $\alpha 7 \mathrm{nAChR}[95,124]$. Além disso, a presença de a7nAChR foi previamente demonstrada em outras células do sistema imunológico, como linfócitos, neutrófilos e eosinófilos, e também em células 
epiteliais [133]. Quando buscamos as células recrutadas para o tecido pulmonar, notamos que os tratamentos com PNU-282987 foram capazes de reduzir as células mononucleares, provavelmente macrófagos presentes no tecido pulmonar, porém apenas o pós-tratamento foi eficaz na redução dos polimorfonucleares, que estão relacionados aos neutrófilos em tecido pulmonar neste modelo [75]. Embora os neutrófilos não sejam a principal célula recrutada para o LBA neste modelo, foi demonstrado que estão presentes no tecido pulmonar induzido pela elastase [131]. Curiosamente, essa destruição da inserção alveolar pode ser mediada pela inflamação dos neutrófilos [134], o que justifica os efeitos do grupo PNU-Pós-tratamento na destruição alveolar, uma vez que apenas este grupo diminuiu os neutrófilos recrutados para 0 tecido pulmonar.

A citocina pró-inflamatória IL-1 $1 \beta$, uma das citocinas envolvidas no início e persistência da inflamação, está aumentada na DPOC em pacientes estáveis e durante as exacerbações [135], Yi Gao et al. [136] mostraram um aumento de IL-1 $\beta$ no epitélio das vias aéreas obtida por broncoscopia de pacientes com DPOC. Também é observado que os macrófagos alveolares e células mononucleares do sangue periférico de fumantes apresentam um aumento das IL-1 $\beta$ em relação a pacientes não fumantes [135]. A IL-6, uma citocina próinflamatória, é uma importante reguladora da ativação de JAK/STAT3 na DPOC [39]. A IL-6 se liga ao receptor gp130 e ativa JAK, fosforilando STAT3 induzindo assim sua translocação para o núcleo [49].

Com base nisso, medimos IL-6, IL-1 $\beta$, IL-17, TNF- $\alpha$ e IL-10 no tecido pulmonar, e observamos que ambos os grupos tratados com PNU apresentam 
níveis reduzidos de IL-1 $1 \beta$ e IL-6. Sabe-se que aumento nos níveis de IL-17 estão associados ao enfisema [137] e neste sentido demonstramos que apenas o pós-tratamento PNU diminuiu os níveis de IL-17 e TNF-a no pulmão. Kurimoto et al. [138] demonstraram que os animais nocaute para IL-17A têm redução na neutrofilia no LBA. Relatos anteriores de nosso grupo mostraram que o tratamento com anti-IL-17 pode prevenir e tratar o enfisema induzido por elastase em camundongos [139]. Coletivamente, sugerimos que a ativação do a7nAChR reduziu a IL-17 e os neutrófilos o que levou a uma redução da destruição alveolar, corroborando a ideia de que a IL-17 e os neutrófilos são relevantes na fisiopatologia da DPOC.

Vários relatórios na literatura focaram em mostrar os efeitos da nicotina e ativação de $\alpha 7 n A C h R$ na redução de citocinas e recrutamento de células inflamatórias $[60,140]$ e, mais recentemente, a ativação de $\alpha 7 n A C h R$ foi sugerida como benéfica para modular a tempestade de citocinas em COVID-19 uma vez que pode reduzir o HMGB-1, que é relatado como aumentando em pacientes graves [141]. Mais especificamente no enfisema, GTS-21, um agonista $\alpha 7 n A C h R$ seletivo, reduziu os níveis de mediadores inflamatórios em células HMGB-1 de pacientes com DPOC [142]. Além disso, o tratamento com GTS-21 inibiu significativamente a secreção de IL6 e TNF induzidas inibiu significativamente a secreção de IL6 e TNF induzidas por LPS em macrófagos isolados de camundongos knockout para $\alpha 7 \mathrm{nAChRs}$, indicando que os efeitos anti-inflamatórios de GTS-21 podem ocorrer independentemente da presença de a7nAChRs [143]. Zhu et al. [144] mostraram que a7nAChRs interagem diretamente com adenilil ciclase- 6 e com isso reduziram os marcadores 
inflamatórios em um modelo de enfisema induzido por elastase. No entanto, os autores avaliaram apenas os efeitos do PNU-282987 em marcadores inflamatórios. Zhang et al. [145] estudando um modelo de ratos expostos à fumaça de cigarro associada ao LPS mostraram que a eletroacupuntura, que sabidamente ativa o sistema anti-inflamatório colinérgico, reduziu os níveis de marcadores inflamatórios associados ao aumento da secreção vagal e melhora da função pulmonar.

O pré-tratamento com PNU-282987 aumentou os níveis de IL-10, enquanto o pós-tratamento com PNU não alterou os níveis dessa citocina. $\mathrm{O}$ papel da IL-10 no enfisema é controverso e os efeitos anti-inflamatórios dos receptores nicotínicos parecem estar associados à redução das citocinas próinflamatórias e ao aumento das anti-inflamatórias [94].

A inflamação crônica no enfisema está associada a um processo de remodelação da matriz extracelular [146] e a um desequilíbrio das metaloproteases e seus inibidores. Nesse sentido, os tratamentos com PNU282987 reduziram a deposição de colágeno e elástica em septos alveolares induzida por elastase. Apenas o pré-tratamento com PNU-282987 induziu uma redução significativa nas células positivas para MMP-9, embora nenhuma alteração no TIMP-1 tenha sido observada. Em um estudo, Li et al. [46] observaram que os níveis elevados das proteínas MMP-9 e TIMP-1, além de estarem correlacionadas com a patogênese da DPOC, essas duas proteínas também podem representar importantes marcadores biológicos para o diagnóstico precoce da DPOC. 
A remodelação do colágeno pode estar associada à presença de macrófagos tipo M2, e mostramos anteriormente que a ativação do $\alpha 7 \mathrm{nAChR}$ pode modular o equilíbrio M1 /M2 [90]. Portanto, nossa hipótese é que essa remodelação nas fibras colágenas e elásticas pode ser atribuída aos macrófagos e a outras metaloproteases não avaliadas.

Considerando que o estresse oxidativo é uma via importante envolvida na fisiopatologia do enfisema, avaliamos se o PNU-282987 modulava a expressão de isoprostano no pulmão, um marcador de estresse oxidativo [147, 148]. A ativação preventiva e terapêutica do $\alpha 7 n A C h R$ pode reduzir a área positiva para isoprostano, sugerindo que o $\alpha 7 \mathrm{nAChR}$ pode estar envolvido no controle do estresse oxidativo. No entanto, se esses efeitos são diretamente sobre o estresse oxidativo ou devido à redução da inflamação, precisam ser mais investigados.

Não observamos alteração da função pulmonar em nosso modelo de enfisema e mesmo nos animais tratados com PNU-282987, diferentemente de Taguchi et al. [149] e Lourenço et al. [150] que demostraram a diminuição do Htis no modelo de enfisema induzido por elastase. Anciaes et al. [132] observaram que os parâmetros avaliados na mecânica respiratória, nem sempre refletem as alterações observadas na análise morfométria após a instilação de elastase. Essas divergências podem ser explicadas por eventuais problemas no equipamento de medida da função pulmonar, que talvez apresente baixa sensibilidade para detectar alterações funcionais mais discretas. 
Finalmente, porque STAT3 é um possível mecanismo envolvido nos efeitos anti-inflamatórios de a7-nAChR [90, 94], avaliamos STAT3 no pulmão e descobrimos que o enfisema induzido por elastase ativa STAT3 no pulmão enquanto reduz os níveis de SOCS3. Um dos mecanismos para explicar como a ativação do $\alpha 7 n A C h R$ modula a resposta inflamatória seria que, após a ligação da $A C h$ ao a7nAChR, ocorre a inibição da translocação do NF-kB para o núcleo, inibindo assim a produção de citocinas pró-inflamatórias, e por ativação da via de ativação JAK2 / STAT3 que também pode regular negativamente a ligação de NF-kB ao DNA e / ou aumentar a atividade do supressor de citocina 3 (SOCS3) [80]. Wang et al. em 2015, em um modelo experimental de DPOC, induzida por LPS / tabagismo, aumentou o STAT3 e a MMP-9. SOCS3 é regulado por STAT3, SOCS3 liga-se a gp130 e inibe a atividade JAK e modula as respostas imunes através da regulação de IL-1 e IL6 [151]. Geraghty et al. [49] mostram em um estudo com animais expostos à fumaça de cigarro e nocaute para níveis baixos de STAT3 de SOCS3. Embora o tratamento com PNU não modulasse significativamente essas respostas, evitou a ativação de STAT3 e a redução de SOCS nos animais tratados com PPE e PNU. De acordo com isso, Zhang et al. [145] encontraram aumento da fosforilação do STAT3 em animais submetidos ao protocolo de fumaça de cigarro e os autores mostraram que o aumento do estímulo vagal está associado à inibição do STAT3.

Para mostrar que os efeitos do PNU dependem da ativação do a7nAChR, alguns animais do grupo PNU-Pós receberam pré-tratamento com MLA, um antagonista específico do a7nAChR. Mostramos que esse tratamento 
reverte os efeitos anti-inflamatórios do PNU na IL-17 e no recrutamento de neutrófilos e macrófagos. Além disso, os animais tratados com MLA aumentaram as células positivas para $\alpha 7 \mathrm{nAChR}$. Coletivamente, nossos dados sugeriram que a ativação do $\alpha 7 n A C h R$ é uma resposta protetora em situação de lesão pulmonar. Isso está de acordo com nossa resposta anterior, que mostra que o sistema colinérgico intacto é necessário para manter a homeostase pulmonar $[93,100]$. 
6.REFERÊNCIAS 
1. GOLD, G.I.f.C.O.L.D., Global Initiative for Chronic Obstructive Lung Disease: GOLD https://goldcopd.org/wp-content/uploads/2019/12/GOLD-2020-FINAL-ver1.203Dec19_WMV.pdf. 2020.

2. Agustí, A. and P.J. Barnes, Update in chronic obstructive pulmonary disease 2011. American journal of respiratory and critical care medicine, 2012. 185(11): p. 1171-1176.

3. Verma, L., et al., A Cross Sectional Study of clinical and Electrocardiographic profile in Chronic Obstructive Pulmonary Disease Patients and Its co-relation with the Severity of Disease. COPD, 2020. 2: p. 3.

4. Mouronte-Roibas, C., et al., COPD, emphysema and the onset of lung cancer. A systematic review. Cancer letters, 2016. 382(2): p. 240-244.

5. Vijayan, V.K., Chronic obstructive pulmonary disease. Indian J Med Res, 2013. 137(2): p. 25169.

6. Salvi, S., Tobacco smoking and environmental risk factors for chronic obstructive pulmonary disease. Clinics in chest medicine, 2014. 35(1): p. 17-27.

7. Rutgers, S.R., et al., Ongoing airway inflammation in patients with COPD who do not currently smoke. Thorax, 2000. 55(1): p. 12-18.

8. $\quad$ Barnes, P.J., Transcription factors in airway diseases. Laboratory investigation, 2006. 86(9): p. 867-872.

9. Ni, W., et al., Potential of serum procalcitonin in predicting bacterial exacerbation and guiding antibiotic administration in severe COPD exacerbations: a systematic review and meta-analysis. Infectious Diseases, 2019. 51(9): p. 639-650.

10. Eklöf, J., et al., Pseudomonas aeruginosa and risk of death and exacerbations in patients with chronic obstructive pulmonary disease: an observational cohort study of 22053 patients. Clinical Microbiology and Infection, 2020. 26(2): p. 227-234.

11. Fijačko, V., et al., Predictors of short-term LAMA ineffectiveness in treatment naïve patients with moderate to severe COPD. Wiener klinische Wochenschrift, 2018. 130(7-8): p. 247-258.

12. Suissa, S., S. Dell'Aniello, and P. Ernst, Comparative effectiveness and safety of LABA-LAMA vs LABA-ICS treatment of COPD in real-world clinical practice. Chest, 2019. 155(6): p. 11581165.

13. Mandal, J., et al., Treatment with long acting muscarinic antagonists stimulates serum levels of irisin in patients with COPD. Pulmonary pharmacology \& therapeutics, 2018. 48: p. 111-116.

14. Lipson, D.A., et al., Once-daily single-inhaler triple versus dual therapy in patients with COPD. New England Journal of Medicine, 2018. 378(18): p. 1671-1680.

15. Wedzicha, J.A., et al., Indacaterol-glycopyrronium versus salmeterol-fluticasone for COPD. New England Journal of Medicine, 2016. 374(23): p. 2222-2234.

16. Anane, I., et al., How to Stage Airflow Limitation in Stable Chronic Obstructive Pulmonary Disease Male Patients? Am J Mens Health, 2020. 14(3): p. 1557988320922630.

17. Celli, B.R. and J.A. Wedzicha, Update on Clinical Aspects of Chronic Obstructive Pulmonary Disease. N Engl J Med, 2019. 381(13): p. 1257-1266.

18. Agusti, A. and J. Zhang, Chronic obstructive pulmonary disease at the beginning of the XXI Century. Journal of Thoracic Disease, 2019. 11(11): p. E210-E213.

19. Mirza, S., et al. COPD guidelines: a review of the 2018 GOLD report. in Mayo Clinic Proceedings. 2018. Elsevier.

20. Santos, L.J.M., B.P. Martinez, and H.F. Correia, Perfil de internações hospitalares $e$ mortalidade por doenças respiratórias obstrutivas crônicas nas regiões brasileiras, entre os anos de 2016 e 2018. Revista de Ciências Médicas e Biológicas, 2019. 18(3): p. 344-346.

21. Menezes, A.M., C.G. Victora, and R. Perez-Padilla, The Platino project: methodology of a multicenter prevalence survey of chronic obstructive pulmonary disease in major Latin American cities. BMC Medical Research Methodology, 2004. 4(1): p. 1-7.

22. Moreira, G.L., et al., PLATINO, estudo de seguimento de nove anos sobre DPOC na cidade de São Paulo: o problema do subdiagnóstico. Jornal Brasileiro de Pneumologia, 2014. 40(1): p. 3037.

23. Brandsma, C.A., et al., Recent advances in chronic obstructive pulmonary disease pathogenesis: from disease mechanisms to precision medicine. The Journal of pathology, 2020. 250(5): p. 624635 .

24. Barnes, P.J., Inflammatory mechanisms in patients with chronic obstructive pulmonary disease. Journal of Allergy and Clinical Immunology, 2016. 138(1): p. 16-27. 
25. Chung, K. and I. Adcock, Multifaceted mechanisms in COPD: inflammation, immunity, and tissue repair and destruction. European Respiratory Journal, 2008. 31(6): p. 1334-1356.

26. Hikichi, M., et al., Pathogenesis of chronic obstructive pulmonary disease (COPD) induced by cigarette smoke. J Thorac Dis, 2019. 11(Suppl 17): p. S2129-S2140.

27. Barnes, P.J., COPD: is there light at the end of the tunnel? Current opinion in pharmacology, 2004. 4(3): p. 263-272.

28. Barnes, P.J., Targeting cytokines to treat asthma and chronic obstructive pulmonary disease. Nature Reviews Immunology, 2018. 18(7): p. 454-466.

29. Chung, K., Cytokines in chronic obstructive pulmonary disease. European Respiratory Journal, 2001. 18(34 suppl): p. 50s-59s.

30. Eapen, M.S., et al., Airway inflammation in chronic obstructive pulmonary disease (COPD): a true paradox. Expert review of respiratory medicine, 2017. 11(10): p. 827-839.

31. Pizov, R., The Nature of Small-Airway Obstruction in Chronic Obstructive Pulmonary Disease. Survey of Anesthesiology, 2005. 49(2): p. 95-96.

32. Hirota, N. and J.G. Martin, Mechanisms of airway remodeling. Chest, 2013. 144(3): p. 10261032.

33. Barnes, P.J., et al., Pulmonary biomarkers in chronic obstructive pulmonary disease. American journal of respiratory and critical care medicine, 2006. 174(1): p. 6-14.

34. Ricciardolo, F.L., et al., Nitric oxide in health and disease of the respiratory system. Physiological reviews, 2004. 84(3): p. 731-765.

35. King, P.T., et al., Lung T-cell responses to nontypeable Haemophilus influenzae in patients with chronic obstructive pulmonary disease. Journal of allergy and clinical immunology, 2013. 131(5): p. 1314-1321. e14.

36. Saetta, M., et al., CD8+ T-lymphocytes in peripheral airways of smokers with chronic obstructive pulmonary disease. American journal of respiratory and critical care medicine, 1998. 157(3): p. 822-826.

37. Buzza, M.S., et al., Extracellular matrix remodeling by human granzyme B via cleavage of vitronectin, fibronectin, and laminin. Journal of Biological Chemistry, 2005. 280(25): p. 2354923558.

38. Jin, Y., et al., Treg/IL-17 ratio and Treg differentiation in patients with COPD. PloS one, 2014. 9(10): p. e111044.

39. Wang, H., et al., Imbalance of peripheral blood $T$ h17 and $T$ reg responses in patients with chronic obstructive pulmonary disease. The clinical respiratory journal, 2015. 9(3): p. 330-341.

40. Doe, C., et al., Expression of the Thelper 17-associated cytokines IL-17A and IL-17F in asthma and COPD. Chest, 2010. 138(5): p. 1140-1147.

41. Zhang, X.-F., et al., Electroacupuncture inhibits IL-17/IL-17R and post-receptor MAPK signaling pathways in a rat model of chronic obstructive pulmonary disease. Acupuncture in Medicine, 2021: p. 0964528421996720.

42. Ritzmann, F. and C. Beisswenger, Preclinical studies and the function of IL-17 cytokines in COPD. Annals of Anatomy-Anatomischer Anzeiger, 2021: p. 151729.

43. Roos, A.B., et al., IL-17A is elevated in end-stage chronic obstructive pulmonary disease and contributes to cigarette smoke-induced lymphoid neogenesis. American journal of respiratory and critical care medicine, 2015. 191(11): p. 1232-1241.

44. Pandey, K.C., S. De, and P.K. Mishra, Role of proteases in chronic obstructive pulmonary disease. Frontiers in pharmacology, 2017. 8: p. 512.

45. MacNee, W., Pathogenesis of chronic obstructive pulmonary disease. Clinics in chest medicine, 2007. 28(3): p. 479-513.

46. Li, Y., et al., Relationships of MMP-9 and TIMP-1 proteins with chronic obstructive pulmonary disease risk: A Systematic Review And Meta-Analysis. J Res Med Sci. 2016; 21: 12. 2016.

47. Jiang, Y., X. Wang, and D. Hu, Mitochondrial alterations during oxidative stress in chronic obstructive pulmonary disease. International journal of chronic obstructive pulmonary disease, 2017. 12: p. 1153.

48. Fischer, B.M., J.A. Voynow, and A.J. Ghio, COPD: balancing oxidants and antioxidants. International journal of chronic obstructive pulmonary disease, 2015. 10: p. 261.

49. Geraghty, P., et al., STAT3 modulates cigarette smoke-induced inflammation and protease expression. Frontiers in Physiology, 2013. 4: p. 267.

50. Kiu, H. and S.E. Nicholson, Biology and significance of the JAK/STAT signalling pathways. Growth factors, 2012. 30(2): p. 88-106. 
51. Linossi, E.M. and S.E. Nicholson, Kinase inhibition, competitive binding and proteasomal degradation: resolving the molecular function of the suppressor of cytokine signaling (SOCS) proteins. Immunological reviews, 2015. 266(1): p. 123-133.

52. Yew-Booth, L., et al., JAK-STAT pathway activation in COPD. European Respiratory Journal, 2015. 46(3): p. 843-845.

53. Maritano, D., et al., The STAT3 isoforms $\alpha$ and $\beta$ have unique and specific functions. Nature immunology, 2004. 5(4): p. 401-409.

54. Nasreen, N., et al., Suppressor Of Cytokine Signaling-3 (SOCS-3): A Quantitative Biomarker For The Efficacy of Therapy In COPD, in A36. INFLAMMATION AND THE AIRWAY EPITHELIUM. 2010, American Thoracic Society. p. A1401-A1401.

55. Springer, J., et al., Transcriptional down-regulation of suppressor of cytokine signaling (SOCS)3 in chronic obstructive pulmonary disease. Journal of Occupational Medicine and Toxicology, 2013. 8(1): p. 1-6.

56. Rosas-Ballina, M. and K. Tracey, Cholinergic control of inflammation. Journal of internal medicine, 2009. 265(6): p. 663-679.

57. Pavlov, V.A., et al., Central muscarinic cholinergic regulation of the systemic inflammatory response during endotoxemia. Proceedings of the National Academy of Sciences, 2006. 103(13): p. 5219-5223.

58. Gallowitsch-Puerta, M. and V.A. Pavlov, Neuro-immune interactions via the cholinergic antiinflammatory pathway. Life Sciences, 2007. 80(24-25): p. 2325-2329.

59. Borovikova, L.V., et al., Vagus nerve stimulation attenuates the systemic inflammatory response to endotoxin. Nature, 2000. 405(6785): p. 458-462.

60. Tracey, K.J., Physiology and immunology of the cholinergic antiinflammatory pathway. The Journal of clinical investigation, 2007. 117(2): p. 289-296.

61. Johnston, G. and N. Webster, Cytokines and the immunomodulatory function of the vagus nerve. British journal of anaesthesia, 2009. 102(4): p. 453-462.

62. Daniel, E., et al., Ultrastructural studies on the neuromuscular control of human tracheal and bronchial muscle. Respiration physiology, 1986. 63(1): p. 109-128.

63. Chesné, J., V. Cardoso, and H. Veiga-Fernandes, Neuro-immune regulation of mucosal physiology. Mucosal immunology, 2019. 12(1): p. 10-20.

64. McGovern, A.E. and S.B. Mazzone, Neural regulation of inflammation in the airways and lungs. Autonomic Neuroscience, 2014. 182: p. 95-101.

65. Kummer, W., K. Lips, and U. Pfeil, The epithelial cholinergic system of the airways. Histochemistry and cell biology, 2008. 130(2): p. 219.

66. Soreq, H. and S. Seidman, Acetylcholinesterase-new roles for an old actor. Nature Reviews Neuroscience, 2001. 2(4): p. 294-302.

67. Prado, C.M., et al., Effects of nitric oxide synthases in chronic allergic airway inflammation and remodeling. American journal of respiratory cell and molecular biology, 2006. 35(4): p. 457465.

68. Prado, M.A., et al., Regulation of acetylcholine synthesis and storage. Neurochemistry international, 2002. 41(5): p. 291-299.

69. Gwilt, C.R., L.E. Donnelly, and D.F. Rogers, The non-neuronal cholinergic system in the airways: an unappreciated regulatory role in pulmonary inflammation? Pharmacology \& therapeutics, 2007. 115(2): p. 208-222.

70. Pavlov, V. and K. Tracey, Controlling inflammation: the cholinergic anti-inflammatory pathway. 2006, Portland Press Ltd.

71. Ribeiro, F.M., et al., The "ins" and "outs" of the high-affinity choline transporter CHT1. Journal of neurochemistry, 2006. 97(1): p. 1-12.

72. Prado, V.F., et al., Mice deficient for the vesicular acetylcholine transporter are myasthenic and have deficits in object and social recognition. Neuron, 2006. 51(5): p. 601-612.

73. Naser, P.V. and R. Kuner, Molecular, cellular and circuit basis of cholinergic modulation of pain. Neuroscience, 2018. 387: p. 135-148.

74. Kudlak, M. and P. Tadi, Physiology, Muscarinic Receptor, in StatPearls [Internet]. 2020, StatPearls Publishing.

75. Jeffery, P.K., Remodeling and inflammation of bronchi in asthma and chronic obstructive pulmonary disease. Proceedings of the American Thoracic Society, 2004. 1(3): p. 176-183.

76. Profita, M., et al., Muscarinic receptors, leukotriene B4 production and neutrophilic inflammation in COPD patients. Allergy, 2005. 60(11): p. 1361-1369. 
77. Yamada, M. and M. Ichinose, The cholinergic pathways in inflammation: a potential pharmacotherapeutic target for COPD. Frontiers in pharmacology, 2018. 9: p. 1426.

78. Fujii, T., et al., Expression and function of the cholinergic system in immune cells. Frontiers in immunology, 2017. 8: p. 1085.

79. Hajiasgharzadeh, K., et al., Alpha7 nicotinic acetylcholine receptors in lung inflammation and carcinogenesis: Friends or foes? Journal of cellular physiology, 2019. 234(9): p. 14666-14679.

80. GALLOWITSCH-PUERTA, M. and K.J. TRACEY, Immunologic Role of the Cholinergic AntiInflammatory Pathway and the Nicotinic Acetylcholine $\alpha 7$ Receptor. Annals of the New York Academy of Sciences, 2005. 1062(1): p. 209-219.

81. Huston, J.M., et al., Splenectomy inactivates the cholinergic antiinflammatory pathway during lethal endotoxemia and polymicrobial sepsis. The Journal of experimental medicine, 2006. 203(7): p. 1623-1628.

82. Martelli, D., M. McKinley, and R. McAllen, The cholinergic anti-inflammatory pathway: a critical review. Autonomic Neuroscience, 2014. 182: p. 65-69.

83. Li, T., et al., The vagus nerve and nicotinic receptors involve inhibition of HMGB1 release and early pro-inflammatory cytokines function in collagen-induced arthritis. Journal of clinical immunology, 2010. 30(2): p. 213-220.

84. Van Westerloo, D.J., et al., The vagus nerve and nicotinic receptors modulate experimental pancreatitis severity in mice. Gastroenterology, 2006. 130(6): p. 1822-1830.

85. Steinebrunner, N., et al., Pharmacologic cholinesterase inhibition improves survival in acetaminophen-induced acute liver failure in the mouse. BMC gastroenterology, 2014. 14(1): p. 148.

86. Su, X., M.A. Matthay, and A.B. Malik, Requisite role of the cholinergic $\alpha 7$ nicotinic acetylcholine receptor pathway in suppressing gram-negative sepsis-induced acute lung inflammatory injury. The journal of immunology, 2010. 184(1): p. 401-410.

87. Wang, H., et al., Cholinergic agonists inhibit HMGB1 release and improve survival in experimental sepsis. Nature medicine, 2004. 10(11): p. 1216-1221.

88. Hofer, S., et al., Pharmacologic cholinesterase inhibition improves survival in experimental sepsis. Critical care medicine, 2008. 36(2): p. 404-408.

89. Pinheiro, N.M., Efeito da redução da função colinérgica na mecânica pulmonar e na histopatologia pulmonar em modelo experimental de inflamação aguda induzida por instilação de LPS em camundongos geneticamente modificados. 2016, Universidade de São Paulo.

90. Pinheiro, N.M., et al., Effects of VAChT reduction and $\alpha 7 n A C h R$ stimulation by PNU-282987 in lung inflammation in a model of chronic allergic airway inflammation. European Journal of Pharmacology, 2020. 882: p. 173239.

91. Santana, F.P., et al., Vesicular acetylcholine transport deficiency potentiates some inflammatory responses induced by diesel exhaust particles. Ecotoxicology and Environmental Safety, 2019. 167: p. 494-504.

92. Jeremias, I., et al., The role of acetylcholine in the inflammatory response in animals surviving sepsis induced by cecal ligation and puncture. Molecular neurobiology, 2016. 53(10): p. 66356643.

93. Santana, F.P., et al., Dehydrodieugenol improved lung inflammation in an asthma model by inhibiting the STAT3/SOCS3 and MAPK pathways. Biochemical Pharmacology, 2020. 180: p. 114175.

94. De Jonge, W. and L. Ulloa, The alpha7 nicotinic acetylcholine receptor as a pharmacological target for inflammation. British journal of pharmacology, 2007. 151(7): p. 915-929.

95. Wang, H., et al., Nicotinic acetylcholine receptor $\alpha 7$ subunit is an essential regulator of inflammation. Nature, 2003. 421(6921): p. 384-388.

96. Su, X., et al., Activation of the $\alpha 7 n A C h R$ reduces acid-induced acute lung injury in mice and rats. American Journal of Respiratory Cell and Molecular Biology, 2007. 37(2): p. 186-192.

97. Sudheer, P., et al., Nicotinic acetylcholine receptors on basophils and mast cells. Anaesthesia, 2006. 61(12): p. 1170-1174.

98. Suzuki, A., et al., CIS3/SOCS3/SSI3 plays a negative regulatory role in STAT3 activation and intestinal inflammation. The Journal of experimental medicine, 2001. 193(4): p. 471-482.

99. Shouda, T., et al., Induction of the cytokine signal regulator SOCS3/CIS3 as a therapeutic strategy for treating inflammatory arthritis. The Journal of clinical investigation, 2001. 108(12): p. 1781-1788. 
100. Pinheiro, N.M., et al., Pulmonary inflammation is regulated by the levels of the vesicular acetylcholine transporter. PLoS One, 2015. 10(3).

101. Blanchet, M., E. Israel-Assayag, and Y. Cormier, Modulation of airway inflammation and resistance in mice by a nicotinic receptor agonist. European Respiratory Journal, 2005. 26(1): p. 21-27.

102. Giebelen, I.A., et al., Stimulation of $\alpha 7$ cholinergic receptors inhibits lipopolysaccharideinduced neutrophil recruitment by a tumor necrosis factor $\alpha$-independent mechanism. Shock, 2007. 27(4): p. 443-447.

103. Douaoui, S., et al., GTS-21, an $\alpha 7 n A C h R$ agonist, suppressed the production of key inflammatory mediators by PBMCs that are elevated in COPD patients and associated with impaired lung function. Immunobiology, 2020: p. 151950.

104. Hajos, M., et al., The selective $\alpha 7$ nicotinic acetylcholine receptor agonist PNU-282987 [N[(3R)-1-azabicyclo [2.2. 2] oct-3-yl]-4-chlorobenzamide hydrochloride] enhances GABAergic synaptic activity in brain slices and restores auditory gating deficits in anesthetized rats. Journal of Pharmacology and Experimental Therapeutics, 2005. 312(3): p. 1213-1222.

105. Vicens, P., et al., Behavioral effects of PNU-282987, an alpha7 nicotinic receptor agonist, in mice. Behavioural brain research, 2011. 216(1): p. 341-348.

106. Liu, Q., et al., $\alpha 7$ nicotinic acetylcholine receptor-mediated anti-inflammatory effect in a chronic migraine rat model via the attenuation of glial cell activation. Journal of pain research, 2018. 11: p. 1129.

107. Li, F., et al., The protective effect of PNU-282987, a selective $\alpha 7$ nicotinic acetylcholine receptor agonist, on the hepatic ischemia-reperfusion injury is associated with the inhibition of highmobility group box 1 protein expression and nuclear factor $\kappa B$ activation in mice. Shock, 2013. 39(2): p. 197-203.

108. Duris, K., et al., $\alpha 7$ nicotinic acetylcholine receptor agonist PNU-282987 attenuates early brain injury in a perforation model of subarachnoid hemorrhage in rats. Stroke, 2011. 42(12): p. 3530-3536.

109. Brégeon, F., et al., Activation of nicotinic cholinergic receptors prevents ventilator-induced lung injury in rats. PLoS One, 2011. 6(8): p. e22386.

110. Yang, Y.-H., et al., Acetylcholine inhibits LPS-induced MMP-9 production and cell migration via the a7 nAChR-JAK2/STAT3 pathway in RAW264. 7 cells. Cellular Physiology and Biochemistry, 2015. 36(5): p. 2025-2038.

111. Turek, J., et al., A sensitive technique for the detection of the $\alpha 7$ neuronal nicotinic acetylcholine receptor antagonist, methyllycaconitine, in rat plasma and brain. Journal of neuroscience methods, 1995. 61(1-2): p. 113-118.

112. Van Westerloo, D.J., et al., The cholinergic anti-inflammatory pathway regulates the host response during septic peritonitis. Journal of Infectious Diseases, 2005. 191(12): p. 2138-2148.

113. CONCEA, CONCEA (Guia Brasil de produção manutenção de animais em atividades de ensino ou pesquisa científica. Fascículo 2 de Brasília, 30 de maio de 2019. https://www.mctic.gov.br/mctic/opencms/institucional/concea/paginas/publicacoes_concea.html. 2019.

114. Ito, S., et al., Mechanics, nonlinearity, and failure strength of lung tissue in a mouse model of emphysema: possible role of collagen remodeling. Journal of applied physiology, 2005. 98(2): p. 503-511.

115. Banzato, R., et al., Reduction In Vacht Levels Induced Pulmonary Inflammation In Experimental Model Of Pulmonary Emphysema, in D28. CHRONIC OBSTRUCTIVE PULMONARY DISEASE: OF MICE AND MEN. 2015, American Thoracic Society. p. A5569-A5569.

116. Maouche, K., et al., $\alpha 7$ nicotinic acetylcholine receptor regulates airway epithelium differentiation by controlling basal cell proliferation. The American journal of pathology, 2009. 175(5): p. 1868-1882.

117. Bates, J., B. Daroczy, and Z. Hantos, A comparison of interrupter and forced oscillation measurements of respiratory resistance in the dog. Journal of Applied Physiology, 1992. 72(1): p. 46-52.

118. Lazarus, S.C., Inflammation, inflammatory mediators, and mediator antagonists in asthma. The Journal of Clinical Pharmacology, 1998. 38(7): p. 577-582.

119. Angeli, P., et al., Effects of chronic L-NAME treatment lung tissue mechanics, eosinophilic and extracellular matrix responses induced by chronic pulmonary inflammation. American Journal of Physiology-Lung Cellular and Molecular Physiology, 2008. 294(6): p. L1197-L1205. 
120. Weibel, E., Principles and methods for the morphometric study of the lung and other organs. Lab Invest, 1963. 12: p. 131-155.

121. Montuschi, P., et al., Anaphylaxis increases 8-iso-prostaglandin F2a release from guinea-pig lung in vitro. European journal of pharmacology, 1999. 365(1): p. 59-64.

122. Milara, J., et al., Non-neuronal cholinergic system contributes to corticosteroid resistance in chronic obstructive pulmonary disease patients. Respiratory research, 2016. 17(1): p. 1-14.

123. Yang, I.A., et al., Common pathogenic mechanisms and pathways in the development of COPD and lung cancer. Expert opinion on therapeutic targets, 2011. 15(4): p. 439-456.

124. Báez-Pagán, C.A., M. Delgado-Vélez, and J.A. Lasalde-Dominicci, Activation of the macrophage $\alpha 7$ nicotinic acetylcholine receptor and control of inflammation. Journal of Neuroimmune Pharmacology, 2015. 10(3): p. 468-476.

125. Fló, C., et al., Effects of exercise training on papain-induced pulmonary emphysema in Wistar rats. Journal of Applied Physiology, 2006. 100(1): p. 281-285.

126. Andersen, M.P., et al., Alveolar fractal box dimension inversely correlates with mean linear intercept in mice with elastase-induced emphysema. International journal of chronic obstructive pulmonary disease, 2012. 7: p. 235.

127. Wright, J.L., M. Cosio, and A. Churg, Animal models of chronic obstructive pulmonary disease. american journal of physiology-lung cellular and molecular physiology, 2008. 295(1): p. L1L15.

128. Mahadeva, R. and S. Shapiro, Chronic obstructive pulmonary disease $\bullet$ 3: Experimental animal models of pulmonary emphysema. Thorax, 2002. 57(10): p. 908-914.

129. Pera, T., et al., Tiotropium inhibits pulmonary inflammation and remodelling in a guinea pig model of COPD. European Respiratory Journal, 2011. 38(4): p. 789-796.

130. Barnes, P. and B. Celli, Systemic manifestations and comorbidities of COPD. European respiratory journal, 2009. 33(5): p. 1165-1185.

131. Jasper, A.E., et al., Understanding the role of neutrophils in chronic inflammatory airway disease. F1000Research, 2019. 8.

132. Anciaes, A.M., et al., Respiratory mechanics do not always mirror pulmonary histological changes in emphysema. Clinics, 2011. 66(10): p. 1797-1803.

133. Bencherif, M., et al., Alpha7 nicotinic receptors as novel therapeutic targets for inflammationbased diseases. Cellular and molecular life sciences, 2011. 68(6): p. 931-949.

134. Polosukhin, V.V., et al., Small airway determinants of airflow limitation in chronic obstructive pulmonary disease. Thorax, 2021.

135. Lappalainen, U., et al., Interleukin-1 $\beta$ causes pulmonary inflammation, emphysema, and airway remodeling in the adult murine lung. American journal of respiratory cell and molecular biology, 2005. 32(4): p. 311-318.

136. Yi, G., et al., A large lung gene expression study identifying IL1B as a novel player in airway inflammation in COPD airway epithelial cells. Inflammation Research, 2018. 67(6): p. 539-551.

137. Jiang, S., et al., Increased serum IL-17 and decreased serum IL-10 and IL-35 levels correlate with the progression of COPD. International journal of chronic obstructive pulmonary disease, 2018. 13: p. 2483.

138. Kurimoto, E., et al., IL-17A is essential to the development of elastase-induced pulmonary inflammation and emphysema in mice. Respiratory research, 2013. 14(1): p. 1-10.

139. Fukuzaki, S., et al., Preventive and therapeutic effect of anti IL-17 in an experimental model of elastase-induced lung injury in C57Bl6 mice. American Journal of Physiology-Cell Physiology, 2020.

140. Ulleryd, M.A., et al., Stimulation of alpha 7 nicotinic acetylcholine receptor $(\alpha 7 n A C h R)$ inhibits atherosclerosis via immunomodulatory effects on myeloid cells. Atherosclerosis, 2019. 287: p. 122-133.

141. Gauthier, A.G., et al., From nicotine to the cholinergic anti-inflammatory reflex-Can nicotine alleviate the dysregulated inflammation in COVID-19? Journal of Immunotoxicology, 2021. 18(1): p. 23-29.

142. Douaoui, S., et al., GTS-21, an $\alpha 7 n A C h R$ agonist, suppressed the production of key inflammatory mediators by PBMCs that are elevated in COPD patients and associated with impaired lung function. Immunobiology, 2020. 225(3): p. 151950.

143. Garg, B.K. and R.H. Loring, GTS-21 has cell-specific anti-inflammatory effects independent of $\alpha 7$ nicotinic acetylcholine receptors. PloS one, 2019. 14(4): p. e0214942. 
144. Zhu, S., et al., Anti-inflammatory effects of $\alpha 7$-nicotinic ACh receptors are exerted through interactions with adenylyl cyclase- 6 . British Journal of Pharmacology.

145. Zhang, X.-f., et al., Electro-acupuncture regulates the cholinergic anti-inflammatory pathway in a rat model of chronic obstructive pulmonary disease. Journal of integrative medicine, 2018. 16(6): p. 418-426.

146. Kulkarni, T., et al., Matrix remodeling in pulmonary fibrosis and emphysema. American journal of respiratory cell and molecular biology, 2016. 54(6): p. 751-760.

147. Montuschi, P., et al., Exhaled 8-isoprostane as an in vivo biomarker of lung oxidative stress in patients with COPD and healthy smokers. American journal of respiratory and critical care medicine, 2000. 162(3): p. 1175-1177.

148. Montuschi, P., et al., Increased 8-isoprostane, a marker of oxidative stress, in exhaled condensate of asthma patients. American journal of respiratory and critical care medicine, 1999. 160(1): p. 216-220.

149. Taguchi, L., et al., A flavanone from Baccharis retusa (Asteraceae) prevents elastase-induced emphysema in mice by regulating $N F-\kappa B$, oxidative stress and metalloproteinases. Respiratory research, 2015. 16(1): p. 1-15.

150. Lourenco, J.D., et al., A treatment with a protease inhibitor recombinant from the cattle tick (Rhipicephalus Boophilus microplus) ameliorates emphysema in mice. PLoS One, 2014. 9(6): p. e98216.

151. Croker, B.A., et al., SOCS3 negatively regulates IL-6 signaling in vivo. Nature immunology, 2003. 4(6): p. 540-545. 